Portland State University

PDXScholar

Summer 12-15-2015

\title{
Quaternary Chronology and Stratigraphy of Mickey Springs, Oregon
}

Leslie Allen Mowbray

Portland State University

Follow this and additional works at: https://pdxscholar.library.pdx.edu/open_access_etds

Part of the Geology Commons, and the Geomorphology Commons Let us know how access to this document benefits you.

\section{Recommended Citation}

Mowbray, Leslie Allen, "Quaternary Chronology and Stratigraphy of Mickey Springs, Oregon" (2015). Dissertations and Theses. Paper 2637.

https://doi.org/10.15760/etd.2633

This Thesis is brought to you for free and open access. It has been accepted for inclusion in Dissertations and Theses by an authorized administrator of PDXScholar. Please contact us if we can make this document more accessible: pdxscholar@pdx.edu. 
Quaternary Chronology and Stratigraphy of Mickey Springs, Oregon

by

Leslie Allen Mowbray

A thesis submitted in partial fulfillment of the

requirements for the degree of

Master of Science

in

Geology

Thesis Committee:

Michael L. Cummings, Chair

Curt D. Peterson

Adam M. Booth

Portland State University

2015 


\begin{abstract}
Mickey Springs in the Alvord Desert, southeast Oregon, is analogous to other Basin and Range hydrothermal systems where the requisite conditions of heat source and permeable pathways are met through crustal thinning due to normal faulting. This study examines the morphology and lifespan of near-surface spring features through use of ground penetrating radar, thermoluminescence $(T L)$ dating, and elevation modeling. Duration of hydrothermal activity at Mickey Springs has not previously been determined, and age determinations of sinter at the site are conflicting. The reason for and timing of this change in silica saturation in the hydrothermal fluid has not been resolved.
\end{abstract}

Three morphologies of silica sinter deposition have been identified at Mickey Springs. These are (1) well-sorted, fine-grained sandstone with ripple marks, cross beds and preserved root casts, to poorly-sorted conglomerate of primarily basalt clasts, both cemented by coeval silica deposition, (2) large depressions (12-32 m diameter) rimmed with sinter, characterized by fine silt and clay blanketing a sinter apron and infilling the central depression, and (3) quaquaversal sinter mounds identified by outcropping pooledge sinter typically surrounding a shallow depression of loose sediment.

Silica-cemented sandstone and conglomerate were the first features formed by coeval hydrothermal processes at the site, and were emplaced prior to 30 kya as suggested by structural and stratigraphic relationships. Structure between two 
interacting fault tips may have constrained the extent of silica cementation. By 30 kya, a left-stepping fault oriented roughly north/south further constrained the near-surface permeable zone. TL dates from sediment stratigraphically below and above sinter aprons around mounds and depressions (former spring vents) indicate sinter deposition between 30 and 20 kya. Location of these features was dictated by development of the left-stepping fault. As pluvial Lake Alvord filled at the end of the Pleistocene, lake sediment filled most vents, which were largely inactive, with fine-grained silt and clay.

Today, hydrothermal activity persists in two modes: (1) The current hightemperature springs, steam vents and mudpots concentrated in a $50 \times 50 \mathrm{~m}$ area south of the sinter mounds and depressions, and (2) scattered springs and steam vents that exploit previous permeable pathways that once provided the hydrothermal fluid which precipitated the sinter aprons. Currently there is no active silica sinter deposition at Mickey Springs.

Structures and stratigraphic relationships identified through this study favor a transport-limited and structurally controlled model of fluid transport. Sinter deposition is determined to have occurred before the most recent highstand of pluvial Lake Alvord. A climate driven model, where groundwater recharge from pluvial Lake Alvord circulates to a deep heat source and enhances spring discharge, is not supported by these findings, as no evidence was found for sinter precipitation after the drying of the lake. Future studies of other hydrothermal systems in the Basin and Range may reveal that permeable pathways along local structures are the primary drivers in this region. 


\section{Dedication}

This work is dedicated to Simbaly, who gave me motivation both to finish, and to take a break when needed. 


\section{Acknowledgements}

I take this opportunity to express gratitude to the numerous friends, family and colleagues whose support helped carry this work to completion. First and foremost, thank you to my loving wife who, while putting up with my long hours of schoolwork and many fieldtrips, made the cutest baby ever.

This work would not have been possible without the guidance of Michael Cummings, whose retirement was not complete until this work was finished. Thank you to the Geological Society of America for support of TL dating, PSU Geology department for research funding, Curt Peterson for guidance and time with GPR, and David Price for TL sample processing. I am grateful for the fieldwork assistance and great company provided by Max Rudolph, Jiaming Yang, Justin McCarley, Dougal Hansen, and David Eibert. Thank you to Adam Booth for help with structure from motion, and to Kenneth Cruikshank for help with sensor design. I also thank the Stratigraphy class of Fall 2014 and the Basin Analysis class of 2015 for your discussions and insights on GPR and field observations at Mickey Springs. Finally, I greatly appreciate the permission granted by BLM to conduct this research on their property. 


\section{Table of Contents}

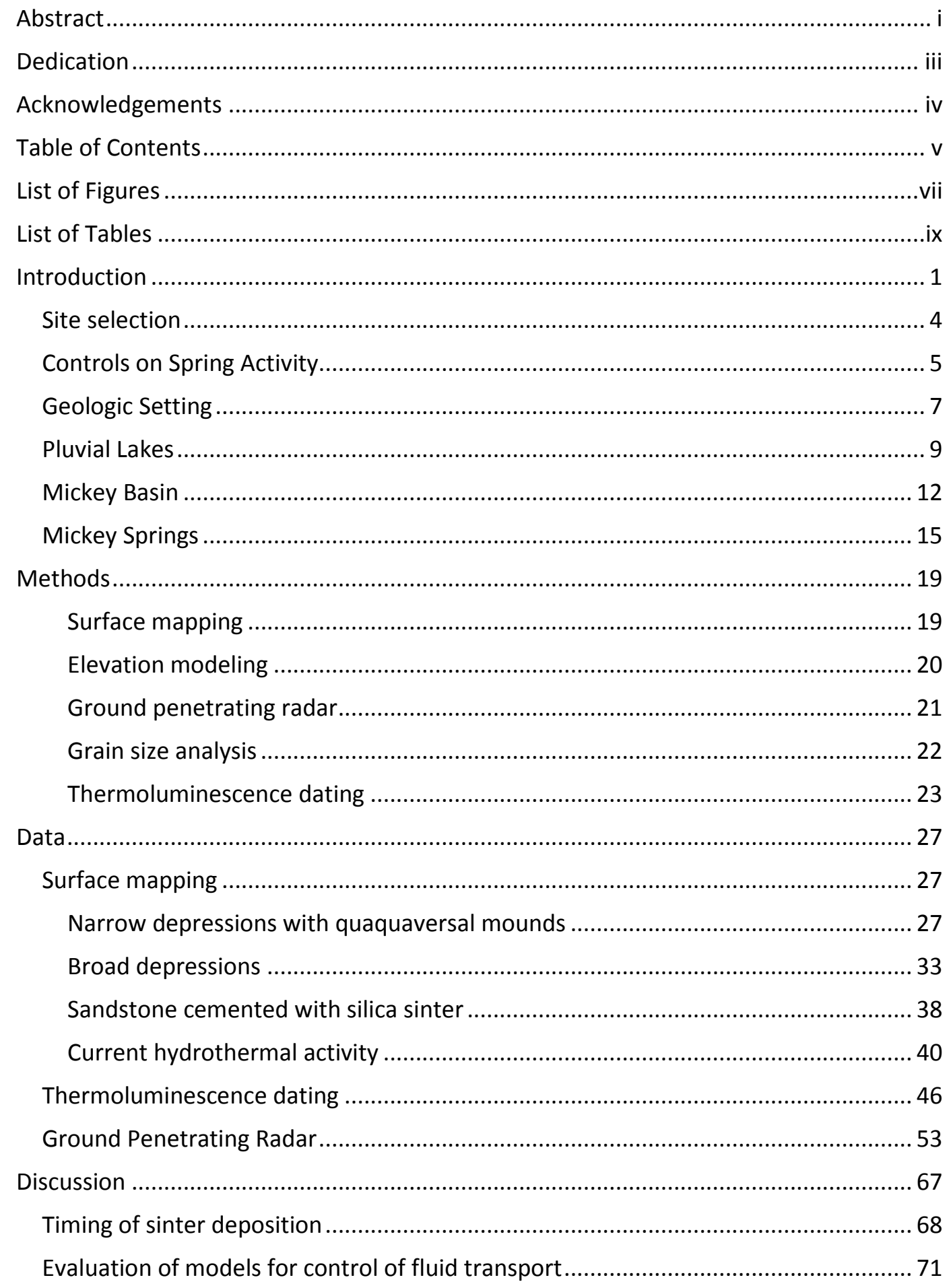




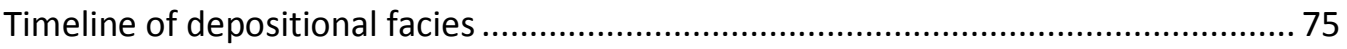

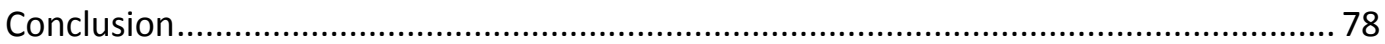

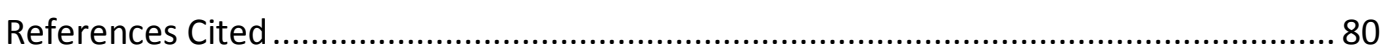

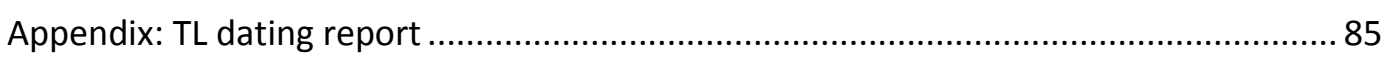




\section{List of Figures}

Figure 1: Location map of the Alvord Valley and Mickey Spring in southeastern Oregon........................... 3

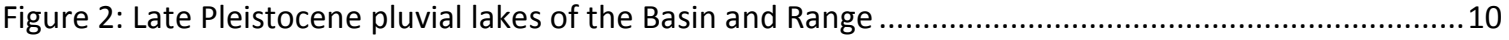

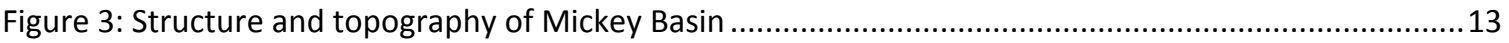

Figure 4: Elevation model of the Alvord Valley within the $1280 \mathrm{~m}$ bounding contour............................15

Figure 5: Topographic map of Mickey Springs area as mapped by J.S. Oldow (Unpublished data from 2006,

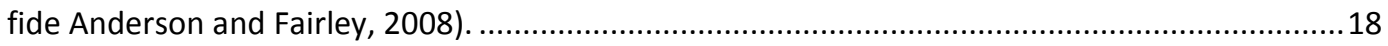

Figure 6: Three morphologies of sinter identified at Mickey Springs. ...............................................28

Figure 7: Quaquaversal sinter aprons and broad, shallow depressions...........................................29

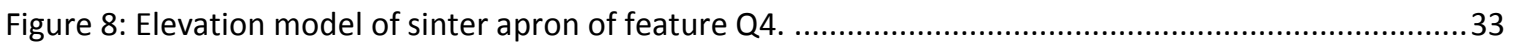

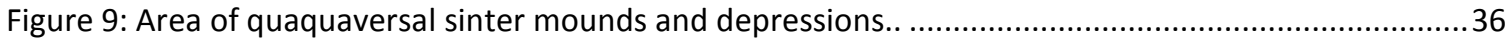

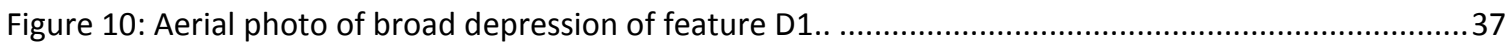

Figure 11: Photo looking west toward sandstone ridge from depression D1....................................38

Figure 12: (a) Photo looking northwest at bedding of sandstone and conglomerate. ...........................40

Figure 13: (a) Photo from March 2014 of main high temperature spring area......................................42

Figure 14: Active springs, mudpots and hot ground in a 50 × $50 \mathrm{~m}$ high temperature area at Mickey

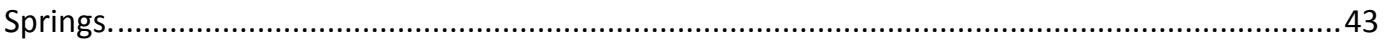

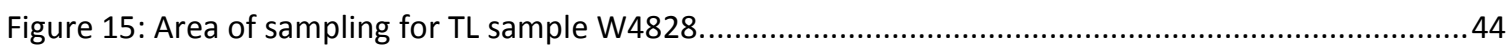

Figure 16: Feature Q9, resurfaced by mud explosion between March and May 2014............................46

Figure 17: Barplot of TL ages, showing age and uncertainty of each sample, from oldest to youngest.......48

Figure 18: Image looking north at feature Q12, location of TL sample W4829...................................50

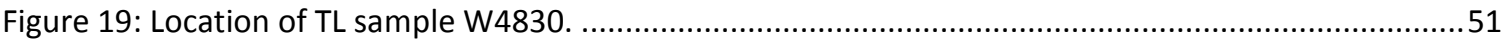

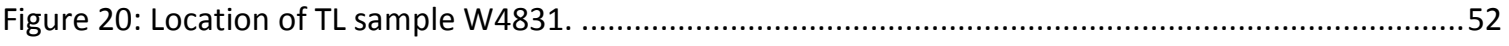

Figure 21: Original GPR data and topographically corrected data for tracks 1 with $50 \mathrm{MHz}$ antennas.......54

Figure 22: Original GPR data and topographically corrected data for tracks 1 with $100 \mathrm{MHz}$ antennas......55 vii 
Figure 23: Original GPR data and topographically corrected data for track 2 with $50 \mathrm{MHz}$ antennas. ........56

Figure 24: Original GPR data and topographically corrected data for track 3 with $50 \mathrm{MHz}$ antennas. ........57

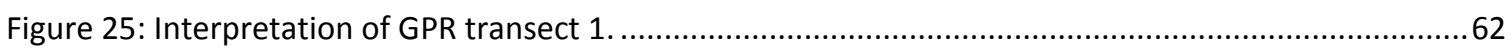

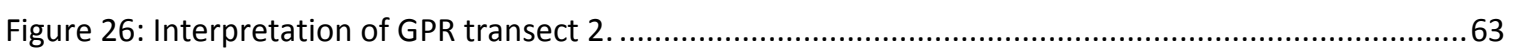

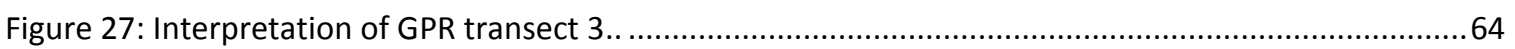

Figure 28: Interpretation of $250 \mathrm{MHz}$ GPR transect from Mowbray and Cummings (2014)...................66

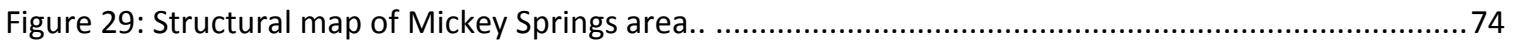

Figure 30: Timeline of major events at Mickey Springs.. ............................................................... 76 


\section{List of Tables}

Table 1: Broad depressions and quaquaversal sinter mounds found at Mickey Springs.............................30

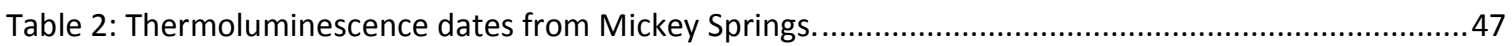




\section{Introduction}

Hydrothermal systems provide geothermal energy and emplace valuable ore deposits through dissolution, transport and precipitation. While many studies have explored the micro-scale dynamics of deposition (Fournier and Rowe, 1977; Cady and Farmer, 1996; Landtwing et al., 2010) and basin-scale tectonics (Hemphill-Haley, 1987; Hemphill-Haley et al., 1989; Singleton, 2005; Oldow and Singleton, 2008) or geochemistry (Cummings and St John, 1993), this study instead examines the mesoscale lifespan and migration of near-surface spring features at Mickey Springs in the Alvord Valley, southeast Oregon (Figure 1). The focus of this work is the stratigraphy and chronology of silica sinter deposits at the site.

The context of geothermal systems in active tectonic settings where the requisite conditions of heat source and permeable pathways are met is potentially confounded by changing climate. Mickey Springs potentially reflects changing system dynamics in response to progressive drying of the Alvord Valley (Mowbray and Cummings, 2014) from conditions of a pluvial lake to a high desert receiving less than 17 cm of precipitation a year (Western Regional Climate Center, 2014).

Duration of hydrothermal activity at Mickey Springs has not previously been determined, and age determinations of sinter at the site are conflicting. A previous study by Cummings and St. John (1993) concluded that a sandstone outcrop west of the springs was a delta which showed co-depositional cementation of sand and gravel from 
hydrothermally deposited amorphous silica, with a maximum age of $16 \mathrm{kya}$. The pooledge and laminar sinter features east of the sandstone outcrop were determined by shallow ground penetrating radar (GPR) to stratigraphically overlie, and thus be younger than, the silicified delta (Mowbray and Cummings, 2014). However, Nicholson et al. (2004) compared silica phases of Mickey Springs and Borax Lake, and determined an approximate age of sinter at Mickey Springs of 30 kya. Further, hydrothermal spring outflow persists at the site, but the current outflow is not associated with sinter deposition. The reason for and timing of this change in silica saturation in the hydrothermal fluid has not been resolved.

The goal of this study is to further constrain the age of sinter features at Mickey Springs to better evaluate the controls on hydrothermal activity. This study uses a variety of surface and subsurface field techniques to examine stratigraphic relationships at Mickey Springs and construct a relative and absolute timeline of sinter deposition to further understand hydrothermal systems in the broader context of the Basin and Range. 


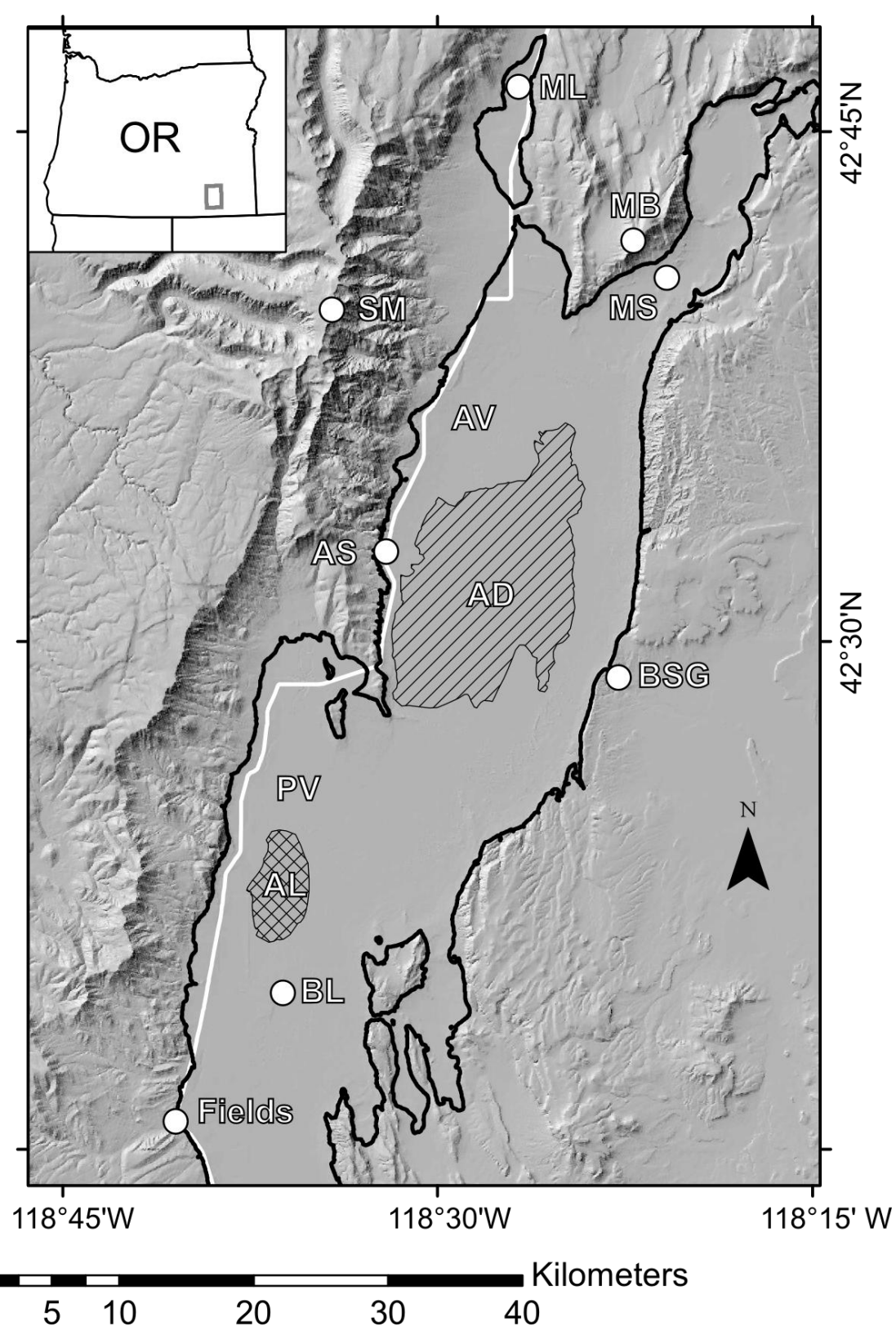

Figure 1: Location map of Mickey Spring (MS) in relation to Alvord Valley (AV) and Pueblo Valley (PV) in southeastern Oregon. High-stand elevation of Pluvial Lake Alvord is outlined in black at $1292 \mathrm{~m}$, before outburst flood at Big Sand Gap (BSG) lowered lake level to $1280 \mathrm{~m}$. Fields-Denio Road represented by white line. Other hydrothermal features in the area: Borax Lake (BL) and Alvord Hot Springs (AS) located at the foot of Steens Mountain (SM). Also located in image: Dry lakebed of Alvord Desert (AD, $1221 \mathrm{~m}$ ), current extent of seasonally wet Alvord Lake (AL, $1227 \mathrm{~m}$ ), community of Fields, Oregon, Mickey Butte (MB), and Mann Lake (ML). Bath House Trench (Hemphill-Haley et al., 1989) located at Alvord Springs. 


\section{Site selection}

Mickey Springs is one of three hot spring complexes that lie east of Steens Mountain in the Alvord Valley (Figure 1). Due to the Steens Mountain Cooperative Management and Protective Act (Public Law 106-399) the Alvord Valley Known Geothermal Resource Area (KGRA) was declared off limits for geothermal development. As part of the agreement, Mickey Springs was designated an Area of Critical Environmental Concern (ACEC) inside a Wilderness Study Area on public land managed by the Bureau of Land Management (BLM). However, Mickey Springs lies within a similar tectonic setting to many other geothermal systems in the Basin and Range (Faulds et al., 2004; Wisian and Blackwell, 2004; McKenna and Blackwell, 2004; Faulds et al., 2006; Waibel, 2011) and beyond (Reynolds, 1979) that have been developed for geothermal energy or mineral extraction. Nicholson et al. (2004) suggest springs of the Alvord basin as candidates for studies on ore emplacement through hydrothermal transport.

In addition, recent work on tectonic evolution of the region provides the framework to place this study in a broader context of the Basin and Range. Scarberry et al. (2010) examined the Abert Rim fault and applied their interpretations as a generalized structural history of the northwest portion of the Basin and Range (p. 7 below). Oldow and Singleton (2008), among others, estimated Holocene fault-slip rates in the Alvord Valley (and Pueblo Valley to the south, Figure 1) by examining offset of wave-cut terraces (p. 11 below). 
Past studies of hydrothermal springs in the Alvord and Pueblo Valleys, and particularly at Mickey Springs, have produced a basic understanding of current hydrothermal activity at Mickey Springs (e.g. Cummings and St. John, 1993; Anderson and Fairley, 2008), and show that the conditions of the system have been different in the past (e.g. Oestreicher, 2004; Nicholson and Garringer, 2004), but make no attempt to piece together this history into a timeline of depositional facies. For the purposes of the current study, Mickey Springs is the ideal place because of its high spring density in a relatively small, undisturbed area. Cummings and St. John (1993) and Oestricher (2004) identified Mickey Springs as an area to study silica sinter deposition processes.

Together, the previous micro- and macro-scale studies provide the framework to place this study into a broader context of the evolution of Basin and Range hydrothermal systems. Three questions have guided the research at this site. (1) What is the relationship between the sandstone and the laminar and pool-edge sinter features? (2) How old are the sinter features, and is there a discernible relationship between morphology, location, and time? (3) How does the hydrothermal activity relate to the presence/absence of a pluvial lake in the Alvord Valley?

\section{Controls on Spring Activity}

Conventional geothermal systems have three requisite components: (1) a heat source, (2) a water source, and (3) permeable zones to allow water circulation. Numerical models describing the inter-relations among these components have been developed by Wisian and Blackwell (2004) and McKenna and Blackwell (2004) for 
extensional geothermal systems of the Basin and Range Province. At Mickey Springs the heat source is provided by the steepened thermal gradient associated with crustal extension in the northwestern Basin and Range Province (e.g. Blackwell et al., 1978; Catchings, 1990, Scarberry et al., 2010). Oxygen/hydrogen isotopes are consistent with meteoric water (Cummings and St. John, 1993). Permeable zones for circulation of heated water are provided by active deformation along fault systems within the Steens Mountain/Alvord Valley system (Hemphill-Halley et al., 1989; Oldow and Singleton, 2008).

Of the three requisite conditions for operation of a conventional geothermal system presented above, the heat source for the Mickey Springs area is viewed as constant because of ongoing extension and crustal thinning. Mowbray and Cummings (2014) examined potential interactions between hydrology and structural development using two end-member conceptual models to describe the system.

The first model is transport-limited and structurally controlled, assuming that a continuous supply of hydrothermal fluid exists at depth. Many hydrothermal systems, including Mickey Springs (Anderson and Fairley, 2008), are attributed to increased permeability at a step-over dilation zone between two interacting fault tips (Sibson, 1987). Spring migration has been attributed to cementation of permeable pathways from subsurface silica deposition diminishing spring activity over time and the development of new springs as new permeable pathways open through fault propagation at dilation zones (Curewitz and Karson, 1997). Historical observations have 
correlated seismic activity with increased spring discharge at Mickey Springs (personal communication with Rick Wells, BLM staff Geologist, Burns District, February 2014) and in general through the Alvord Valley (Hemphill-Haley et al., 1989).

A second, supply-limited and climate driven model attributed the apparent discrepancy between current spring activity and extent of past sinter deposition to a lagged hydraulic response to the drying and warming of the climate at the end of the Pleistocene. When Pluvial Lake Alvord was present in the valley, it provided recharge to the deep heat source below the Steens Basalt, possibly initiating spring activity. Fault slip has continued through the Holocene in Mickey Basin and the Alvord Valley (Hemphill-Haley et al., 2000; Oldow and Singleton, 2008). Currently, earthquake rupture may maintain permeable pathways, but the meteoric water available to the system has been diminished with the drying of the lake and groundwater supply.

\section{Geologic Setting}

Steens Mountain exposes the volcanic stratigraphy common in the mountains surrounding the Alvord Valley. The capping unit is the $1 \mathrm{~km}$-thick, Miocene age, Steens Basalt (Hooper et al., 2002), which is underlain by older Tertiary volcanic and volcaniclastic rocks, and overlain by siliceous tuff and tuffaceous sediments of Late Miocene to Early Pliocene age (Walker and Repenning, 1965).

Recent analysis of the Abert Rim fault (135 km west of Alvord Valley, on the east side of Pluvial Lake Chewaucan (Figure 2) by Scarberry et al. (2010) used ${ }^{40} \mathrm{Ar} /{ }^{39} \mathrm{Ar}$ ages to constrain the timing of two major fault orientations, and applied these 
interpretations as a generalized structural history of the northwest portion of the Basin and Range Province. They argue that the NW-striking faults formed prior to the NNEstriking range-front faults, which initiated formation of the Alvord Valley as a graben by normal faulting at 10 Mya.

The Alvord Valley is bounded by generally north-northeast striking normal faults along range fronts to the west (Steens Mountain) and east (Tule Springs Rim). Vertical displacement along the Steens range front has been estimated at $2.6 \mathrm{~km}$ to $2.9 \mathrm{~km}$ (Hemphill-Haley et al., 1989), creating Steens Mountain (the upthrown western side of the fault), and the Alvord Valley (the eastern, downthrown side of the fault). Seismic profiles across the Pueblo Valley (South end of the Alvord Valley) show basin fill up to $800 \mathrm{~m}$ thick, and on average $500 \mathrm{~m}$ thick (Bradford et al., 2006). Vertical slip is estimated for the Alvord segment of the Steens Mountain fault zone at $0.3 \mathrm{~mm} / \mathrm{yr}$ over the last 9.3 million years by Hemphill-Haley et al. (1989). East of the Alvord Valley, the Sheepshead and Trout Creek mountains bound the valley with north-striking, west-dipping normal faults of lower slip rate and approximate equal age. Singleton (2005) and Oldow and Singleton (2008) have documented Holocene fault movements up to $4 \mathrm{~mm} / \mathrm{yr}$, indicating continued fault movement into present time. Oldow and Singleton (2008) also estimated that $50 \%$ of total east/west extension across the Alvord Valley has occurred on the Steens range front faults, $20 \%$ has happened on the eastern margin of the valley, and $30 \%$ across the basin floor in faults hidden by basin fill. Many of the structural 
features and inferred structural history is similar to that outlined by Scarberry et al. (2010) for the Abert Rim fault system.

\section{Pluvial Lakes}

Several lakes formed in valleys of the Basin and Range Province during the late

Pleistocene (Figure 2). Lake Lahontan and Lake Bonneville were the two largest pluvial lakes and have been the most studied. Benson and Thompson (1987) reported lake levels for Lake Lahontan dating back to 50 kya. They show a gradual deepening of the lake until 15 kya, and a sharp increase in lake level lasting from 15-12 kya, after which the lake quickly dried. Allison (1982) summarized pluvial lake levels studied by other authors with various periodicity going back to 200 kya. Many of these pluvial lakes, including Lake Lahontan, may have had a dry period of little or no standing water from 35 - 20 kya (Smith and Stuiver, 1979). Radiocarbon ages of snail shells in lake-bottom muds from Lake Chewaucan (now Summer Lake, Abert Lake, and Upper and Lower Chewaucan Marshes) date back to more than 25.9 kya (Allison, 1982). 


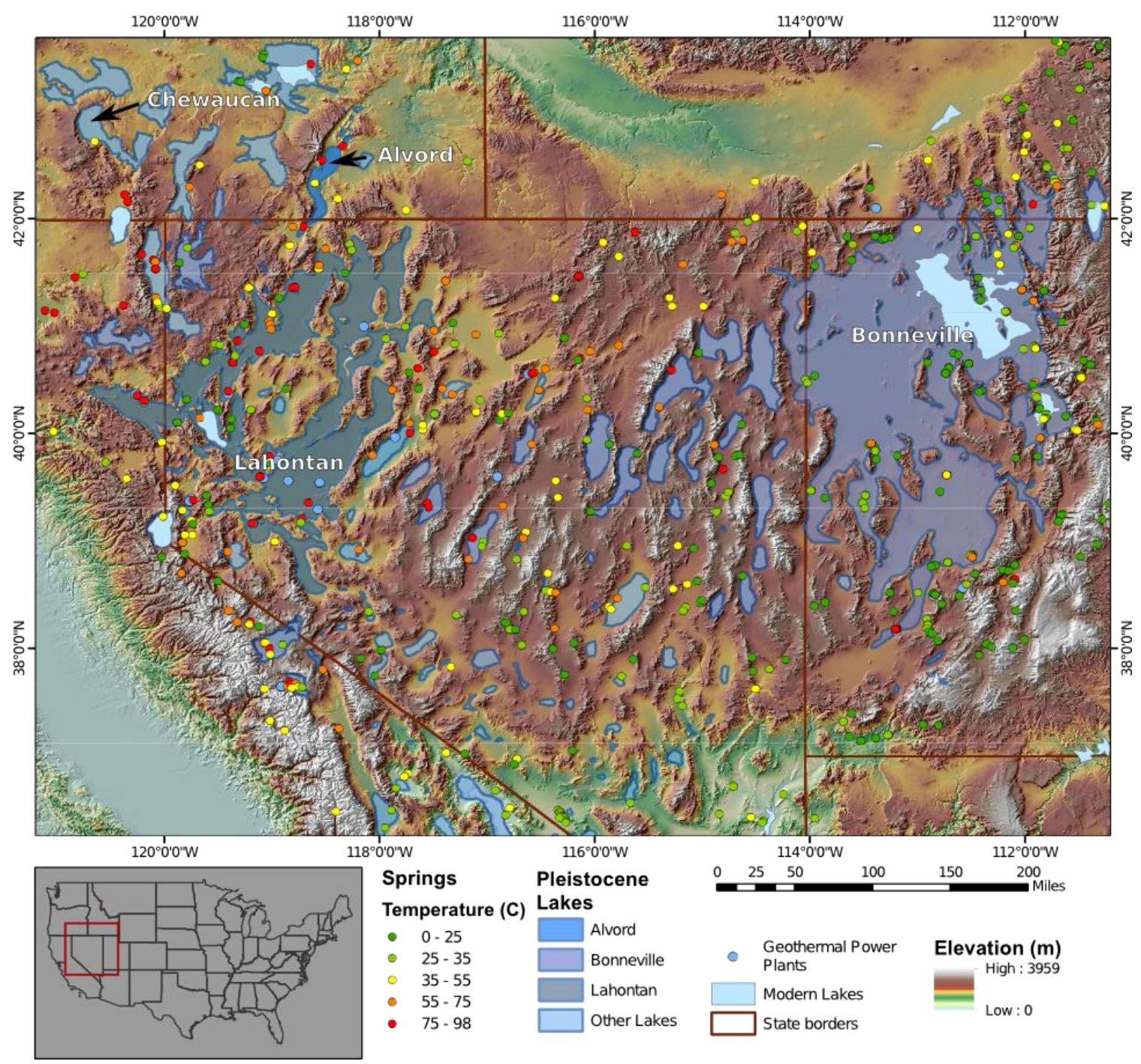

Figure 2: Many lakes filled valleys in the Basin and Range during the late Pleistocene. Shown here are Lakes Alvord, Bonneville, Chewaucan, and Lahontan, as well as other lakes. Modern lakes are shown in light blue. Water levels in many modern lakes on the map are artificially maintained by dams.

Pluvial lake Alvord has had two studied high-stands. Paleoshorelines ring the Alvord Valley up to $100 \mathrm{~m}$ above the playa and indicate the presence of a late

Pleistocene pluvial Lake Alvord (Hemphill-Haley, 1987; Hemphill-Haley et al., 1989;

Carter et al., 2006). 
Oldow and Singleton (2008) provide a summary of wave-cut terraces in the Alvord and Pueblo Valleys. Their study grouped central Alvord Valley paleoshorelines into the Serrano terraces (elevation from 1320 to $1280 \mathrm{~m}$ ) and the Alvord terraces (elevations from 1294 to $1256 \mathrm{~m}$ ), both of which have been offset by faults. The ages of the three older Serrano terraces are estimated by correlation with the better-studied (yet still poorly dated) Eetza highstand of Lake Lahontan, and loosely constrained between 200 and 130 kya.

Age estimates of the Alvord terraces vary (e.g. Carter et al., 2006; Oldow and Singleton, 2008). The age of the highest shoreline of the Alvord terraces is constrained by luminescence dating of shorelines in Bog Hot Valley (Personius et al., 2006) as 17.8 +/- 1 kya. Lake level may have retreated to as low as $15 \mathrm{~m}$ above the floor of the Alvord Valley by 10-12 kya, as determined through arrowhead analysis at archaeological sites by Pettigrew (1984). This date range is considered here to be a minimum age for the youngest shoreline at $1280 \mathrm{~m}$.

At least one episode of rapid lake-level decrease has been documented by Carter et al. (2006) when the lake overtopped Big Sand Gap (Figure 1). The overtopping water incised Big Sand Gap from 1292 m to $1280 \mathrm{~m}$, draining $11.3 \mathrm{~km}^{3}$ of water to the east and into Coyote Basin, eventually draining into the Owyhee River. Chemical correlation of an ash layer at $1243 \mathrm{~m}$ with deposition of Mt. St. Helens ash (set Sg tephra, age of 13-14 kya) suggests deep-water conditions at time of deposition, but it is 
not determined by the authors if it was deposited before or after the overtopping and incision which lowered the lake level to $1280 \mathrm{~m}$.

Archaeological evidence from Alvord Valley indicates a pattern of drying through the Holocene. After a possible lake-level minimum at around 11.5 kya (Negrini, 2002), basin lakes are known to have been habitation centers for native people. The Western Pluvial Lakes Tradition (Bedwell, 1973) was marked by continuous habitation around pluvial lakes from 9 to 5 kya. These lakes were generally not as deep as the late Pleistocene lakes (Negrini, 2002). Beck (1984) argues that the period from 5 to 3 kya saw location-dependent alternating periods of wet and dry in eastern Oregon with shallow lakes or seasonal wetlands occupying the valleys of the former deeper pluvial lakes. Today, the Alvord Desert is the driest area in Oregon, receiving less than $17 \mathrm{~cm}$ of precipitation a year (Western Regional Climate Center, 2014). In recent years, the Alvord Desert and Alvord Lake (Figure 1) have been only seasonally wet.

\section{Mickey Basin}

The Alvord Valley bifurcates to the north with a western fault-bounded valley along the Steens Mountain front and an eastern fault-bounded valley which extends with a north/northeast trend to Mickey Basin (Figure 3). The horst block between the two valleys includes Mickey Butte, which lies northwest of Mickey Springs. A small playa approximately $3 \times 5 \mathrm{~km}$ lies southwest of Mickey Springs and is referred herein as Mickey playa. This sub-basin includes isolated vegetation-stabilized mounds of sediment that indicate erosion from a once higher elevation valley floor. 


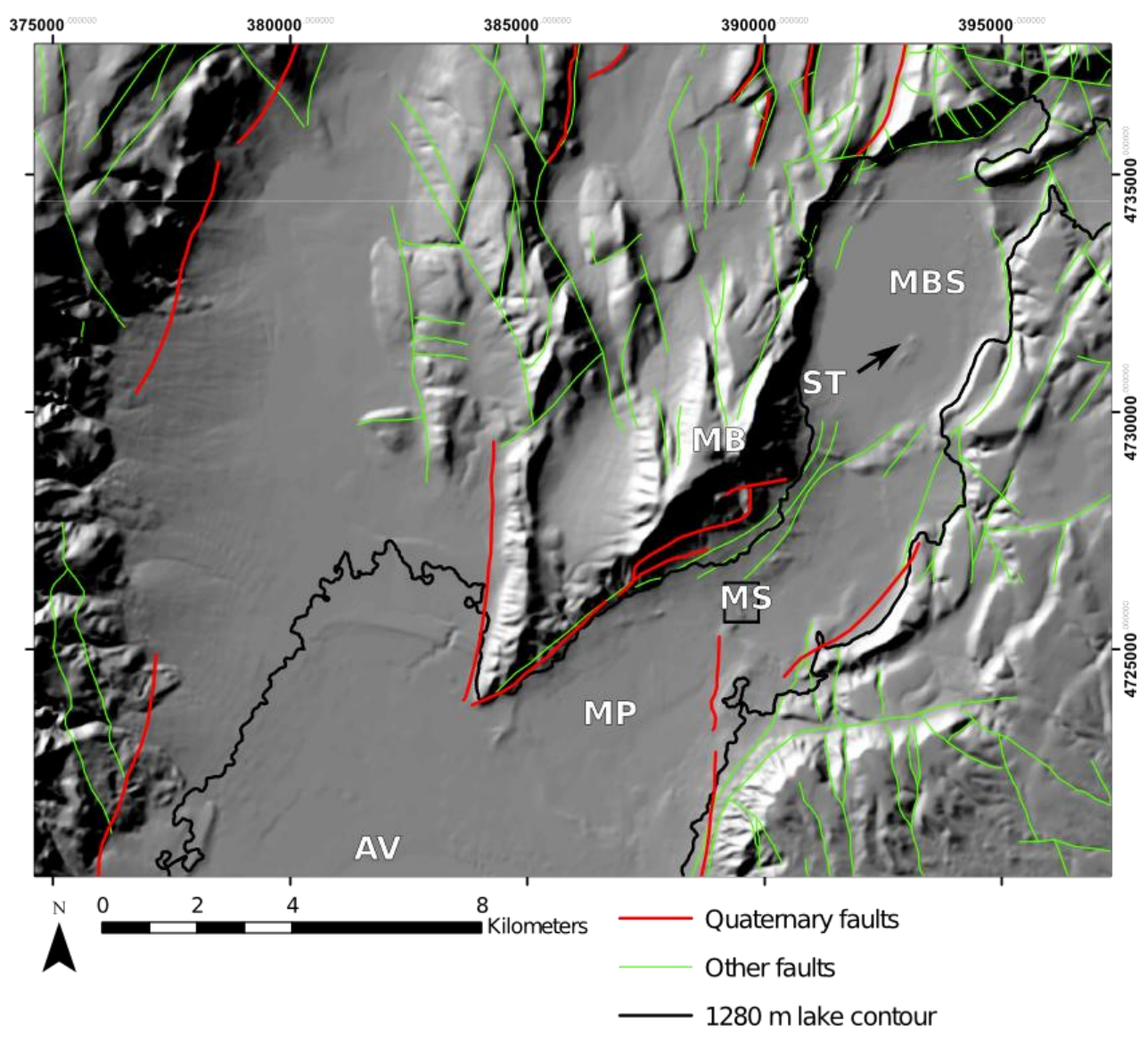

Figure 3: Mickey Basin (MBS) is a sub-basin extending to the NE from the Alvord Valley (AV). Mickey Butte (MB) is part of the horst block that separates the two arms of the Alvord Valley. Mickey Springs (MS) is directly southeast of Mickey Butte. A third sub-basin, here called Mickey playa (MP), is southwest of Mickey Springs. Several Quaternary faults have been mapped (red lines), and some have offset shorelines from pluvial Lake Alvord (1280 m shoreline indicated by black line). Several other faults have been mapped in the vicinity of varying age (green lines). Stromatolites (ST) of unknown age are located on a rocky point in Mickey Basin. Fault data are from USGS (http://earthquake.usgs.gov/hazards/qfaults/) and DOGAMI (http://www.oregongeology.org/arcgis/rest/services/Public).

The subtle topographic divides between the basins may reflect structural subdivisions (see faults in Figure 3) of the northeast arm of the Alvord Valley and suggest the shallow groundwater system may be segmented. Figure $4 a, b$ contains digital elevation models for the Alvord Valley (a) and Mickey Basin (b) below the $1280 \mathrm{~m}$ shoreline. Figure $4 \mathrm{~b}$ includes a solid black line at an elevation of $1225 \mathrm{~m}$ which delimits 
three sub-basins of the greater Alvord Valley: (1) the main valley which drains toward the Alvord Desert to the southwest, (2) Mickey playa, between the Alvord Desert and Mickey Springs, and (3) the northernmost sub-basin including Mickey Basin-the topographically lowest area.

Several surface features indicate intermittent flow from Mickey playa toward Mickey Basin. An intermittent stream channel connects the Mickey playa sub-basin and Mickey Basin between the silicified sandstone outcrop to the north and a N/NE-trending topographic high to the south. Another scoured stream channel just south of Mickey Basin along an E/NE-trending rock outcrop indicates flow into the basin from the south. 


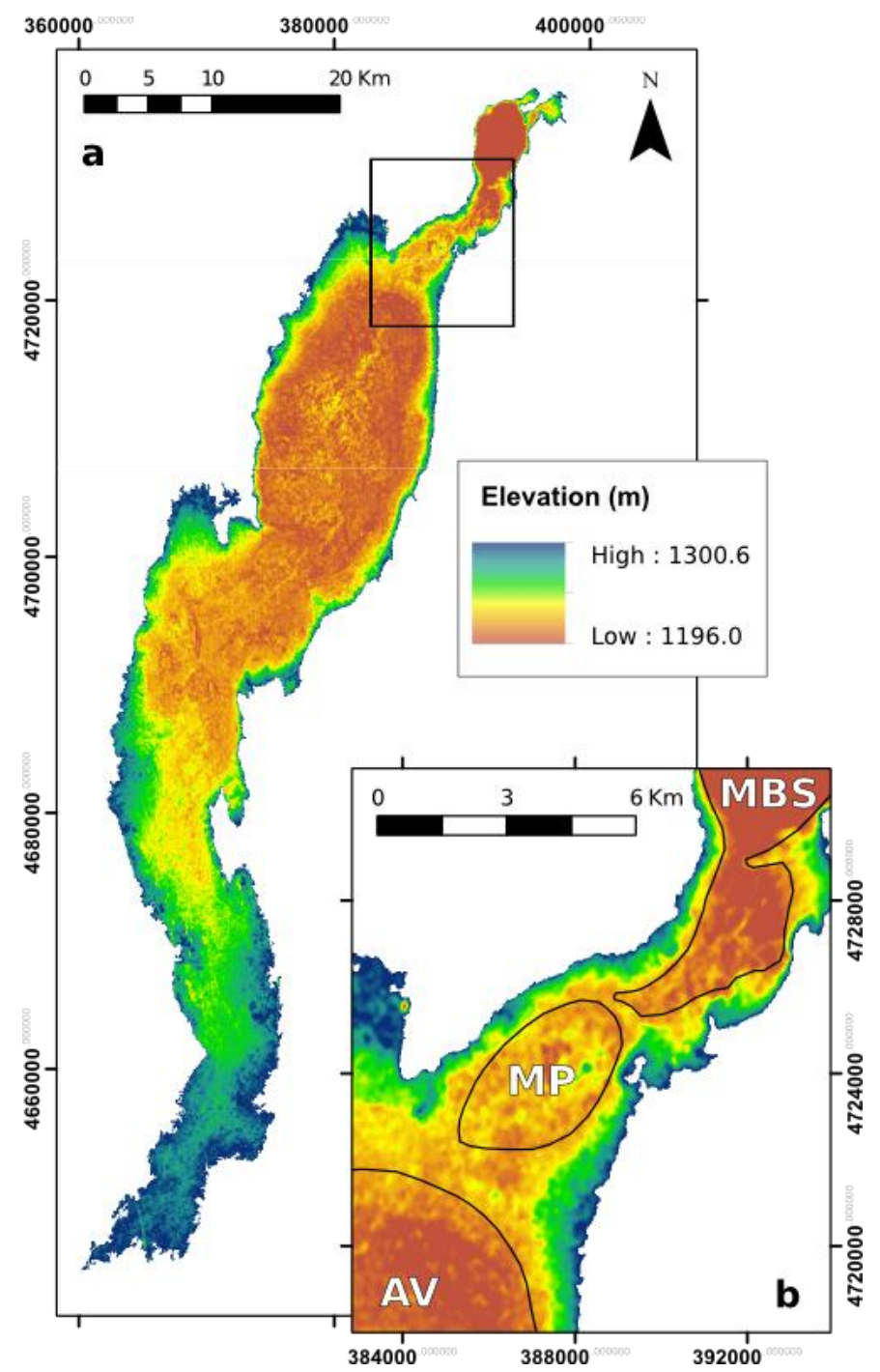

Figure 4: (a) Elevation model of the Alvord Valley within the $1280 \mathrm{~m}$ bounding contour. Elevation range is up to $1300.6 \mathrm{~m}$, as some features in the southern valley are higher than the lake contour. The sub-basin of Mickey Basin is the lowest part of the Alvord Valley basin. (b) Sub-basins with the Alvord Valley (AV) include Mickey Basin (MBS) and a topographic depression referred to herein as Mickey playa (MP). The $3 \times 5 \mathrm{~km}$ Mickey playa is isolated from Alvord Valley and Mickey Basin by subtle topographic ridges. The black line is a generalization of the $1225 \mathrm{~m}$ contour to emphasize the three separate basins.

\section{Mickey Springs}

The relatively pristine Mickey Springs consists of a tight cluster of active and inactive springs in an area smaller than 4 hectares (Figure 7) and provides a unique opportunity to study spring distribution over time. Over 50 active vents are present at 
Mickey Springs. While several high-temperature mud pots and steam vents are currently active at Mickey Springs, only one spring outflow is near boiling, and none are actively precipitating sinter (Cummings and St. John, 1993; St. John, 1993; Oestreicher, 2004). Other lower-temperature springs $\left(30-60^{\circ} \mathrm{C}\right)$ are present and have a visually estimated combined outflow volume less than the single high temperature area.

Oestreicher (2004) studied the micro-scale textures of sinter at Mickey Springs and compared them to current microbial colonies in spring outflow channels. He determined the outflow fluid temperatures at time of sinter deposition to be $40-60^{\circ} \mathrm{C}$, and supersaturated with amorphous silica. This silica precipitated from the thermal water onto the microbial communities present at the time, preserving the texture of the silicified microfossils. These findings indicate that the pool-edge sinter found in the sinter aprons at Mickey Springs was formed around or near thermal springs.

Nicholson et al. (2004) analysed the microcrystaline structure of silica sinter at Mickey Springs and Borax Lake. The samples analysed from Borax Lake were predominantly amorphous silica (opal-A), while the silica sinter at Mickey Springs has a significant portion of paracrystaline silica (opal-CT). As both spring systems have similar water chemistry, the primary deposits of silica were assumed to be amorphous, with the transition to microcrystalline structure taking place over time after deposition. This led the authors to conclude, based on silica phase, that Mickey Springs was older (up to 30 kya) than Borax Lake (4 kya). 
Anderson and Fairley (2008) modelled heat flux at Mickey Springs using temperature probes to assess the structural context of the spring system. Their work sought to classify the type of structural setting for the springs based on the conceptual models of Curewitz and Karson (1997) and favored a model of interacting fault tips, with areas of shear and extension. Further, the authors compared this finding to an unpublished fault map (Figure 5) of the Mickey Springs area by J.S. Oldow (unpublished data, 2006). The authors correlated the areas of high heat flux to the areas of extension expected in a releasing fault step.

Cummings and St. John (1993) determined that fluids from the three major hydrothermal systems in the Alvord and Pueblo Valleys (Alvord Hot Springs, Borax Lake, and Mickey Springs) are meteoric in origin. They estimate a minimum reservoir temperature for Mickey Springs of $168^{\circ} \mathrm{C}$ based on oxygen-sulfate isotope geothermometry, and interpret the reservoir stratigraphically beneath Steens Basalt, at a depth of 1 to $2 \mathrm{~km}$. 


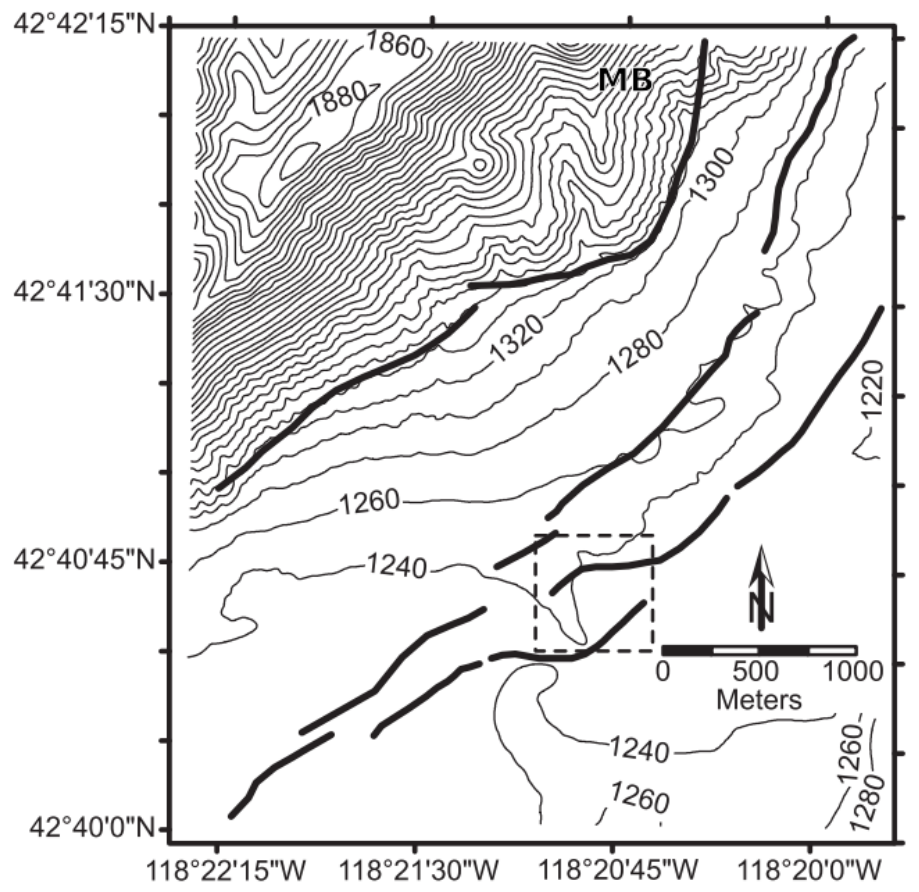

Figure 5: Topographic map of Mickey Springs area as mapped by J.S. Oldow (Unpublished data from 2006, fide Anderson and Fairley, 2008). Dashed box is study area of Anderson and Fairley (2008), and approximate extent of current study. 


\section{Methods}

\section{Surface mapping}

Surface mapping was conducted in the ACEC to identify features for further investigation. The results of this survey gave the basis for the four morphologies of spring deposits referenced in Mowbray and Cummings (2014). It also informed where to construct elevation models, use ground penetrating radar (GPR), collect sediment samples for grain size analysis, and select sites for thermoluminescence dating.

Two types of features were mapped in the spring survey: sinter morphologies and active spring vents. Both features were mapped using a handheld GPS (Garmin GPSmap 60CSx,$+/-\sim 2 \mathrm{~m})$, and a Sokkia Set 4BII total station $(+/-1 \mathrm{~cm}$, as used). Elevations were tied to USGS benchmark 28 STR (PID NX0385), with an elevation of 1,247.101 m adjusted to the North American Vertical Datum of 1988.

Sinter features were measured in both north/south and east/west directions. Central depressions were measured at the slope break to the surrounding sinter apron. Crest diameter was measured from the visually-determined topographic highs of the apron on opposing sides of the depression. Apron diameters were measured where the outer extent of the sinter was apparent, or where a slope break between the edge of the apron and the surrounding landscape was observed.

Active springs were identified visually by presence of water or moist ground supporting vegetation. Temperatures of active vents were recorded using temperature probes (Vernier TMP-BTA temperature sensor with LabQuest). 
Thermal profiles were determined in auger holes using a custom made temperature probe controlled by an Arduino microcontroller. The temperature array consisted of 10 DS18B20 temperature sensors spaced $14 \mathrm{~cm}$ apart with insulated PVC (total of $1.5 \mathrm{~m}$ length, $1 \mathrm{~cm}$ diameter), and was left in the hole for 10 minutes to 1 hour while acclimating to the temperature of the host material, and removed when observed temperature variation was less than $0.5^{\circ} \mathrm{C}$ over two minutes.

\section{Elevation modeling}

Elevation modeling of the ACEC and specific spring features was done using Structure from Motion (SfM), a photogrammetric technique which uses multiple photos of an object to build a point cloud model by matching features and comparing differences between photos. SfM has become an important tool in archeology (e.g. Stal et al., 2012; Green et al., 2014), and allows for precision scaling based on camera distance, number of angles of view, and the density of photographs taken. It has been used to model objects at a variety of scales (Westoby et al., 2012) without the large financial costs of aerial or ground-based LiDAR. While early applications of SfM had relatively high error compared to LiDAR, recent developments have shown higher accuracy (Stal et al., 2012; Westoby et al., 2012; Javernick, 2013).

A series of photos of the spring area taken from multiple elevated positions (camera on a vertical mast and a kite and balloon with attached camera) were digitally processed using VisualSfM (Wu, 2011) to create an elevation point-cloud. This point cloud was imported to Meshlab (Cignoni and Ranzuglia, 2014) for removal of erroneous 
points, and then into CloudCompare (Girardeau-Montaut, 2012) for georeferencing by visually matching GPS coordinates of photographed objects with points in the model. This georeferenced point cloud was then exported as a .las file and imported into ArcMap (ESRI, 2014) as a LiDAR dataset to create a digital elevation model (DEM), and a selection of the aerial images were georeferenced in ArcMap to the DEM.

\section{Ground penetrating radar}

Ground penetrating radar (GPR) is a nondestructive field technique that uses radar pulses to image the shallow subsurface (Davis and Annan, 1988). It is commonly used to image shallow sediments in beach deposits (Meyers et al., 1996) and river deltas (Smith and Jol, 1997), and has been used in desert settings to image alluvial fans on range fronts (Anderson et al., 2003). GPR has recently been used to image the extent of silica sinter in spring deposits (Dougherty and Lynne, 2010; Lynne and Dougherty, 2010). Mowbray and Cummings (2014) used $250 \mathrm{MHz}$ GPR at Mickey Springs and were able to resolve sinter and sedimentary structure to $2 \mathrm{~m}$ depth.

A total of three GPR transects were made in May 2014 using $50 \mathrm{MHz}$ unshielded antennas spaced $2 \mathrm{~m}$ apart operating at 1000 volts with horizontal resolution of $50 \mathrm{~cm}$ and $17 \mathrm{~m}$ penetration depth, with one line being duplicated with $100 \mathrm{MHz}$ unshielded antennas spaced $1 \mathrm{~m}$ apart operating at 1000 Volts at equal horizontal spacing and $10 \mathrm{~m}$ penetration depth. Ground wave velocity was estimated at $0.08 \mathrm{~m} / \mu \mathrm{s}$ at the crest of feature Q4 (Figure 8) with the $100 \mathrm{MHz}$ antennas by relating observed bedding changes in the exposed central depression to features in the GPR signal. The purpose of using 
these more powerful antennas for this study (compared to Mowbray and Cummings, 2014) was to look for deeper structure and bedding in the subsurface. Initial field observations of the GPR signal indicated penetration to $\sim 20 \mathrm{~m}$, which was used to set the time window. Post-processing suggested that a larger time window may have allowed resolution of deeper features, perhaps $\sim 50 \mathrm{~m}$.

Each line was surveyed using a total station (Sokkia Set 4BII), and elevations were corrected to the same USGS benchmark as the surface mapping. Ekko_View Deluxe (Sensors and Software, 2009) was used to process and visualize the GPR data. Grayscale scan displays are used for all included figures of GPR data, rather than individual wiggle traces, due to the large number of traces per transect.

\section{Grain size analysis}

Sediment samples were collected from surface sediments and auger holes both within and outside the ACEC at Mickey Springs. Auger holes were dug using an AMS 7.6 $\mathrm{cm}\left(3^{\prime \prime}\right)$ hand auger. A total of 32 samples were selected for grain size analysis: 20 samples from inside the ACE and 12 samples from outside the ACEC. Samples represented in figures are named with the convention $X X-(Y Y)$, where $X X$ represents either the auger hole or site it was collected from (e.g. 3A) or indicates it was taken immediately above a sample taken for TL dating, and optional (YY) represents an arbitrary site descriptor.

Samples were first washed through a $2 \mathrm{~mm}$ and 63 micrometer screen to separate pebbles ( $>2 \mathrm{~mm}$ ) and sand ( $2 \mathrm{~mm}-63$ micrometer) from silts and clays (<63 
micrometer). Samples were sealed in plastic bags in the field and in the lab were placed directly into the screens for wet separation, without a drying process. Up to $500 \mathrm{~mL}$ of tap water was used to rinse samples through the screens. Water was collected and passed over the samples multiple times (up to 10 passes) before being collected in a beaker. The beaker was then heated on a heating plate (Lab-Line Pyro-multi-magnestir 1268 , on High setting 1 ) to remove excess water before final drying in an oven (Precision Scientific Model 18 , set at $100^{\circ} \mathrm{C}$ ). Maximum drying time was 8 hours on a hot plate and 12 hours in the oven. The collected sand was then dried in the same oven at $100^{\circ} \mathrm{C}$ overnight, and then shaken through a series of nine screens. The gravel was re-added to the sample, and the sample was shaken for five minutes using a W.S. Tyler, Inc., RX-86 Sieve Shaker. The results are reported here on the phi scale $(\phi)$, where:

$$
\left.\phi=-\log _{2} \text { (grain size in } \mathrm{mm}\right)
$$

Silt and clay are grouped here as all grains smaller than $4 \Phi(0.063 \mathrm{~mm})$. Sand-size grains are 4 to $-1 \Phi$ (0.063 to $2 \mathrm{~mm}$ ), and pebbles range from -1 to $-6 \Phi(2$ to $64 \mathrm{~mm})$.

\section{Thermoluminescence dating}

Thermoluminescence $(\mathrm{TL})$ dating measures the amount of thermoluminescent energy stored by trapped electrons in a crystal lattice (typically quartz grains). This energy is acquired in the grains through radioactive decay of naturally occurring isotopes of elements including uranium and thorium, and the amount of energy trapped increases over time (Aitken, 1985). Exposure to sunlight releases the energy trapped in 
the grains, so TL dating is essentially measuring the time since a sediment sample was last exposed to sunlight.

TL dates can overestimate the residence time in a certain location if the grains were not sufficiently exposed to sunlight during their transport to reset the TL clock. For example, if sediment has been buried in one location for a period of time, then eroded and transported in deep water to another location, the TL date may reflect the time since burial in the original location (e.g. before lacustrine transport and deposition). If sediments have not been in place long enough to acquire a buildup of TL energy, the sample cannot be dated. Likewise, if the sample does not locally contain a sufficient concentration of radioactive parent material, or sufficient quartz crystals to trap and store the TL energy, sample ages may not be determinable or have high uncertainty. It is assumed here that dated sediments had sufficient exposure to sunlight during transport to be fully bleached and reset the TL clock.

This dating technique has been commonly used since the late 1980 's to date fluvial and coastal sediments (e.g. Groube et al., 1986; Fullagar et al., 1996). The functional range for TL dating is $500 \mathrm{k}$ to 1000 years. Thermoluminescence has been previously used to date travertine deposits in Denizli, Turkey (Ozkul et al., 2004) but has not been used in areas associated with hot spring sinter deposition.

Potential underestimation of the true time of deposition by the TL process as used here may emerge from heating of sediments by the hydrothermal water, cosmic 
ray contamination, or moisture content of the sample at time of processing. Sufficient heating can excite electrons, allowing them to escape from the crystal lattice, effectively reducing the $T L$ age. Since all plateau and analysis temperatures were at or above $275^{\circ} \mathrm{C}$, it is assumed here that near-boiling spring water has not provided sufficient heating to bleach the samples. Despite the shallow sample depth used in this study, it is assumed that samples were sufficiently deep such that cosmic ray contamination has not significantly bleached the samples. Finally, the presence of moisture in sediment acts as radiation shielding, slowing the accumulation of electrons in the traps. The moisture content of the sample during the dating process is assumed to be constant through time; if the moisture content was higher in the past (as is argued in the following discussion section) then actual age of sediments would be older than those determined by the TL process. Therefore, ages reported here are considered minimum ages.

Sediments were sampled opportunistically where available in the near-surface (from $<1 \mathrm{~m}$ auger depth), and were not collected from specific sequence boundaries or lithology changes. Sample sites were selected based on stratigraphic relationships. Due to field conditions soil sample collection was limited to within $1 \mathrm{~m}$ of the surface. Sample depths were reached with a $7.6 \mathrm{~cm}\left(3^{\prime \prime}\right)$ AMS hand auger. Samples for dating were collected with an AMS soil core sampler and driven with a slide hammer. The core sampler was a $12 \mathrm{~cm}$ long, $6 \mathrm{~cm}$ diameter (6" long by 2.5 " diameter) stainless steel core cup with plastic liner. Samples were twisted out of the ground with an auger handle to minimize disturbance of the core. Once the sample and liner were removed from the 
core cup, the ends of the liner were capped and the sample inserted into a black PVC casing and sealed for shipping.

Samples were sent to D. Price at the University of Wollongong, Australia, for processing as part of a collaborative research effort. The following is a summary of the lab procedure used (summarized from Price, 2010): The sediment is sieved to separate the $90-125$ micron grains and washed with a series of solutions resulting in $99 \%$ pure quartz grains. Samples are then split into two parts, and one part is bleached under UV light. Both groups are then further separated into smaller groups, and each group is heated to $500^{\circ} \mathrm{C}$. Comparison of the emitted light (TL) from the bleached and unbleached samples allows quantification of the total absorbed radiation. The remaining sample is crushed and placed in a scintillation screen for alpha counting to determine the uranium and thorium content. Rubidium and potassium content are also measured by X-ray fluorescence and emission spectroscopy, respectively. Combined with sample moisture content and an assumed cosmic contribution, these factors are used to determine the annual radiation dose. The age- determination of the sample is a function of the total acquired TL (paleodose) and the annual radiation dose (ARD):

$$
\text { TL Age }=\frac{\text { Paleodose }}{(\mathrm{ARD})}
$$




\section{Data}

\section{Surface mapping}

Surface mapping of the ACEC identified three sinter morphologies (Figure 6) recognized primarily by the surface expression of the feature. These features can be grouped by elevation and proximity. The following descriptions are expanded from the same field data as the "spring survey" in Mowbray and Cummings (2014), but wording has been revised for clarity and to fit the current understanding of the site. The description of the three sinter morphologies is followed by a description of the current hot springs at the site.

\section{Narrow depressions with quaquaversal mounds}

Several mounds with pool-edge sinter and quaquaversal aprons were identified (Figure 7). Most of these features lie on a topographic bench between 1235 and $1240 \mathrm{~m}$. The more southern of these features typically have aprons elongated along the southdipping slope toward the lower-elevation, high-temperature spring area. 


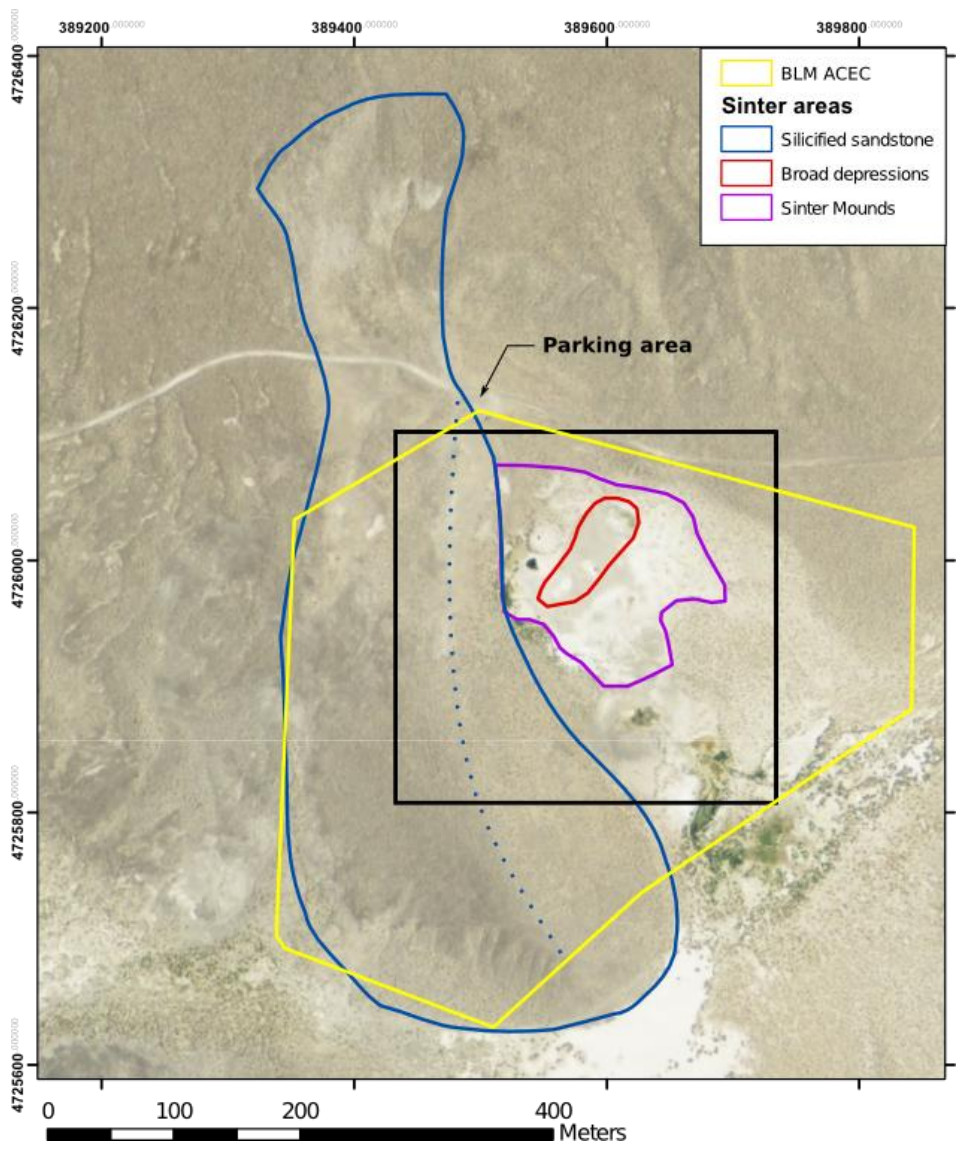

Figure 6: Three morphologies of sinter were identified at Mickey Springs. (1) silica-cemented conglomeratic to fine-grained sandstone (outlined in solid blue), (2) sinter-rimmed broad depressions blanketed with loose, fine grained sediment (outlined in red), and (3) quaquaversal sinter aprons surrounding narrow depressions (outlined in purple). Black box indicates outline for Figure 7. Yellow line indicates extent of Area of Critical Environmental Concern (ACEC) managed by Bureau of Land 
Management (BLM). Dashed blue line indicates topographic ridge of sandstone/conglomerate unit.

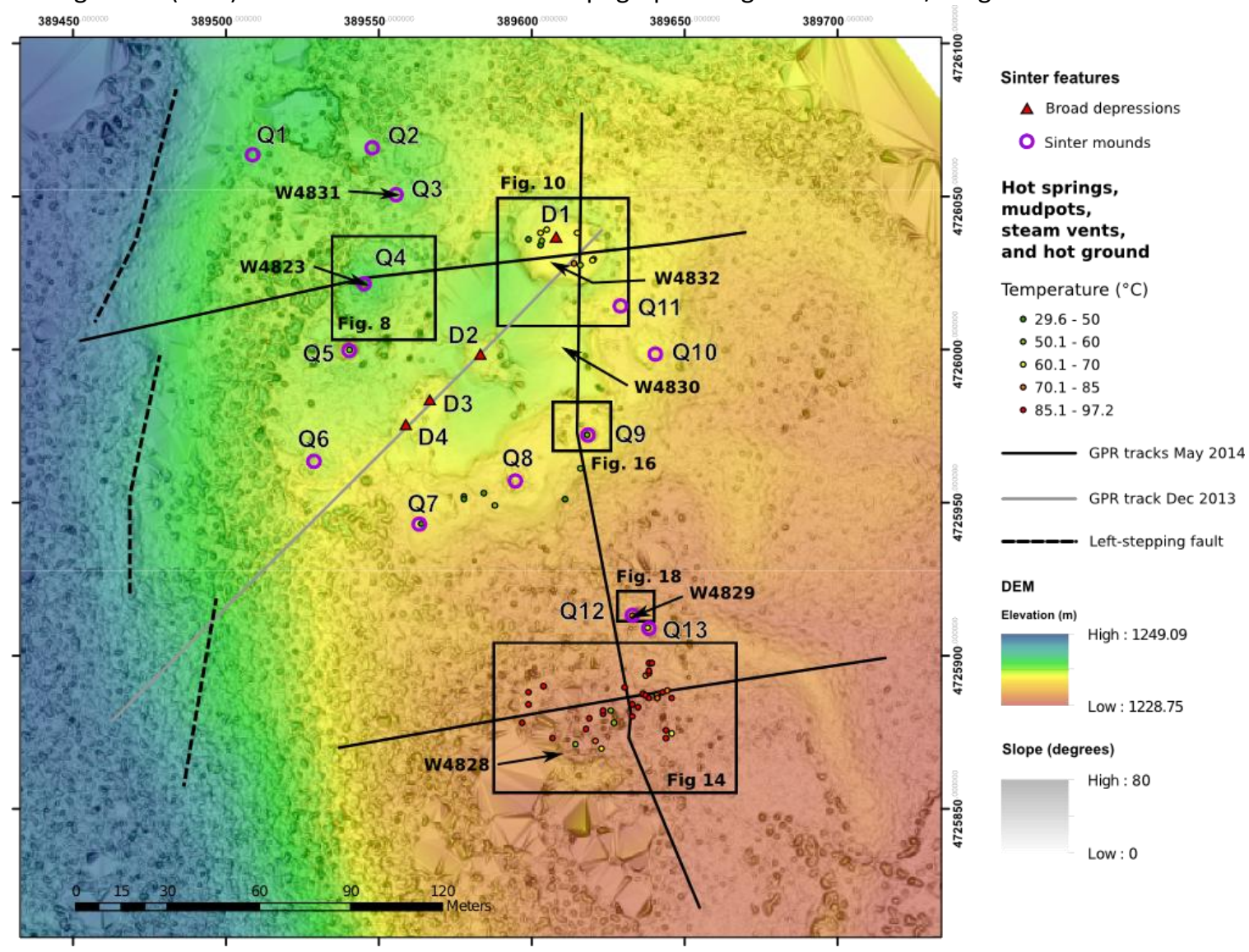

Figure 7: Quaquaversal sinter aprons (purple O) and broad, shallow depressions (red triangle). The more southern of these features (Q7, Q8, Q10), have asymmetric aprons that dip south with topography. Feature Q4, D1, and the current high temperature spring area are shown in more detail in Figures 8, 10, and 14. Feature Q9 and Q12 are shown in more detail in Figures 16 and 18, respectively. The round points colored red to green are active springs, steam vents and mud pots mapped by University of Idaho (http://webpages.uidaho.edu/BioGeoChemistry/data.htmIREF), and are colored by temperature (green: $29.6^{\circ} \mathrm{C}$ to red $97.2^{\circ} \mathrm{C}$ ). GPR track from Dec 2013 (Mowbray and Cummings, 2014) shown in gray, and tracks from May 2014 (current study) are shown as solid black line. Surface morphology and the elevation model suggest a left-stepping fault striking N-NW (dashed line). 
Table 1: Broad depressions (e.g. D1) and quaquaversal sinter mounds (e.g. Q1) found at Mickey Springs.

\begin{tabular}{|c|c|c|c|c|}
\hline & Description & $\begin{array}{l}\text { Surveyed } \\
\text { Elevation } \\
(\mathrm{m})^{1}\end{array}$ & $\begin{array}{l}\text { Depression } \\
\text { diameter } \\
(\mathrm{m})^{2}\end{array}$ & $\begin{array}{l}\text { Interior } \\
\text { vertical } \\
\text { relief }(m)^{1}\end{array}$ \\
\hline $\mathrm{D} 1$ & $\begin{array}{l}\text { Largest diameter depression in ACEC. Fine grained sediment common in depression floor, with blocks of } \\
\text { sinter exposed in rim and collapsed blocks on depression floor. Two vegetated areas are present in } \\
\text { eastern portion of depression, where two springs with no visible outflow are present. } 7 \text { other springs or } \\
\text { steam vents are present in depression floor. Temperatures of active springs range from } 38.6 \text { to } 72.5^{\circ} \mathrm{C} \text {. }\end{array}$ & 1236.72 & 32.05 & 1.77 \\
\hline D2 & $\begin{array}{l}\text { Broad depression with floor of moderately sorted silt and clay with clasts of sinter. Mound of sinter at } \\
\text { center of depression protruding from sediment with }<10 \mathrm{~cm} \text { relief. Extent of depression marked by slope } \\
\text { break coincident with transition to exterior blanket of well-sorted silt and clay. }\end{array}$ & 1237.63 & 21.25 & 0.93 \\
\hline D3 & Two overlapping depressions, both with sinter blocks exposed in depression floor. No sinter is exposed & 1237.12 & 19.55 & 1.13 \\
\hline \multirow[t]{3}{*}{ D4 } & $\begin{array}{l}\text { in walls of the depression. Slope break at edge of depression floor consistent with transition to uniform } \\
\text { exterior blanket of fine-grained silt and clay. }\end{array}$ & 1237.06 & 11.65 & 0.58 \\
\hline & & mean & 21.13 & 1.10 \\
\hline & & $s d v$ & 8.40 & 0.50 \\
\hline Q1 & $\begin{array}{l}\text { Sinter apron around slight depression of loose sediment. Apron slopes to the east, and is not apparent } \\
\text { west of the depression, where slope increases toward the topographic ridge and sandstone outcrop } \\
\text { west of spring area. }\end{array}$ & 1239.78 & 4.90 & 0.10 \\
\hline Q2 & Extensive sinter apron around slight depression of loose sediment with blocks of broken sinter. & 1238.86 & 3.55 & 0.34 \\
\hline Q3 & $\begin{array}{l}\text { Extensive sinter apron around area of loose sediment and blocks of broken sinter. Pool edge sinter } \\
\text { exposed around area of loose sediment. }\end{array}$ & 1238.80 & 3.35 & 0.12 \\
\hline Q4 & $\begin{array}{l}\text { Quaquaversal sinter apron with deep central depression. Vertical exposure in depression exposes } 90 \mathrm{~cm} \\
\text { of pool edge sinter above } 110 \mathrm{~cm} \text { of laminated sinter interbedded with coarse sand and silicified root } \\
\text { casts. Lower throat of depression broadens, and depression floor consists of loose, poorly sorted sand } \\
\text { and silt with blocks of pool edge sinter up to } 1.5 \mathrm{~m} \text { collapsed from apron above. }\end{array}$ & 1239.80 & 3.30 & 2.61 \\
\hline
\end{tabular}


Q5 Active spring pool with visually estimated $5 \mathrm{~m}$ of vertical relief visible in pool. Near horizontal sinter

Q6 Quaquaversal sinter apron around slight depression. Outflow channel from Q5 passes west and south of apron. Apron more extensive to south and east of depression, following slope of local topography.

Q7 Sinter apron surrounding slight depression of loose sediment. Depression is near northern extent of apron, and apron slopes away to south and east with local topography.

Q8 Sinter apron exposed in half-circle on souther portion, dipping away with local topography. Flat area of loose poorly sorted sand and sinter clasts inside radius of pool edge sinter. Mound of loose well-sorted silt and clay in center of flat area.

Q9 Sinter apron around central depression. Active spring pool with cloudy brown water and green microbial mats covers $1 / 4$ of depression floor. Inward-dipping pool edge sinter overhangs pool in depression. In March 2014, sinter apron was exposed, and in May 2014 was coated by $13 \mathrm{~cm}$ of moderately sorted silt and clay erupted from the depression spring pool.

Q10 Extensive sinter apron forming complete cap with no central depression, but thickness of sinter $(0.4 \mathrm{~m})$ is exposed by collapsed block, which reveals open space extending for $2.8 \mathrm{~m}$ laterally and $0.6 \mathrm{~m}$ vertically between the bottom of the sinter apron and a base of fine-grained sediment and sinter blocks.

$\stackrel{\omega}{\mapsto}$ Q11 Circular sinter apron with central depression. Sinter apron exposed and broken in blocks, with no sediment blanket coating the apron.

Q12 High-relief sinter apron with exposed pool-edge sinter surrounding small depression. Sediment in depression was poorly sorted silt up to $4 \mathrm{~cm}$ clasts of sinter. A fracture in the sinter apron extends N/NE from the depression. Water is present in fracture approximately $50 \mathrm{~cm}$ below ground surface, and depression sediment temperature is $59^{\circ} \mathrm{C} 27 \mathrm{~cm}$ below the surface of the depression floor.

Q13 Small active spring pool rimmed with sinter apron. No current outflow but visible established outflow channel into depression of Q12. Spring vent in center of central spring pool.

${ }^{1}$ Elevations measured with Sokkia Set 4BIl total station $(+/-1 \mathrm{~cm})$.

${ }^{2}$ Pool dimensions measured by tape measure $(+/-1 \mathrm{~cm})$ on east-west and north-south axis

* mean excludes vertical relief of Q4 
Many of these features have narrow, shallow central depressions, but some have no identifiable center. Feature Q4 has typical morphology, but is unique in that it has over $3 \mathrm{~m}$ of relief in the central depression (Figure 8). The central depression is rimmed with inward-dipping pool-edge sinter from the highest point on the sinter apron down to $90 \mathrm{~cm}$ within the vertical wall of the depression. Below this, laminar sinter is exposed from $90 \mathrm{~cm}$ to $2 \mathrm{~m}$. Moderately sorted, subangular to rounded, coarse-grained sand is common between sheets of sinter, and silicified root casts are common. Both the pooledge and laminar sinter are exposed in steeply dipping outcrops. Below the laminar sinter, uncemented, moderately sorted, subangular to rounded, coarse-grained sand is exposed (1A-DT). Silicified root-casts are also present in this sediment down to $2.9 \mathrm{~m}$. The depression widens below $2 \mathrm{~m}$ and some cavities extend at least $2 \mathrm{~m}$ horizontally under the laminar sinter and above the floor of the depression (see Figure $8 \mathrm{c}$ ). The sediment below $2.9 \mathrm{~m}$ is well sorted, subrounded to rounded fine sand and silt (1C-DT). A large block of pool-edge sinter, broken from the rim, lies on the floor of the depression. 

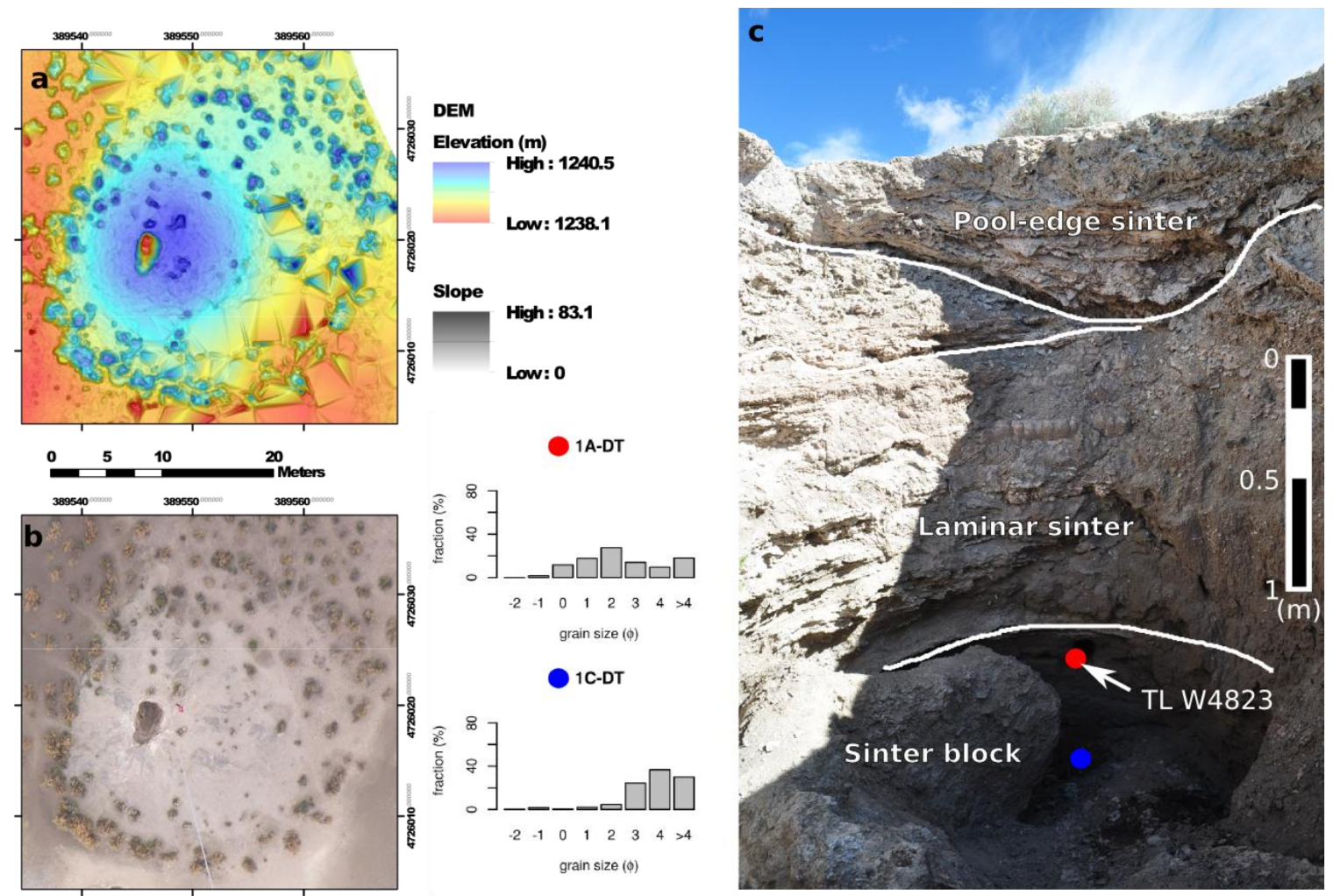

Figure 8: (a) Elevation model of sinter apron of feature Q4 with draped slope map to show detail. (b) Georeferenced aerial photo of feature Q4 at same extent as (a). (c) Stratigraphy exposed in the central depression of feature $\mathrm{Q} 4$, looking north while standing on floor of central depression. Inward-dipping pool-edge sinter is exposed at the surface down to $90 \mathrm{~cm}$. Laminar sinter interbedded with coarse sand is present from $90 \mathrm{~cm}$ to $2 \mathrm{~m}$. Uncemented sediment with silicified root-casts are present between layers of laminar sinter. Location of TL sample indicated by arrow. Grain sizes charts of two sediment samples are shown in center of image, with sample location indicated by corresponding colored dot.

\section{Broad depressions}

Several broad depressions are present in the ACEC (Figure 9). The largest of

these features has pool-edge sinter exposed around much of the rim surrounding the depression, and is shown in Figure 10. These depressions are 12 to $32 \mathrm{~m}$ in diameter, with an average depth of $1.1 \mathrm{~m}$. The depressions form a linear trend on a E/NE to W/SW axis, at an elevation of $1237 \mathrm{~m}$. The floors of the depressions are typically dry, loose sediment, but blocks of sinter up to $1 \mathrm{~m}$ are visible at the surface. A $0.6 \mathrm{~cm}(1 / 4) \times 1.5 \mathrm{~m}$ 
metal rod was used to probe the subsurface to identify areas of loose sediment (rod will penetrate when pushed by hand) and sinter (rod will not penetrate). Probing in the depression floor varied between smooth to gritty-sounding and easily inserted, to meeting refusal at as little as a few centimeters below the surface. In areas of the depression rim where sinter is exposed, probing laterally with a metal rod beneath the exposed sinter is able to penetrate to the length of the rod, which indicates the sinter apron here does not have great vertical thickness but overlies loose sediment in a similar stratigraphic relationship as exposed in the depression of feature Q4.

Sediments in the depression floor are fine-grained silt and clay with blocks of pool-edge sinter and silicified root casts (Figure $11 \mathrm{c}$ ). An auger was used to sample sediments in the southwest part of the depression, where probing with the metal rod met no refusal. The sediment was removed as intact as possible and reassembled for the photo in Figure $11 \mathrm{~d}$. The top $27 \mathrm{~cm}$ consisted of $70 \%$ well-sorted brown silt and clay. The coarse portion (larger than fine sand) of the near-surface sediment was composed primarily (60\%) of angular to rounded sinter fragments that did not effervesce with $\mathrm{HCl}$ (Figure $11 \mathrm{~b}$ ). Root fragments were also common in the coarse portion (40\%). Both the root and sinter fragments have a coating of carbonate which dissolves in $\mathrm{HCl}$. Less than $1 \%$ of this sample was comprised of lithic fragments. The surface of this sediment is often crunchy underfoot when dry, but makes a thick sticky mud when moistened by precipitation. A sample collected from the surface in dry 
conditions from a thin $(<1 \mathrm{~cm})$ cohesive crust dissolved completely in $\mathrm{HCl}$. This crust overlies loose, powdery silt and clay.

Grain size decreased with depth, while uniformity and rounding of grains increased with depth down to $40 \mathrm{~cm}$. Below $40 \mathrm{~cm}$, sediment was $85 \%$ well-sorted green silt and clay which did not react with $\mathrm{HCl}$ (Figure 11 b). Sand grains are subrounded to rounded. The coarse portion was $80 \%$ sinter and $20 \%$ lithic fragments (mostly basalt), and lithic and crystal content increased to $50 \%$ of total at the finest sand-grain sizes. This auger hole was dug to $113 \mathrm{~cm}$, where the sediment was saturated and too fine to be brought up in the auger. The water table was at $35 \mathrm{~cm}$. The temperature probe was inserted into the auger hole, and pushed easily further into the saturated soil to a total depth of $165 \mathrm{~cm}$. Soil temperature increased with depth, from $28^{\circ} \mathrm{C}$ at $40 \mathrm{~cm}$, to $47^{\circ} \mathrm{C}$ at $165 \mathrm{~cm}$.

Sinter is seldom exposed in the higher ground surrounding the depressions. Instead, the sinter aprons are often buried by loose fine grained, well-sorted silt that effervesces with $\mathrm{HCl}$. The coarse-grained portion is primarily rounded sand-size grains of sinter. The extent of the silt is indicated in Figure 9. The sediment blanket was probed with a metal rod to investigate total thickness of the unit, and penetrated to depths up to $1.5 \mathrm{~m}$ before meeting refusal. Sediments outside the area of blanketing silt are typically poorly sorted coarse- to fine-grained sand (Figure 9). 


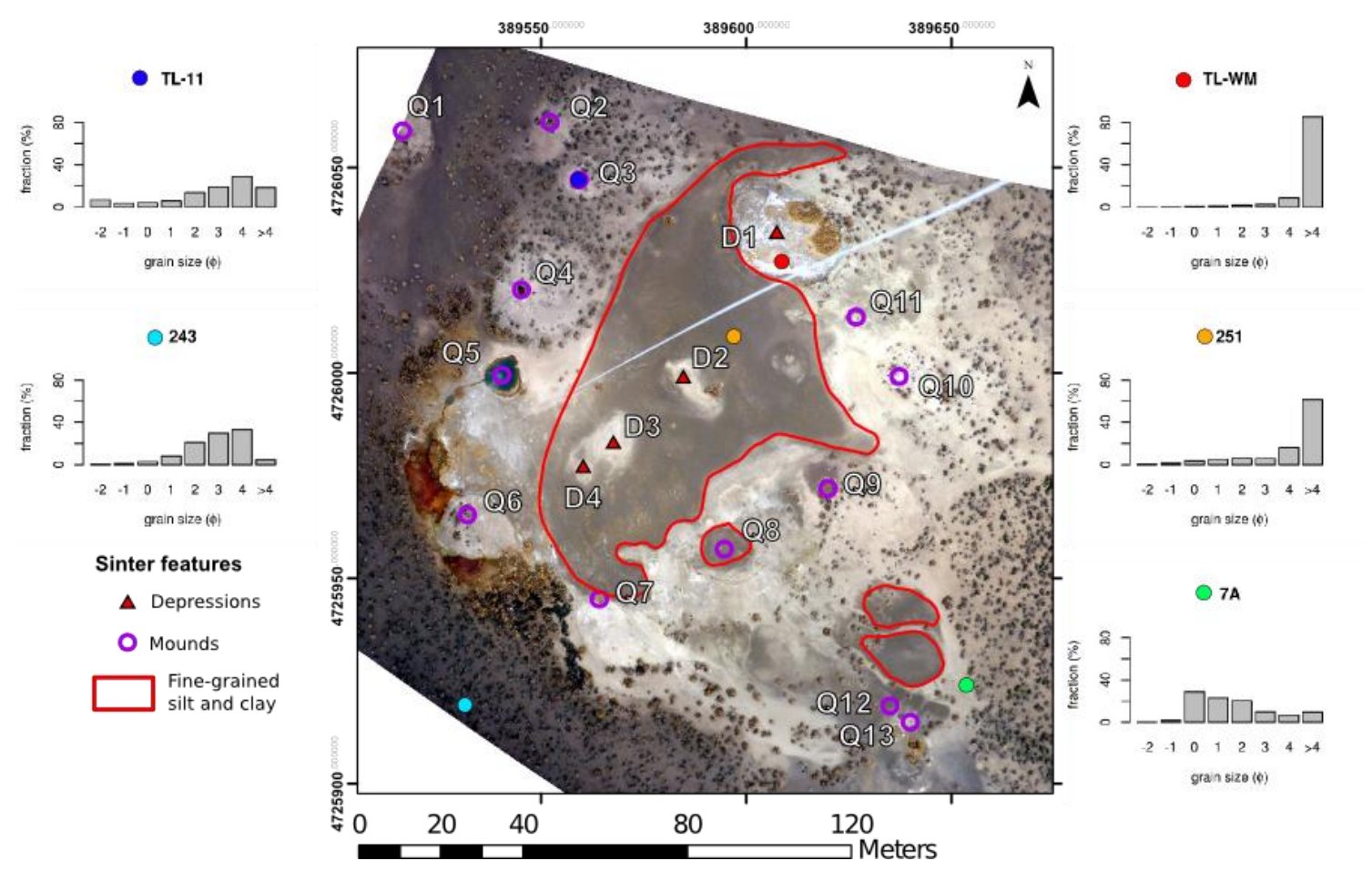

Figure 9: Area of quaquaversal sinter mounds and depressions. Depressions are blanketed with fine-grained silt and clay (corresponding red and orange dots) that effervesces with $\mathrm{HCl}$ (areas outlined with red line). White areas in photo are exposed sinter or broken sinter gravel and sediment. Typical sediment outside of this area is poorly sorted coarse- to fine-grained sand (blue, teal, and green dots). 


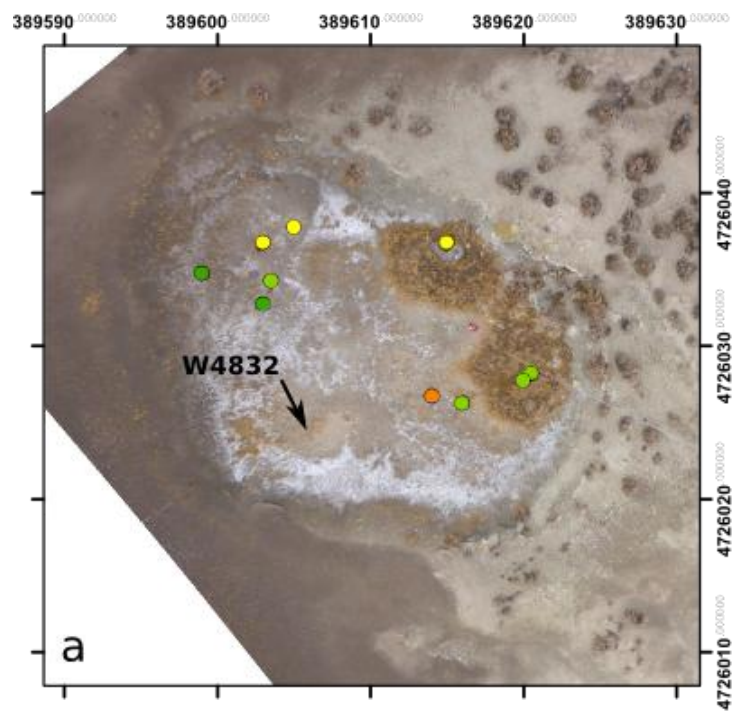

Springs and steam vents

Temperature $\left({ }^{\circ} \mathrm{C}\right)$

○ 38.6 - 50 ○ 60.1 - 70

० $50.1-60 \circ 70.1-72.5$

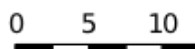

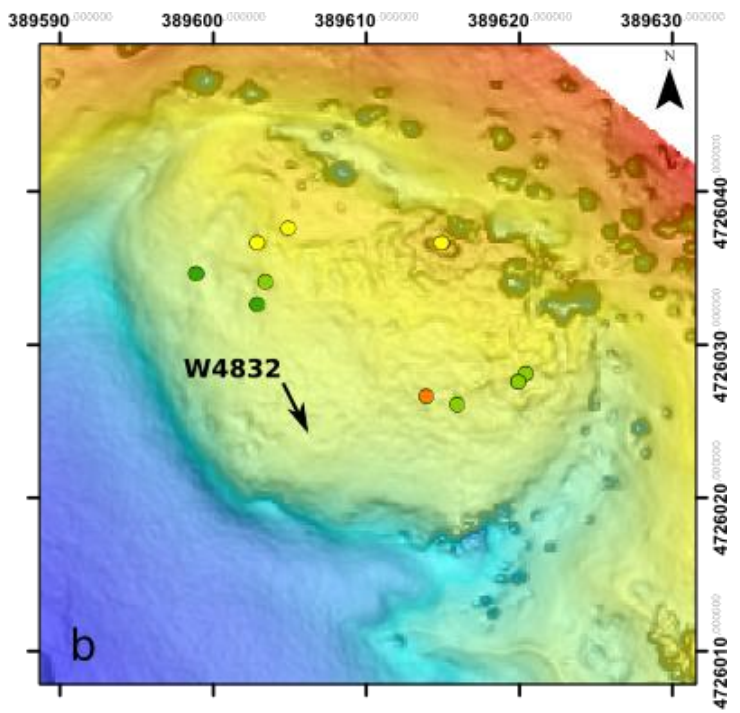

DEM

Elevation (m)

High : 1238.97
Meters

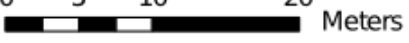

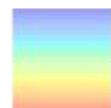

Low : 1233.68

Figure 10: (a) photo of broad depression of feature D1. (b) Elevation model of feature D1 showing relatively sharp interior slope of depression. Apron surrounding depression gradually slopes away from depression where sinter is exposed (northeast portion) and is relatively horizontal where blanketed with fine-grained silt and clay (southwest portion). Pool-edge sinter outcrops at high-slope areas around edge of depression. 


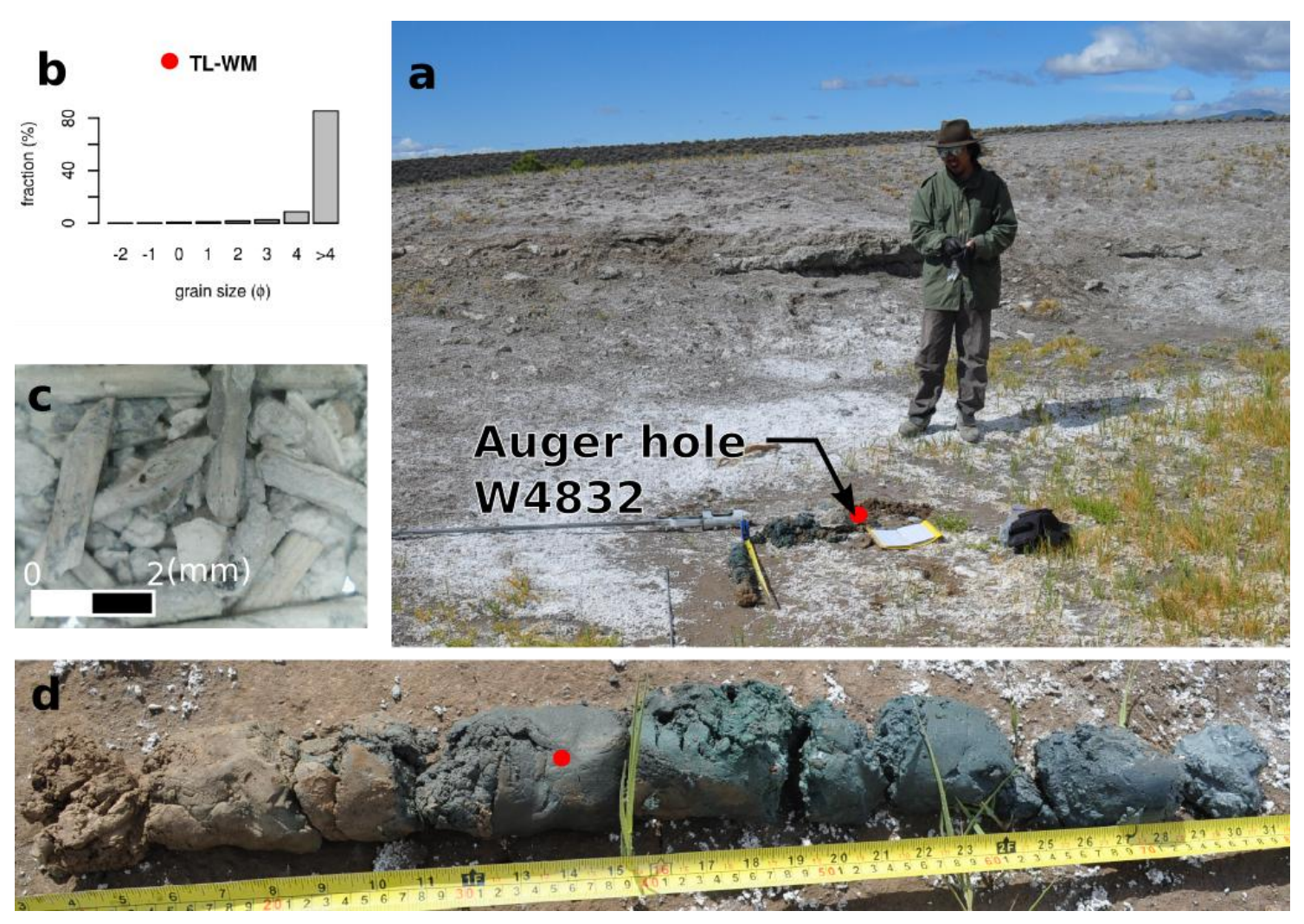

Figure 11: (a) Looking west toward sandstone ridge (distant vegetated ridge) from depression D1. Auger hole for TL sample W4832 is in loose sediment in depression floor (red dot). Sinter outcrop is visible $1 / 2$ way up rim around central depression. Sinter surrounding depression is blanketed with loose finegrained sediment. (b) Grain size analysis for sediment sample collected from $20 \mathrm{~cm}$ below the surface, and immediately above the TL sample. (c) Root fragments and silica sinter from coarse portion of sediment collected from surface of D1. (d) reconstructed soil column from auger hole in D1. Surface sediments (left) were loose sand and silt with fragments of sinter and roots. Grain size decreased with depth, while sorting increased. Approximate TL sample depth indicated by red dot.

\section{Sandstone cemented with silica sinter}

Silica-cemented sandstone and conglomerate outcrops in a topographic ridge

with morphology similar to an alluvial fan extending southward from the Mickey Butte horst block north of Mickey Springs. This fan covers the southwest half of the ACEC.

Figure 6 shows the extent of the sandstone/conglomerate unit, and location of a topographic ridge oriented roughly $\mathrm{N} / \mathrm{S}$ at an elevation of $\sim 1247 \mathrm{~m}$ (blue dotted line). Outcrop is common in three areas: (1) along the ridge, (2) in a scoured channel north of the parking area and road, and (3) on the southwest margin of the fan. 
The outcrops in this area vary between fine-grained, well-sorted sandstone to poorly sorted conglomerate, typically in beds $\sim 10 \mathrm{~cm}$ thick. In the conglomerate units, clast sizes are up to $5 \mathrm{~cm}$. Clasts are mainly basalt with rare andesite and rhyolite (St. John, 1993). The coarser-grained conglomerates are toward the north and east exposures, and maximum grain size decreases toward the southwest.

Immediately west of the ridge, topography dips gently to the southwest. Bedding is primarily horizontal and outcrop is more common on the western and southern extent of the fan where the slope increases. Ripple marks and trough cross-beds are common in the finer-grained beds. Root casts are common in exposures in the southwest portion of the sandstone, and sparse petrified wood is preserved in the matrix. Locally, sediment grains are suspended in opaline silica matrix (Figure 12 b), indicating that the fan was accumulating in the presence of hydrothermal fluids saturated in opaline silica discharged from hot springs (Cummings and St. John, 1993).

East of the ridge, a sharp slope break exposes blocks of sandstone and conglomerate on the east-facing slope. Dip angle and dip direction of bedding are not constant and do not necessarily follow topography of the slope, but generally dip to the northeast at angles up to $45^{\circ}$. The elevation model indicates a left-stepping fault pattern at the slope break on the ridge line (Figure 7). Although much of the eastern portion of the ACEC has silica sinter, no outcrop of the silica-cemented sandstone is present east of the outflow channel from feature Q5 (Figure 9). 
In outcrops of the conglomerate and sandstone north of the parking area (Figure

6), bedding along an incised valley dips to the north. Northeast of the parking area, slope wash at and below $\sim 1247 \mathrm{~m}$ contains clasts of loosely cemented to compacted sand, but no outcrop of silica-cemented sandstone is present.
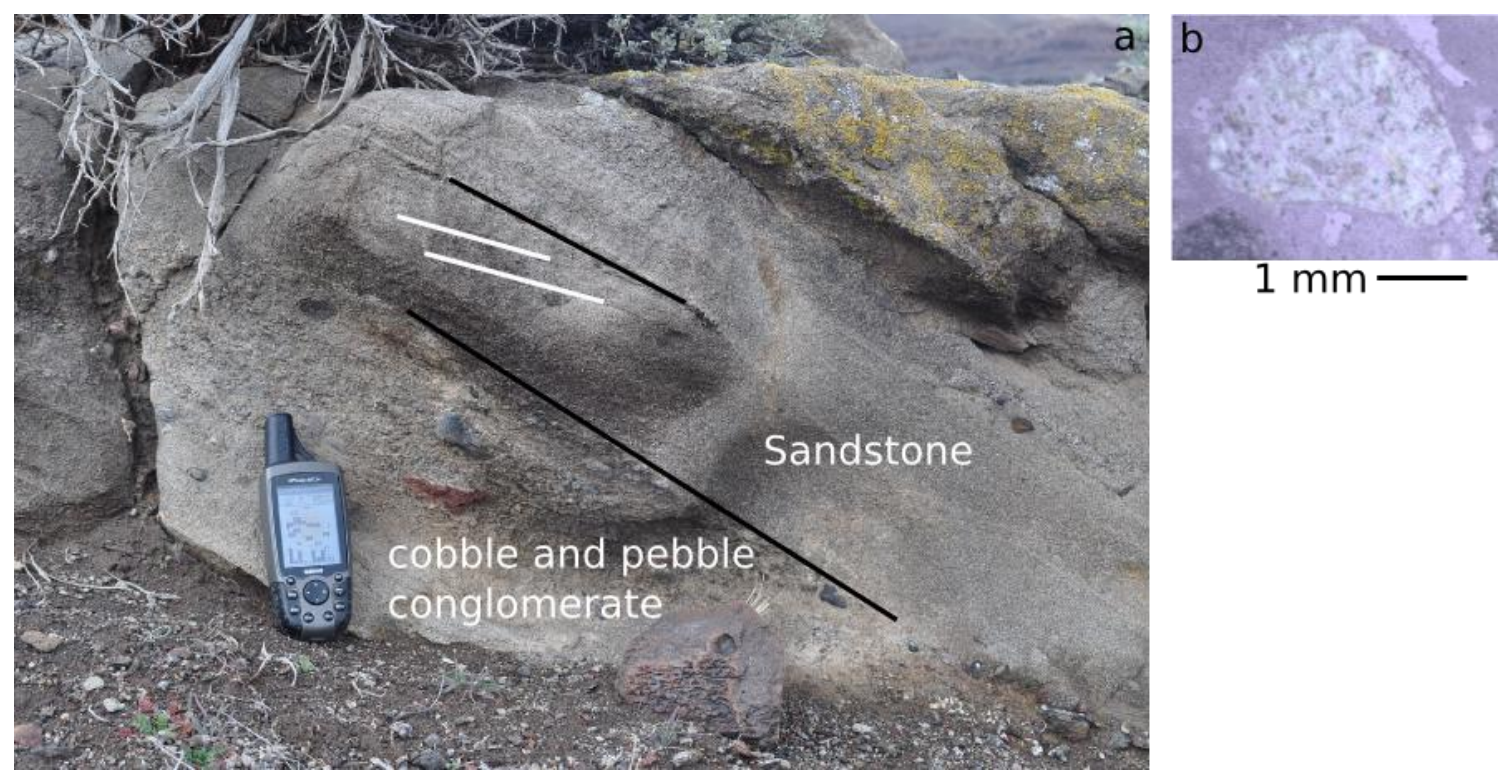

Figure 12: (a) Photo looking northwest at bedding of sandstone and conglomerate. Bedding (black lines) dips to the northeast. Bedding orientation is not continuous across outcrops. Sandstone layer has cross bedding (white lines) indicating flow toward upper left. Cobbles in conglomerate unit measure up to $10 \mathrm{~cm}$. (b) Photomicrograph of thin section from sandstone. Sand grains are matrix-supported in silica sinter.

\section{Current hydrothermal activity}

The current hydrothermal activity at Mickey Springs is described here in two

parts. First, the springs located at a lower elevation from the sinter features are described. These features make up the majority of the active springs at Mickey Springs. The second group of springs are those located in proximity to the sinter features described above. 


\section{Current hydrothermal activity not associated with sinter}

The highest temperature current hydrothermal activity at Mickey Springs is a cluster of springs, steam vents, mud pots and hot ground (Figure 14). These features are located in a $50 \times 50 \mathrm{~m}$ area at an elevation of $1230 \mathrm{~m}$ below and to the south of the sinter mounds and depressions. There is no evidence of current or past sinter deposition in this area, but carbonate is being deposited in outflow channels where effluent temperatures are approximately $73^{\circ} \mathrm{C}$. The morphology of features is diverse. The mud pots are typically 1-2 m diameter depressions with a floor of wet, bubbling mud. The steam vents are higher in elevation and just north of the high-temperature springs. The hot ground is again north and higher elevation from the other features. An irregularlyshaped, lower-temperature pool is located amongst the high-temperature springs and mud pots.

The majority of the high-temperature water outflow emits from two springs located along N/NE oriented cracks (Figure 13). Over the course of fieldwork, the main outflow volume shifted between these two springs. In March 2014, the main outflow from the high-temperature area emanated from a horseshoe-shaped spring, while a series of three $20 \mathrm{~cm}$ diameter bubbling pools east of the horseshoe had water $10 \mathrm{~cm}$ below the ground surface but no outflow. In May 2014, these three springs had an outflow visually estimated to be greater than that of the horseshoe spring. Vegetation around the new outflow channel had died, and colonization by high-temperature 
biofilms was observed. This condition persisted until at least Feb 2015, which was the last site visit before completion of this study.
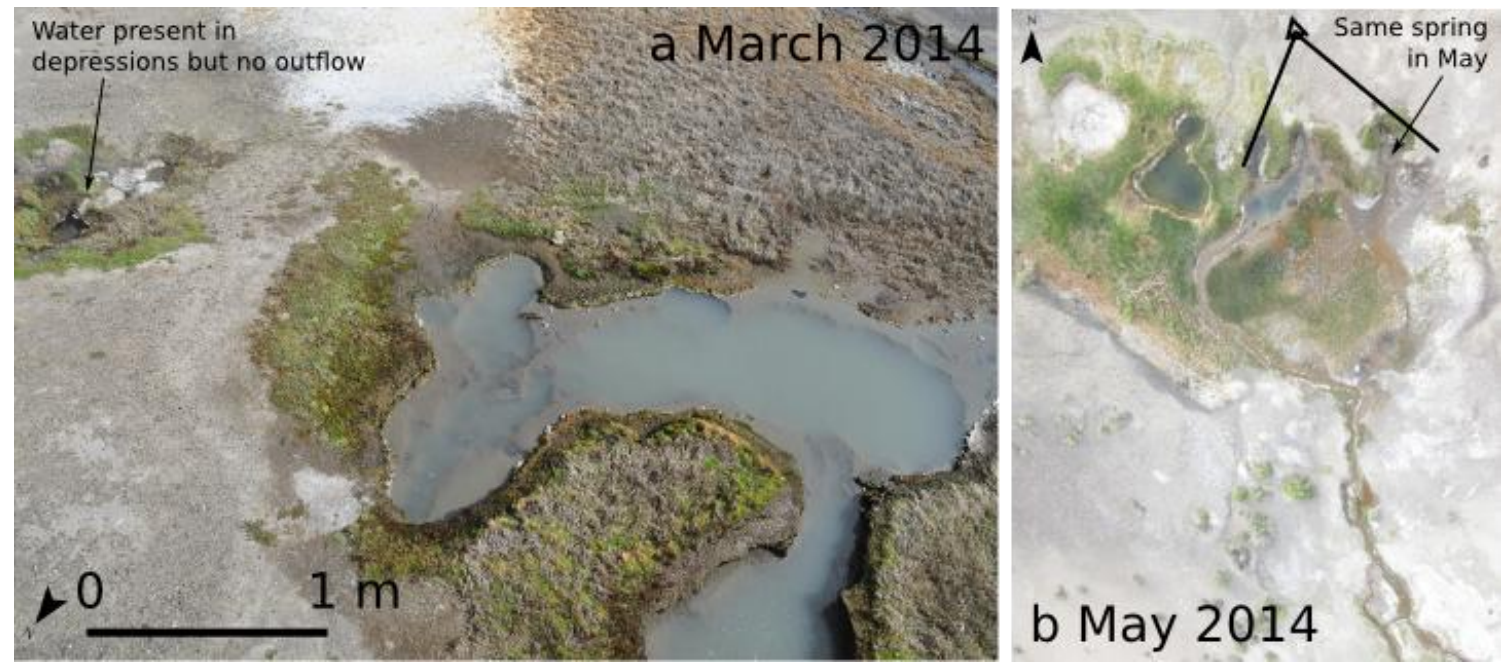

Figure 13: (a) Photo from March 2014 when main outflow of high temperature area was from horseshoe-shaped spring. Left of the horseshoe spring were three small springs with standing water but no outflow. Photo oriented looking toward the south. (b) Aerial photo from May 2014, when outflow had shifted from horseshoe-shaped spring to the three springs. Photo with north oriented up. Photopoint and view direction for photo in (a) indicated.

A mud pot (MP in Figure 14) in this high-temperature area exploded mud during the same time period (between March and May) as the shift in discharge from the hightemperature springs described above. The deposited sediments were $70 \%$ moderately sorted silt and clay (See grain size chart in Figure 15). The coarse portion was primarily basalt clasts and contained no silica sinter fragments.

The ground surface immediately north and west of the high-temperature springs is warm to the touch. Near-surface ground temperatures measured with a $10 \mathrm{~cm}$ Vernier temperature probe recorded temperatures between 67 and $95^{\circ} \mathrm{C}$ in the areas appearing white in Figure 14. A $1.5 \mathrm{~m}$ high berm surrounds the southwest portion of the 
high-temperature area (Figure 15). On the east side of this area, a sharp change in sediment type is visible (Figure 14, right of image). Together, the hot ground, berm, and sediment change encircle the high-temperature area and mark its outer extent. The water discharged from the springs here travels south toward dug-out ponds for watering cattle outside the ACEC fence, but no additional springs feed into the outflow channel outside of the circular area.

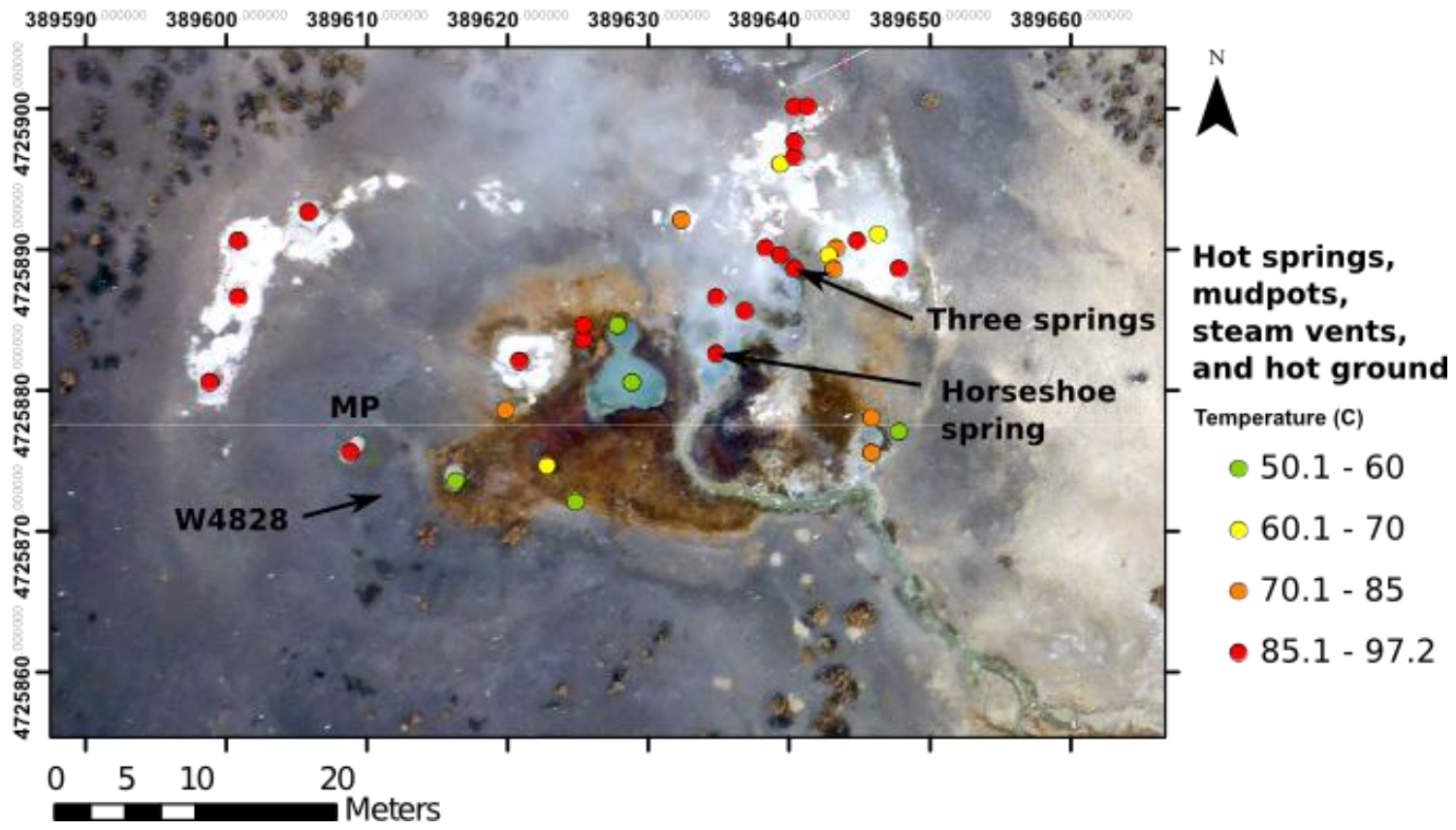

Figure 14: Most active springs, mudpots and hot ground are concentrated in a $50 \times 50 \mathrm{~m}$ area at Mickey Springs. No sinter is present in this area, which is located $5 \mathrm{~m}$ below most sinter features. Location of TL sample W4828 indicated, and mudpot (MP) which exploded over course of study, resurfacing the area within $3 \mathrm{~m}$ radius. Location of three springs and horseshoe spring shown in Figure 13 indicated with arrow. 


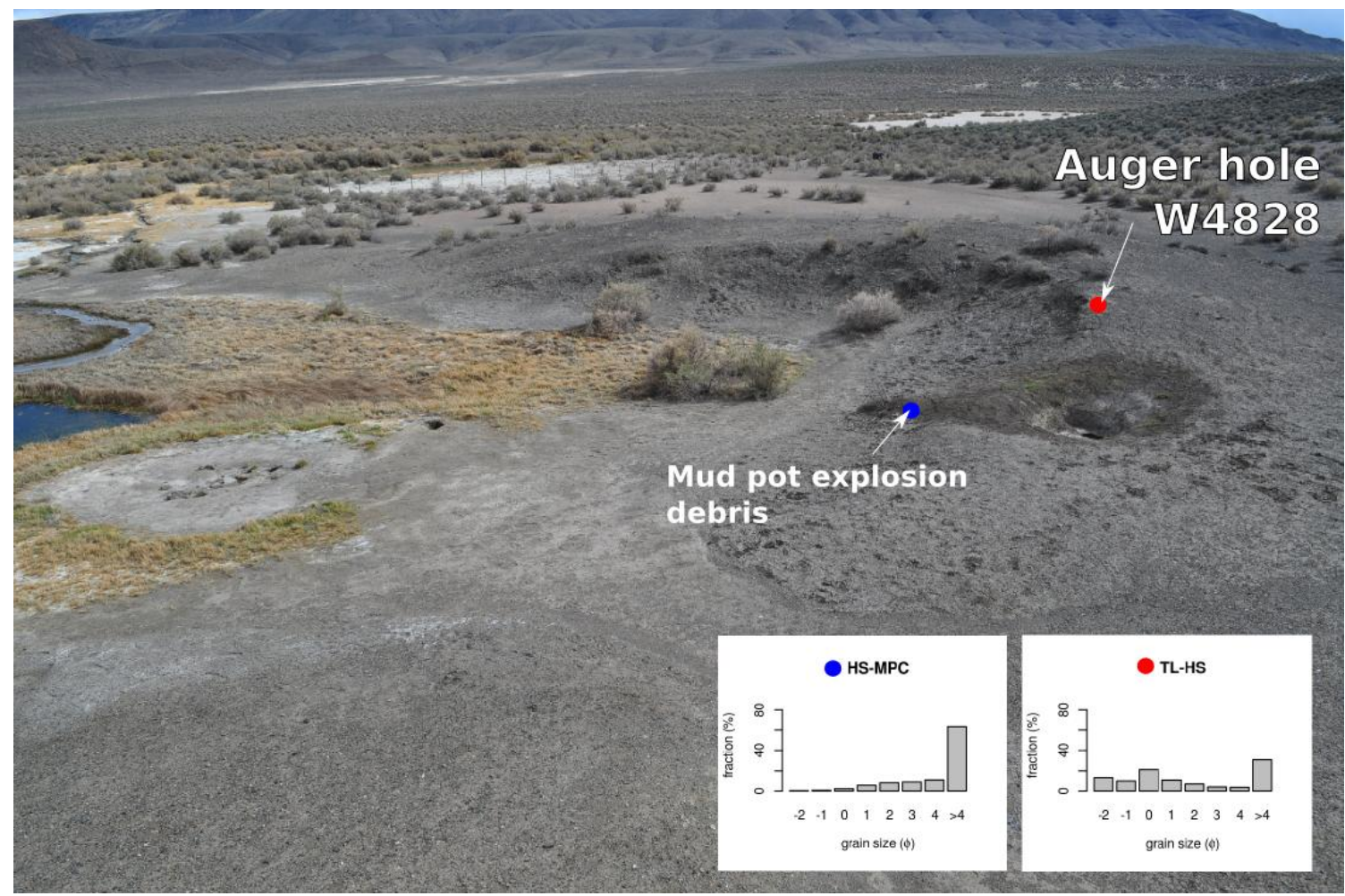

Figure 15: Area of sampling for TL sample W4828 (and corresponding grain size chart from sediment at sample depth, indicated by corresponding red dots) near a mud pot in the high temperature area of Mickey Springs, looking south. Grain size chart HS-MPC of mud deposited from mud pot explosion indicated by corresponding blue dots. Note elevated rim surrounding SW portion of high-temperature area, up to $1.5 \mathrm{~m}$ in height.

\section{Current hydrothermal activity within sinter features}

Several springs are present in proximity to the sinter features. Primarily, these are located within the central depressions of feature D1 and a few quaquaversal mounds. Only one spring (Q5) has surface outflow.

Feature Q9 (Figure 16) is rimmed by up to $1 \mathrm{~m}$ (measured vertically) of inward dipping pool edge sinter, with an apron diameter of $25 \mathrm{~m}$ and central depression diameter of $5 \mathrm{~m}$. The relief between the apron rim and the depression is $1 \mathrm{~m}$. A muddy spring is present on the north edge of the floor of the depression. The water surface is continually rippling, presumably from gas discharge, which circulates microbial mats 
around the pool. Probing this pool with a metal rod reveals that the pool extends north under the sinter apron for at least the length of the rod $(1.5 \mathrm{~m})$.

Feature Q9 was also resurfaced by a mud explosion that occurred between March and May 2014, emanating from the spring in the depression. The eruption deposited moderately sorted silt and clay over an area of $\sim 50 \mathrm{~m}^{2}$ to a maximum thickness of $13 \mathrm{~cm}$. During the site visit in May, the sediment coating the apron and in the depression floor was dry and hexagonally cracked. The coarse-grained portion of this sediment $(3 \mathrm{C}-\mathrm{MB}$, collected as arrow indicates in Figure 16 at maximum thickness of sediment) is $80 \%$ subangular to rounded lithic fragments, and $20 \%$ angular to subangular sinter.

An auger hole in the depression (stratigraphic column right side of Figure 16) reached the rooted zone from the grass previously growing in the depression at a depth of $13 \mathrm{~cm}$. Below this rooted zone, sediment was primarily silty sand and sorting increased with depth down to $60 \mathrm{~cm}$. From 60 to $78 \mathrm{~cm}$ was another rooted zone, with poorer sorting and higher percentage of coarse sand. Below this rooted zone, grain size decreased to $85 \%$ well-sorted silt and clay, green in color and similar to the deeper sediment in D1. The water table was at $72 \mathrm{~cm}$. At a depth of $105 \mathrm{~cm}$, the auger broke through several gravel-sized sinter clasts. Total depth reached with the auger was 127 $\mathrm{cm}$ where saturation prevented recovery of material. 

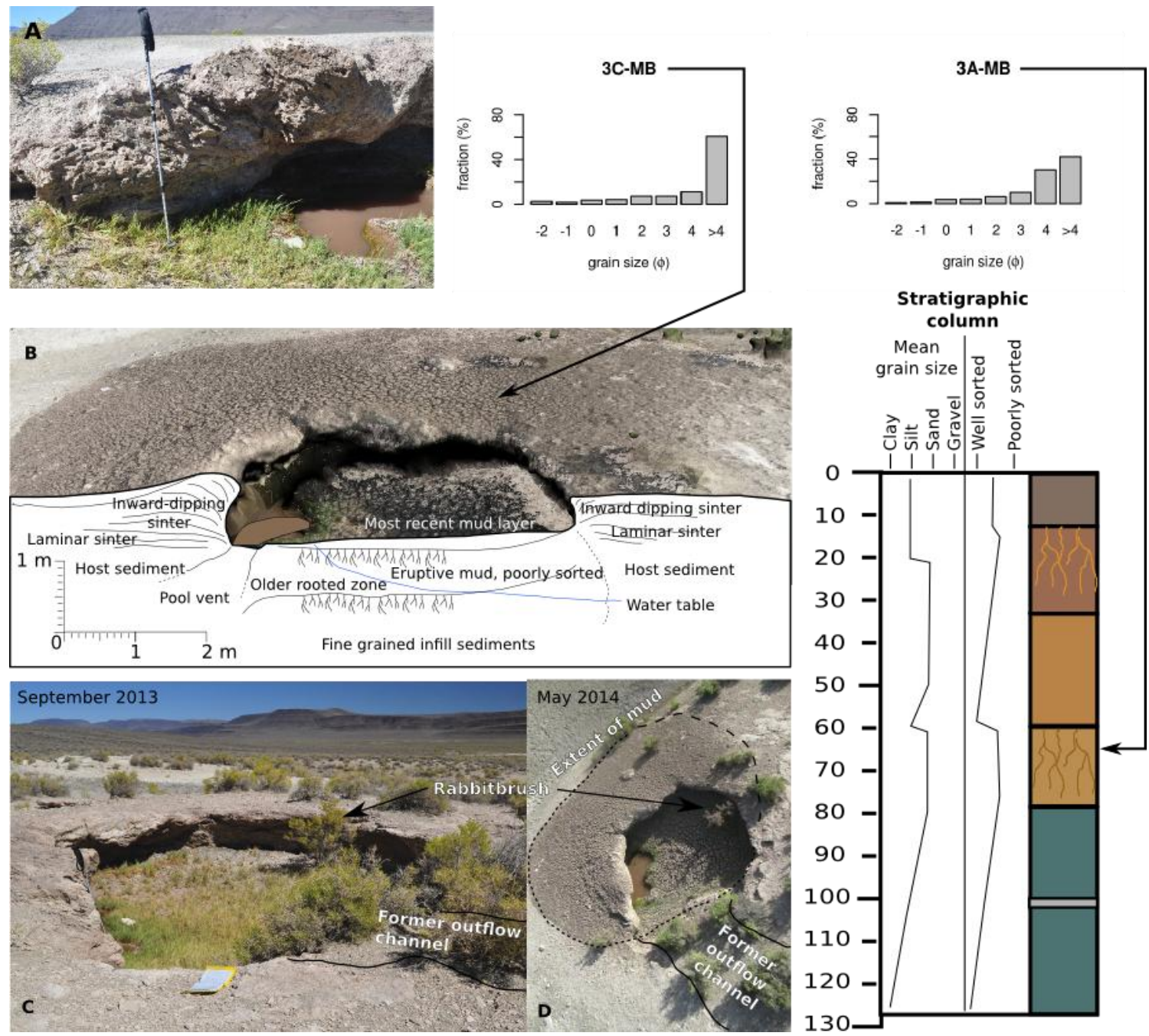

Figure 16: Feature Q9, resurfaced by mud explosion between March and May 2014. (a): Inward dipping, pool edge sinter with wavy texture. (b): Cross-section of Feature Q9. The central depression has been filled at least in part by explosive mud eruptions, killing vegetation and depositing up to $13 \mathrm{~cm}$ of new sediment in a single event. Grain size of erupted sediment is $70 \%$ fine-grained silt and clay, with few larger grains up to small pebbles. (c): Feature Q9 in September 2013, with grass present in bottom of depression and live rabbit brush. (d): Feature Q9 in May 2014. Extent of mud crust indicated, thickest crust was $13 \mathrm{~cm}$, thinning toward outer edges. Stratigraphic column (right of image) from auger hole in center of depression.

\section{Thermoluminescence dating}

Six sample sites were selected for TL dating. The results of the TL dating are

summarized in Table 2 and Figure 17. Ages ranged from 30 to $0.8 \mathrm{kya}$. One sample was

collected from the depression wall of feature Q4 to constrain age of sediment 
underlying the sinter apron, giving a maximum age of sinter deposition for at least that site. Samples for TL dating were collected from the floor of depressions D1, Q3 and Q12. Assuming the depression sediments were deposited after sinter deposition, this constrains a minimum age for each site. A TL date from the sediment blanket covering the broad depressions was also collected to provide a minimum age for the sinter in these features. Finally, a sample from the current hot source provides a date for sediments in that area. Location of each TL site is shown in Figure 7.

Sample sites were limited in depth and quantity. Funding by the Geological Society of America covered the cost of six samples. Due to ACEC restrictions and dangerously high ground temperatures, samples were limited to the shallow $(<1 \mathrm{~m})$ subsurface.

Table 2: Thermoluminescence dates from Mickey Springs, ordered on left by Sample ID \#.

\begin{tabular}{cccccc}
$\begin{array}{c}\text { Sample } \\
\text { ID }\end{array}$ & $\begin{array}{c}\text { Associated } \\
\text { feature }\end{array}$ & $\begin{array}{c}\text { Temperature at sample } \\
\text { depth }\left({ }^{\circ} \mathrm{C}\right)\end{array}$ & $\begin{array}{c}\text { Sample depth } \\
(\mathrm{cm})\end{array}$ & $\begin{array}{c}\text { TL age } \\
(\mathrm{kya})\end{array}$ & $\begin{array}{c}\text { Uncertainty } \\
(+/-\mathrm{kya})\end{array}$ \\
\hline W4823 & Q4 & 29 & 220 & 30.7 & 7.9 \\
W4828 & $\begin{array}{c}\text { High-temp } \\
\text { springs } \\
\text { Q12 }\end{array}$ & 84 & 40 & 9.2 & 1 \\
W4829 & Q12 & 59 & 27 & 18.1 & 2.1 \\
W4830 & D1 apron & 33 & 47 & 17.5 & 3 \\
W4831 & Q3 & 36 & 53 & 0.8 & 0.4 \\
W4832 & D1 depression & 28 & 24 & 12.8 & 4.4
\end{tabular}




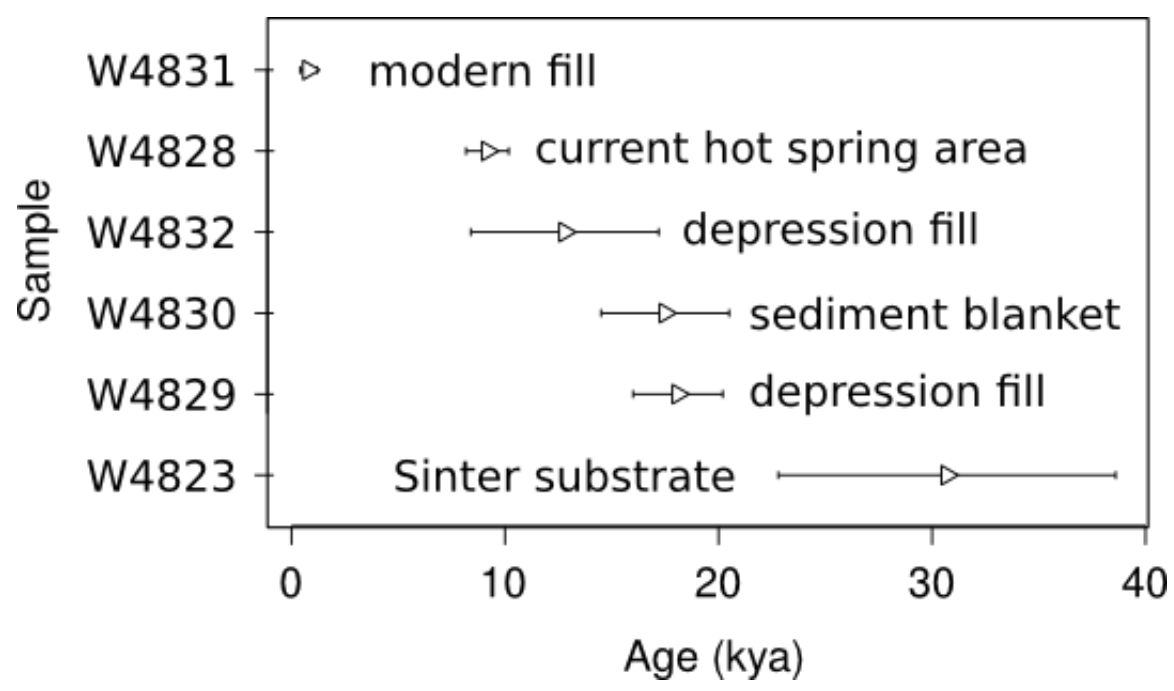

Figure 17: Barplot of TL ages, showing age (triangle) and uncertainty (lines) of each sample, from oldest (right) to youngest (left). Material beneath the laminar sinter of Q4 is the oldest dated sample at 30 kya. Well-sorted, fine-grained sediment from depressions and blanketing sinter aprons range in age from 18 - 12 kya. Age of sediment from near the current high-temperature springs is $\sim 9$ kya. The youngest TL date is from poorly sorted sand in feature Q3.

Sample W4823 was collected from $220 \mathrm{~cm}$ below the surface in feature Q4

(Figure 8), from the sediment immediately below the laminated sinter. Soil temperature at time of sampling was $29^{\circ} \mathrm{C}$ and moisture content as determined in the TL procedure was $22.2 \%$. The sample was acquired by augering horizontally into the wall of the central depression and from a horizontal auger distance of $30 \mathrm{~cm}$. Grain size of these sediments is described above. TL age of this sample is $30.7+/-7.9$ kya. Low TL sensitivity led to a temperature plateau comparison between $275^{\circ}$ and $350^{\circ} \mathrm{C}$, resulting in scattered TL data and an unusually large age uncertainty.

Sample W4828 was collected near the rim of the mud pot in the hightemperature area that erupted mud between April and May, 2014 as described above. The sample was collected from $40 \mathrm{~cm}$ below the surface on the south side of the mud pot, away from the recent resurfacing. Soil temperature here was the highest for any TL 
samples at $84^{\circ} \mathrm{C}$. Moisture content was reported as $10.1 \%$. The sample position is on a high ridge (locally $\sim 1 \mathrm{~m}$, elsewhere up to $1.5 \mathrm{~m}$ ) that circles the southwest portion of the high temperature area (Figure 15). The sample sent for TL analysis included a large rock approximately half the volume of the total sample. This can distort the results of the TL process, but the grain size analysis and local observation show poor sorting of the sediments in this area, and therefore the sample was not considered anomalous for TL age determination. Age of this sample was $9.2+/-1.0$ kya.

Sample W4829 was collected from feature Q12 from an auger hole $27 \mathrm{~cm}$ below the surface of the central depression. Soil temperature was $59^{\circ} \mathrm{C}$ at time of sampling, and moisture content of $34.3 \%$ was reported from the TL procedure. Sediments from 0$56 \mathrm{~cm}$ were poorly sorted, loose, sandy silt, with sparse clasts of sinter up to $4 \mathrm{~cm}$, but the sample sent for TL analysis was primarily sand and silt. TL output plateaued between $300^{\circ}$ and $500^{\circ} \mathrm{C}$, with a resulting age of $18.1+/-2.1$ kya. 


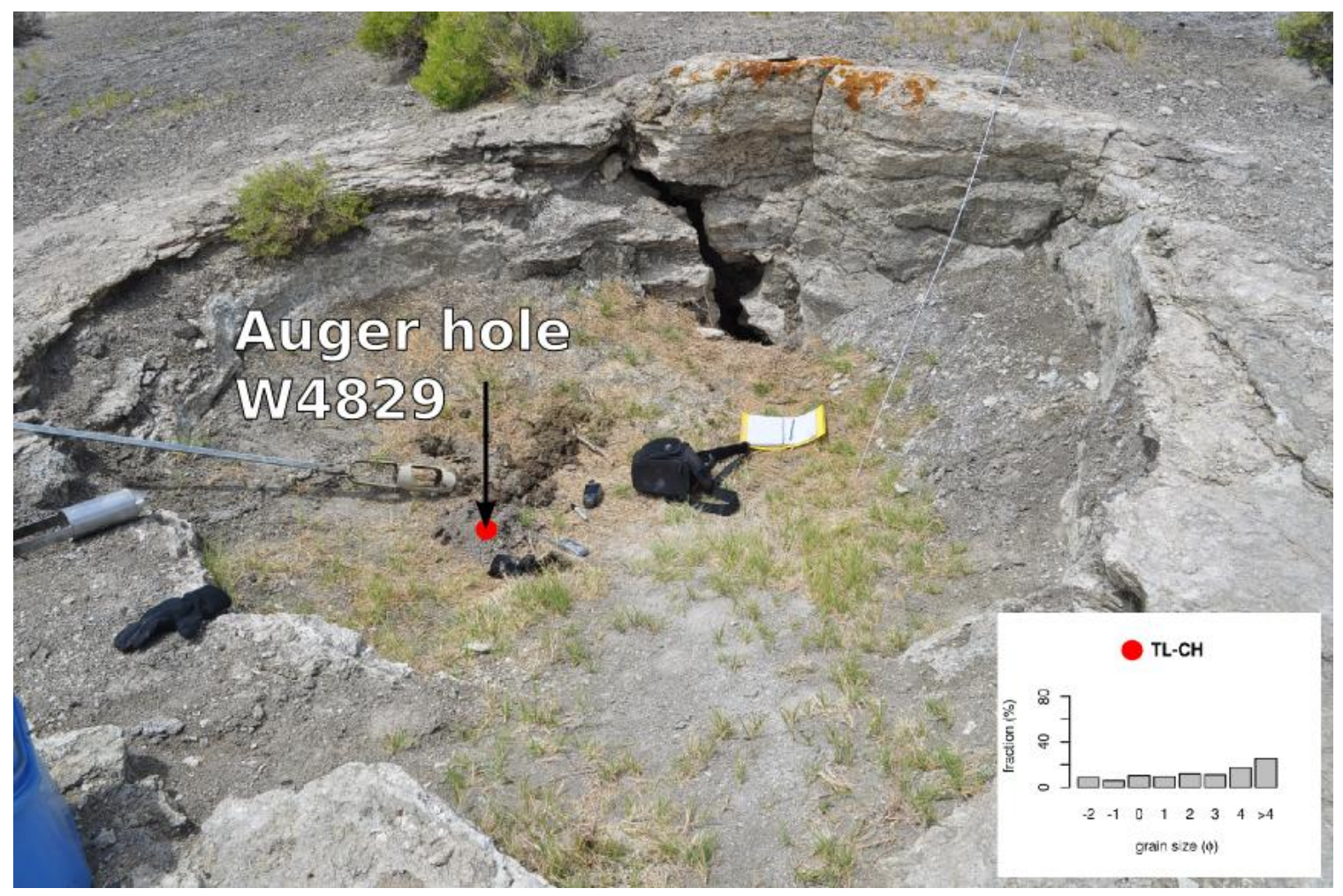

Figure 18: Image looking north at feature Q12, location of TL sample W4829. Fracture in sinter is oriented N/NE and continuation is indicated by linear orientation of bushes in image. Grain size chart shown for sample TL-CH, which was collected immediately above the TL sample depth of $27 \mathrm{~cm}$.

Sample W4830 was collected from fine-grained sediments blanketing the apron of feature D1, $47 \mathrm{~cm}$ below the surface (Figure 19). Sediment at TL sample depth was well-sorted subrounded to rounded sandy silt with $65 \%$ fine silt and clay. Soil temperature at time of sampling was $33^{\circ} \mathrm{C}$. Moisture content was reported as $32.2 \%$. The TL age of this sample is $17.9+/-3.0$ kya. TL sensitivity was similar to sample W4829, and the TL ages overlap within one standard deviation. 


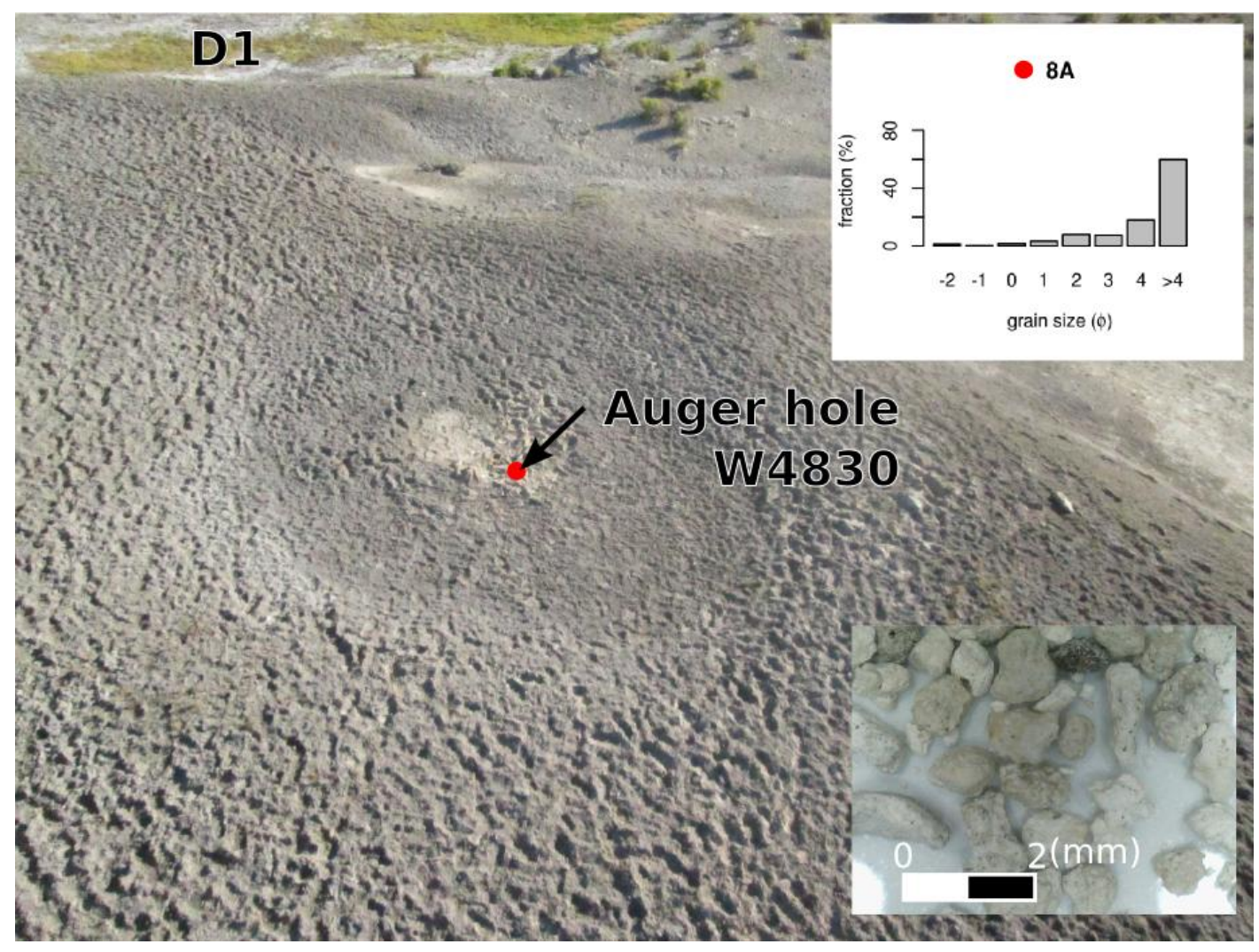

Figure 19: of TL sample W4830. Photo is looking north toward feature D1, on fine grain sediment blanketing exterior of depressions. Photo taken in June 2014 under dry conditions. Sediment in auger hole is uniform, primarily (65\%) silt and clay with clasts of subangular to rounded sinter up to $6 \mathrm{~mm}$. Auger hole met refusal at $100 \mathrm{~cm}$. Grain size chart $8 \mathrm{~A}$ for sediment collected immediately above TL sample depth of $47 \mathrm{~cm}$.

Sample W4831 was collected at a depth of $53 \mathrm{~cm}$ from feature Q3 (Figure 20). A sinter apron surrounds this feature and pool edge sinter is visible immediately surrounding an area of loose, poorly sorted silty sand with pebbles, flush with the sinter elevation. In the portion of the TL dating process that involved cleaning the grains with hydrofluoric acid (after treatment with $\mathrm{HCl}$ ), the sample reacted violently to the acid, indicating a high feldspar content. The coarse portion of the sediment contained $\sim 75 \%$ angular clasts of sinter up to $6 \mathrm{~cm}$ brought up in the auger and $\sim 25 \%$ coarse basalt sand 
up to $2 \mathrm{~mm}$. Soil temperature at time of sampling was $36^{\circ} \mathrm{C}$ at $50 \mathrm{~cm}$ below the surface.

Moisture content was reported as $4.1 \%$. The TL age was $0.8+/-0.4$ kya.

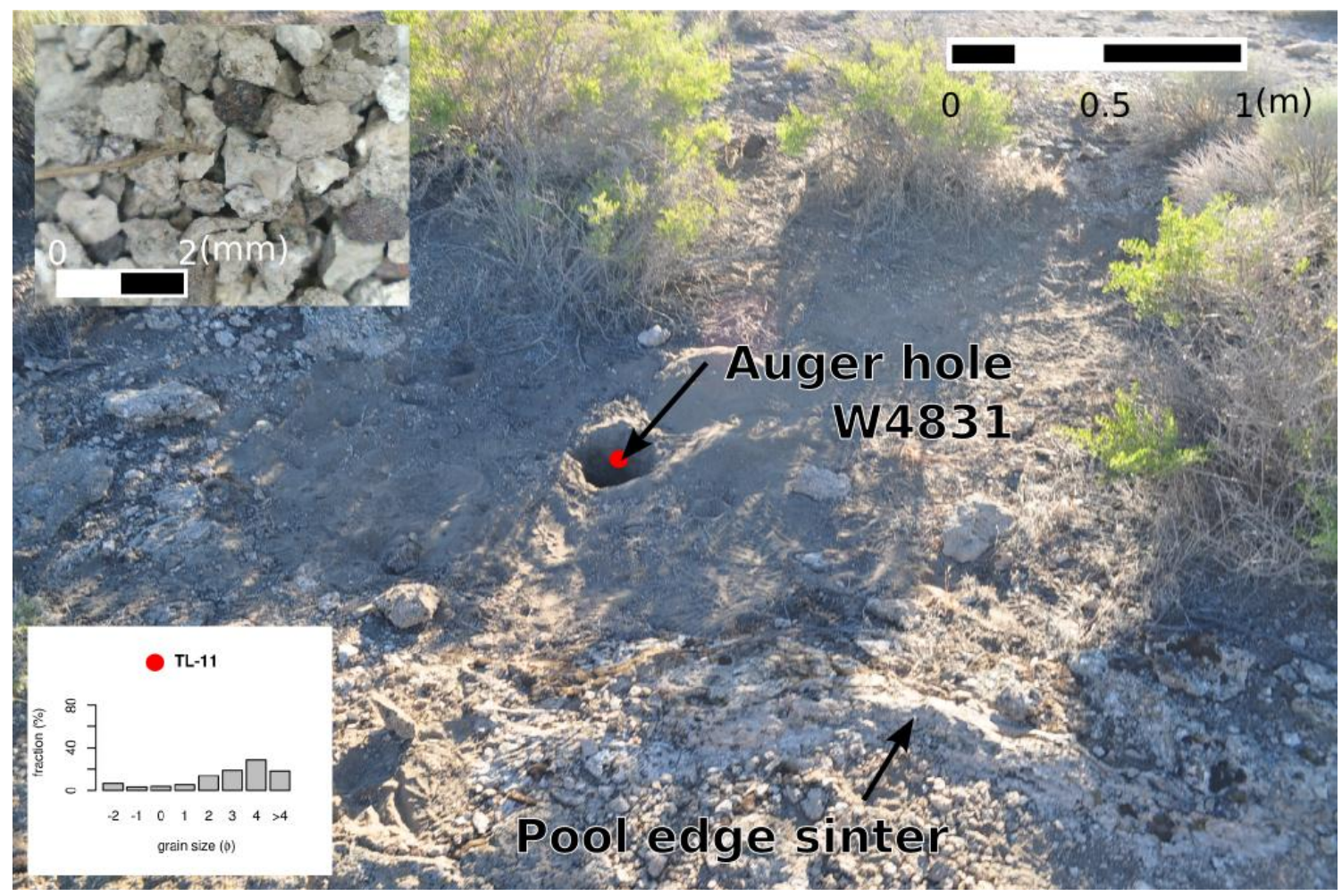

Figure 20: of TL sample W4831. The sinter apron is relatively flat, with a central area of loose sediment level with the pool-edge sinter surrounding it. Sediment from the auger hole immediately above the TL sample depth (corresponding red dot) was $30 \%$ fine sand, poorly sorted with gravel-size pieces of angular sinter and pebbles of sub-rounded basalt (inset top left).

Sample W4832 was collected from feature D1(Figure 10) from a shallow auger

hole $24 \mathrm{~cm}$ below the surface near the south edge of the central depression (Figure 11).

This auger hole was adjacent to the hole for sediment sampling described above.

Sample depth was $27-37 \mathrm{~cm}$, and was selected initially for practicality, as soil saturation

made acquiring a deeper, intact sample problematic with the tools used. However, this

depth is at the transition from the surface sediment containing root fragments and the lower, well-sorted silt and clay. Moisture content was reported as $47.0 \%$ from the TL 
procedure. TL sensitivity was again low, leading to an above-average TL age uncertainty. Age of this sample was $12.8+/-4.4$ kya.

\section{Ground Penetrating Radar}

Three transects of the spring area were surveyed with 1000 volt GPR for this study. With these higher-voltage antennas (compared to the $165 \mathrm{~V}$ antennas used in Mowbray and Cummings, 2014), the top meter of the surface is noisy from the strength of the GPR signal extending in all directions, and only resolves subsurface features greater than 1-2 meters below the surface, below the maximum depth of most sinter aprons. Two tracks ( 1 and 3 ) were made from west to east, and one track (2) was oriented north/south. The locations of the tracks are shown in Figure 6. All GPR tracks are shown with and without topographic correction in Figures 21-24 below. Both 50 and $100 \mathrm{MHz}$ antennas were deployed on Track 1, while only $50 \mathrm{MHz}$ antennas were deployed on track 2 and 3. The $50 \mathrm{MHz}$ antennas were able to penetrate to a depth of approximately $17 \mathrm{~m}$, while the $100 \mathrm{MHz}$ antennas penetrated to a depth of approximately $10 \mathrm{~m}$. 


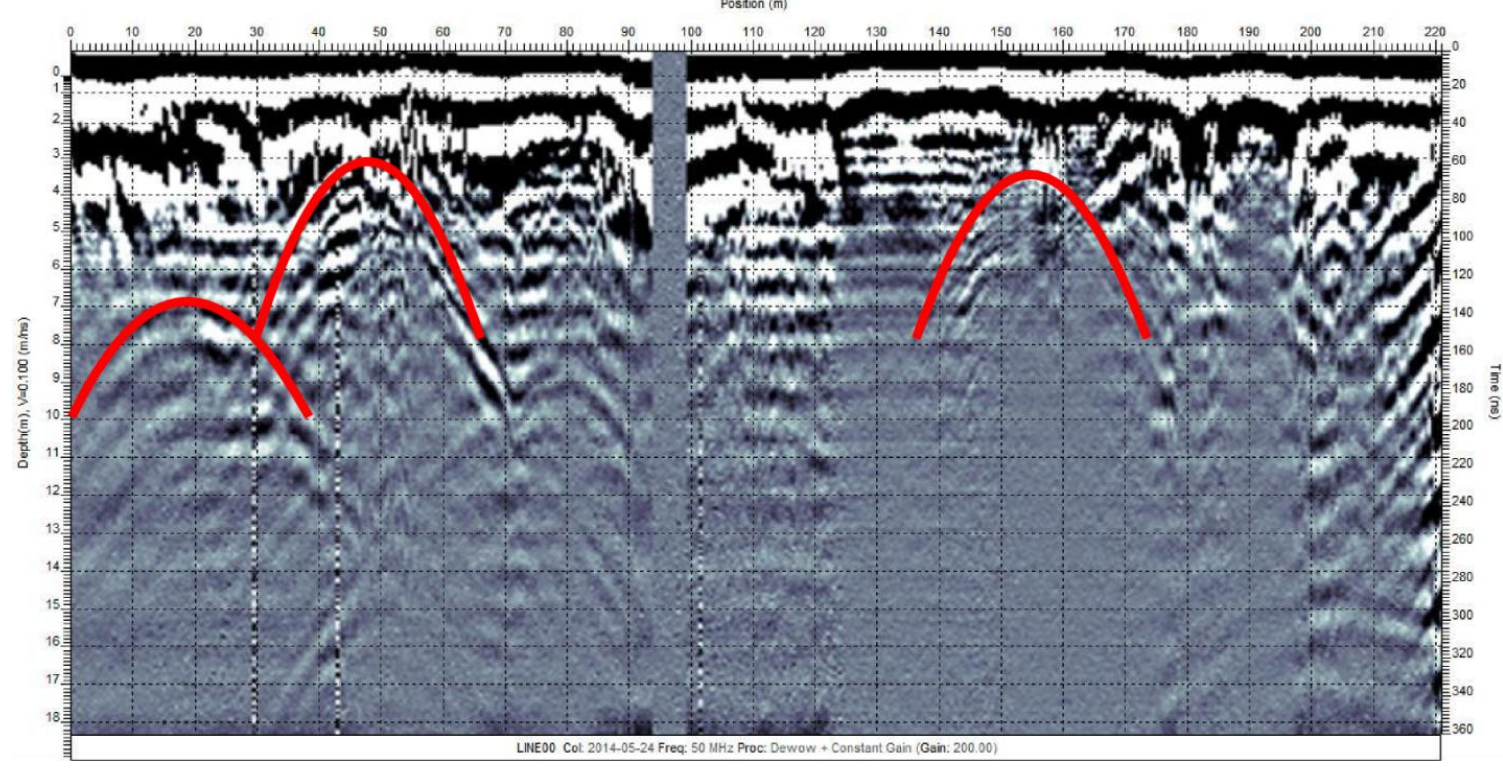

\section{Topographically shifted}

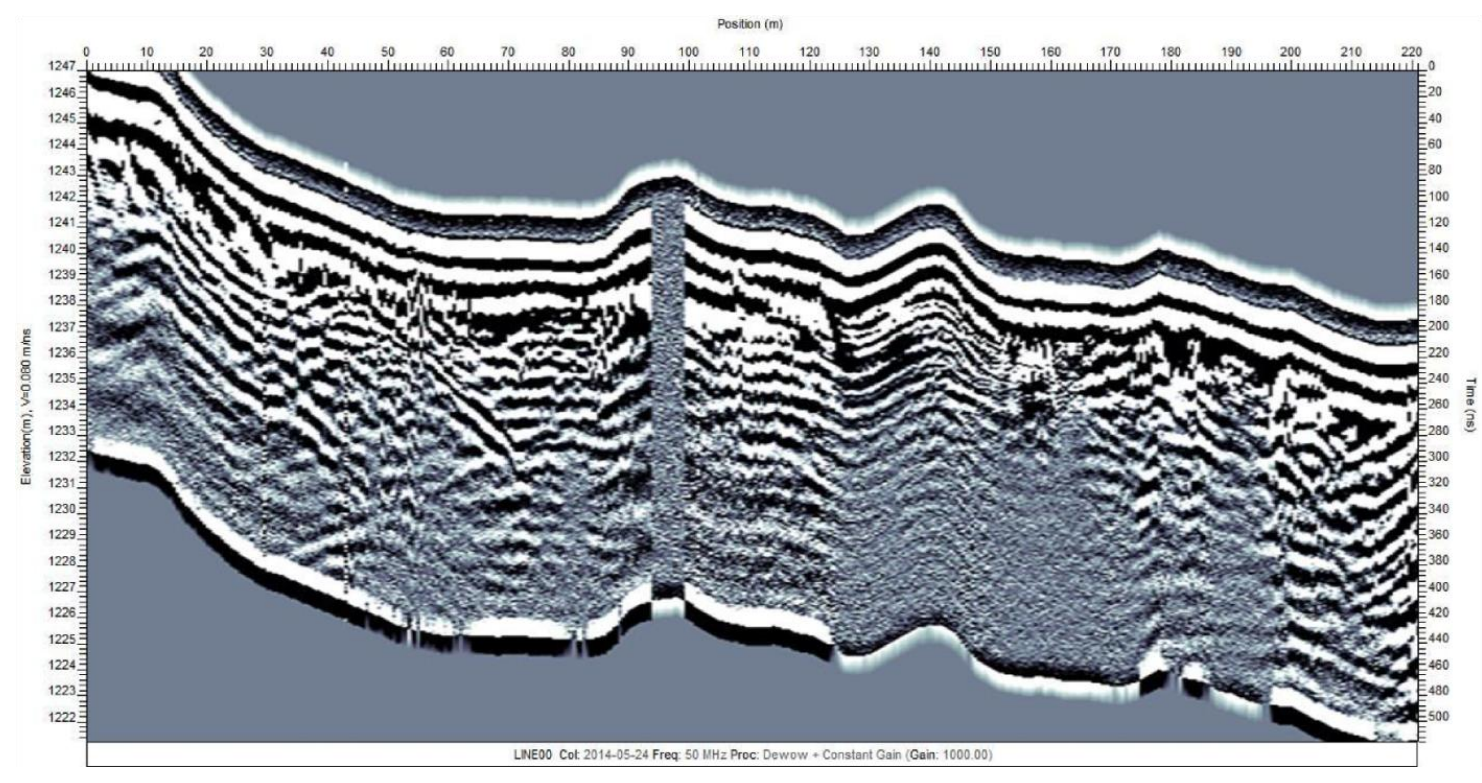

Figure 21: Original GPR data (top) and topographically corrected data (bottom, using ground velocity of $0.08 \mathrm{~m} / \mathrm{us}$ ) for tracks 1 with $50 \mathrm{MHz}$ antennas. Several parabolic reflections can be identified in the track before addition of topographic correction. These features are not visually obvious once topography is added. Broad parabolic features are produced by zones of material with a different density or electrical properties to that of the surrounding area, and may indicate either a zone of hydrothermal alteration (former vent) or a damage zone around a fault. 


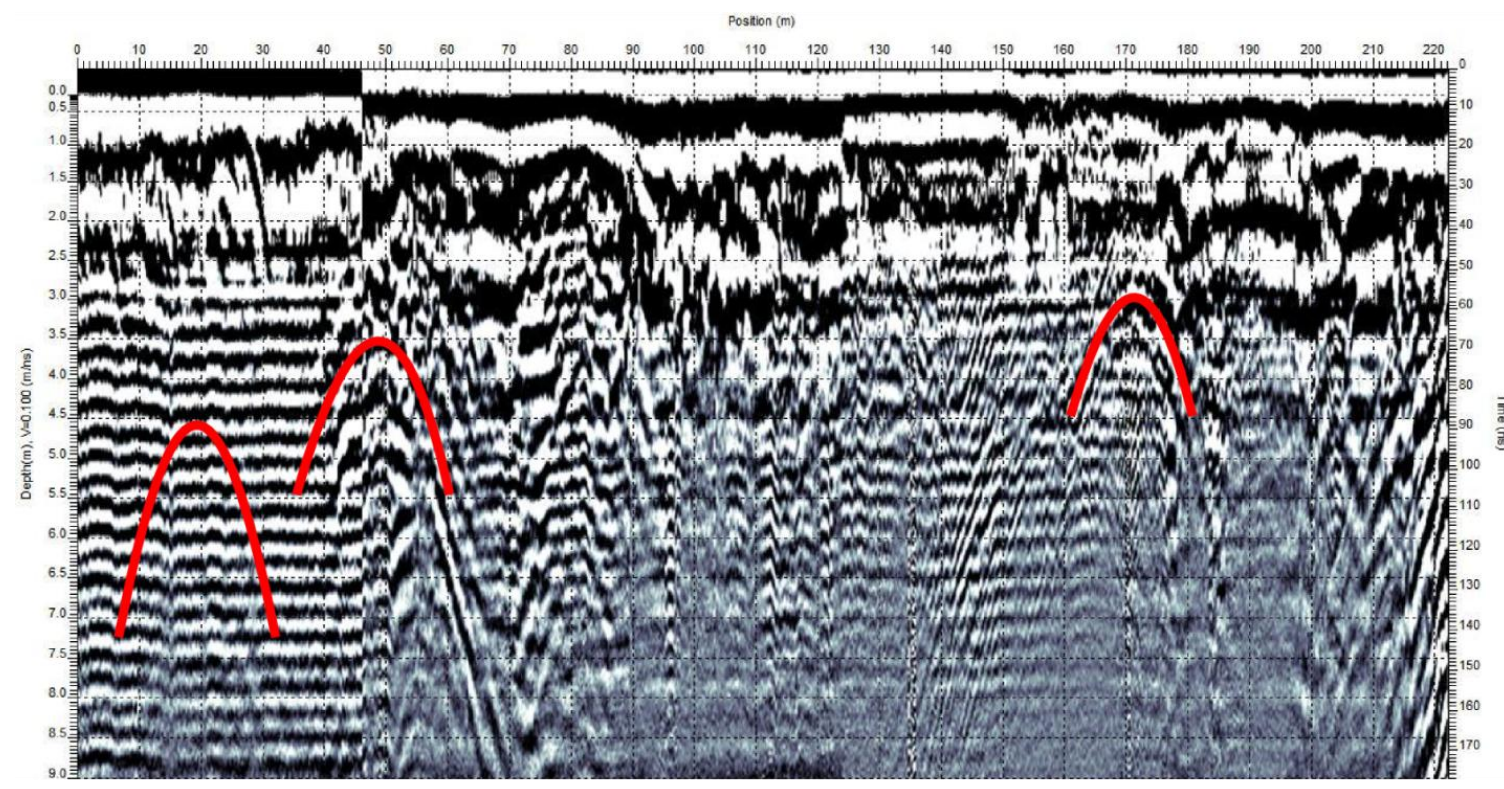

Topographically shifted

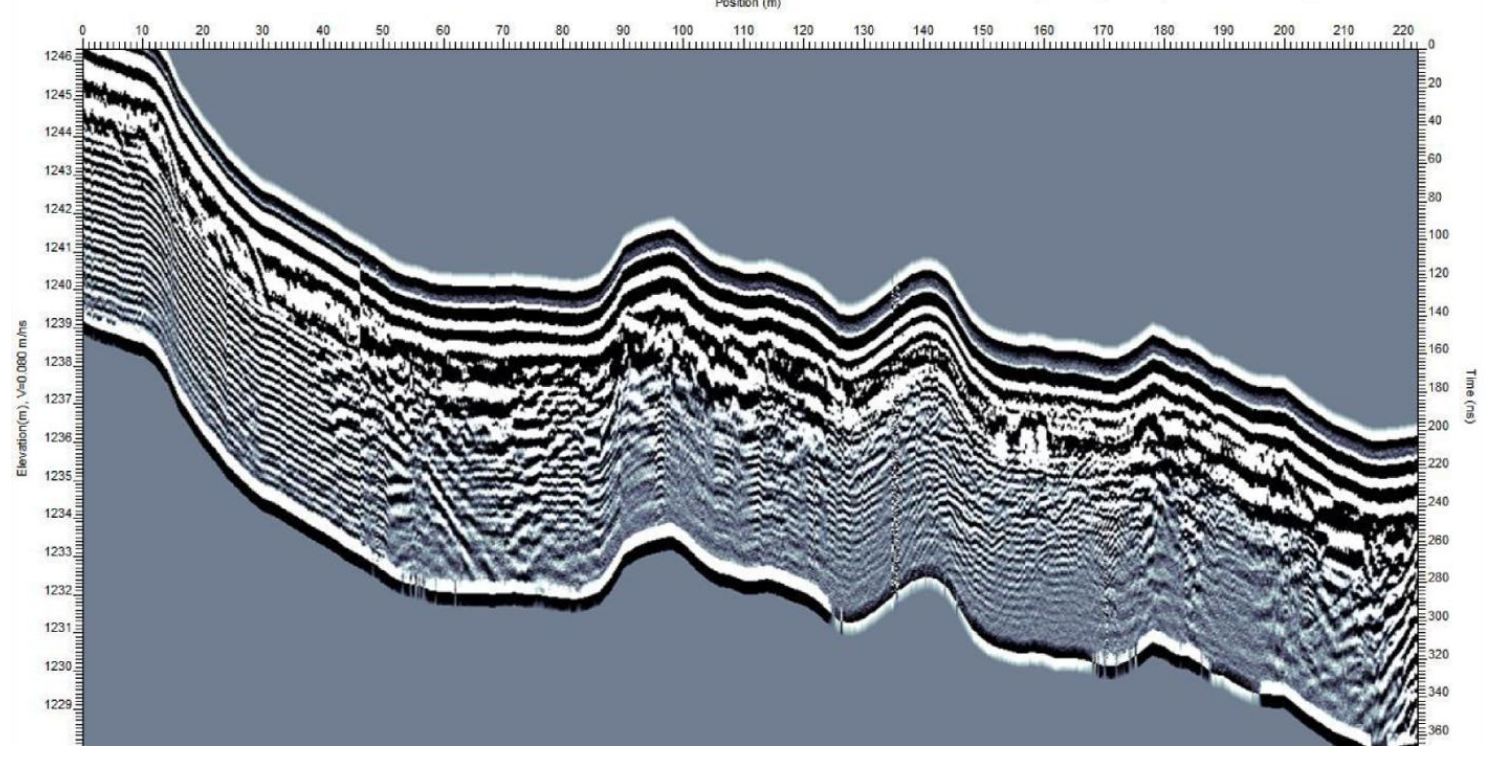

Figure 22: Original GPR data (top) and topographically corrected data (bottom, using ground velocity of $0.08 \mathrm{~m} / \mathrm{us}$ ) for tracks 1 with $100 \mathrm{MHz}$ antennas. Similar parabolic reflectors can be seen here as in the $50 \mathrm{MHz}$ track. 
Track 2, $50 \mathrm{MHz}$

Raw GPR data

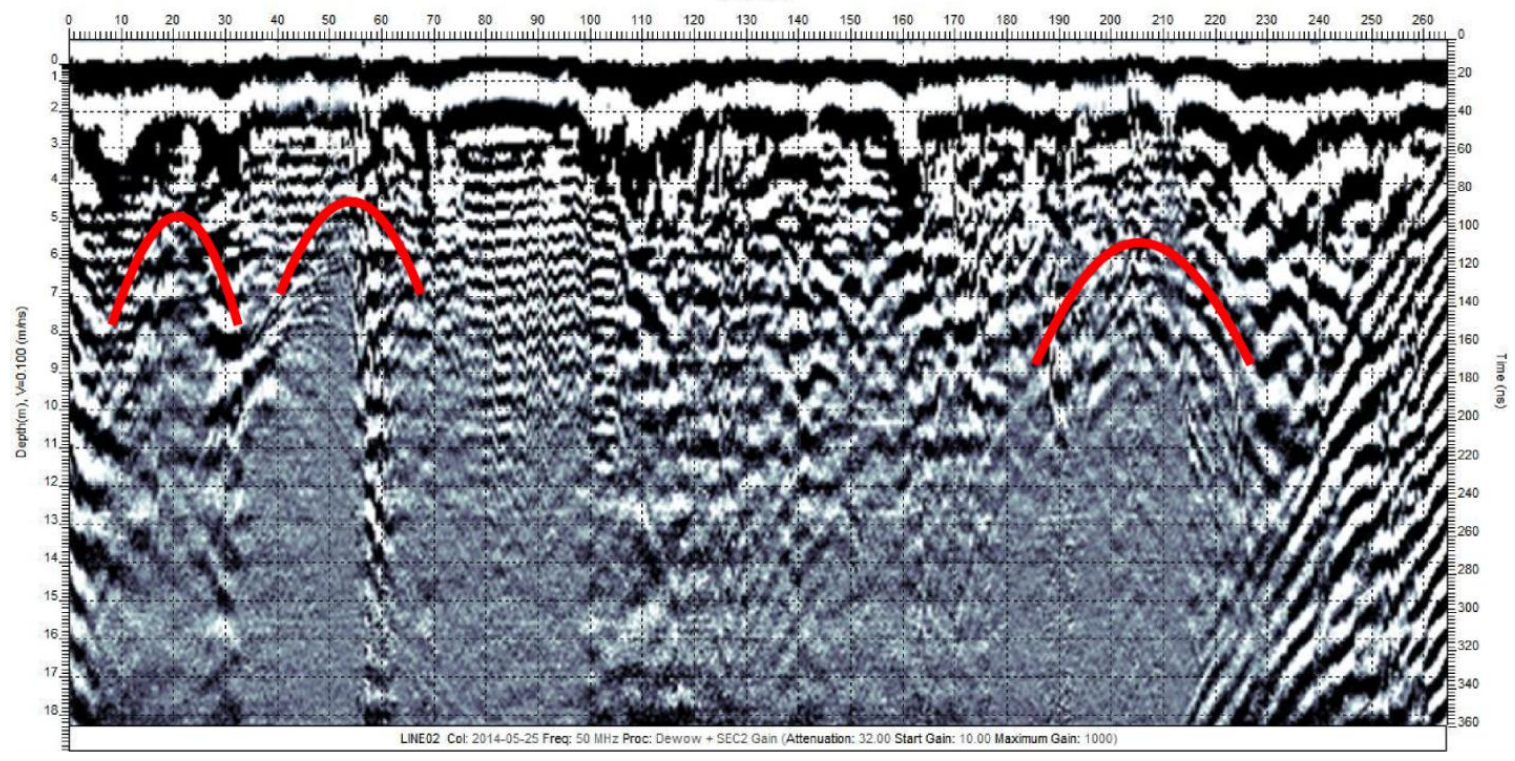

Topographically shifted

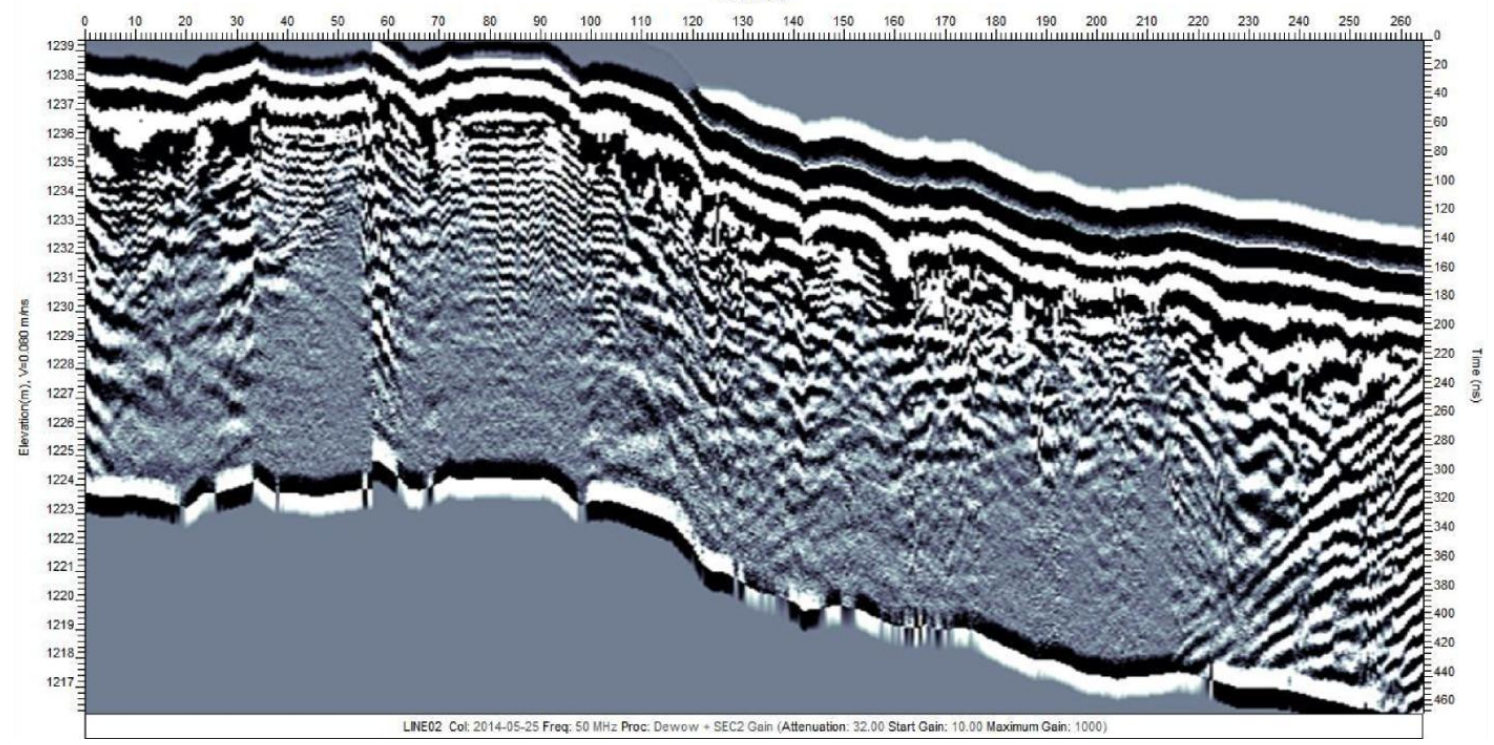

Figure 23: Original GPR data (top) and topographically corrected data (bottom, using ground velocity of $0.08 \mathrm{~m} / \mathrm{us}$ ) for track 2 with $50 \mathrm{MHz}$ antennas. Parabolic reflections are apparent beneath feature Q4 and the current high-temperature spring area, possibly indicating conduits of hydrothermal fluid. 


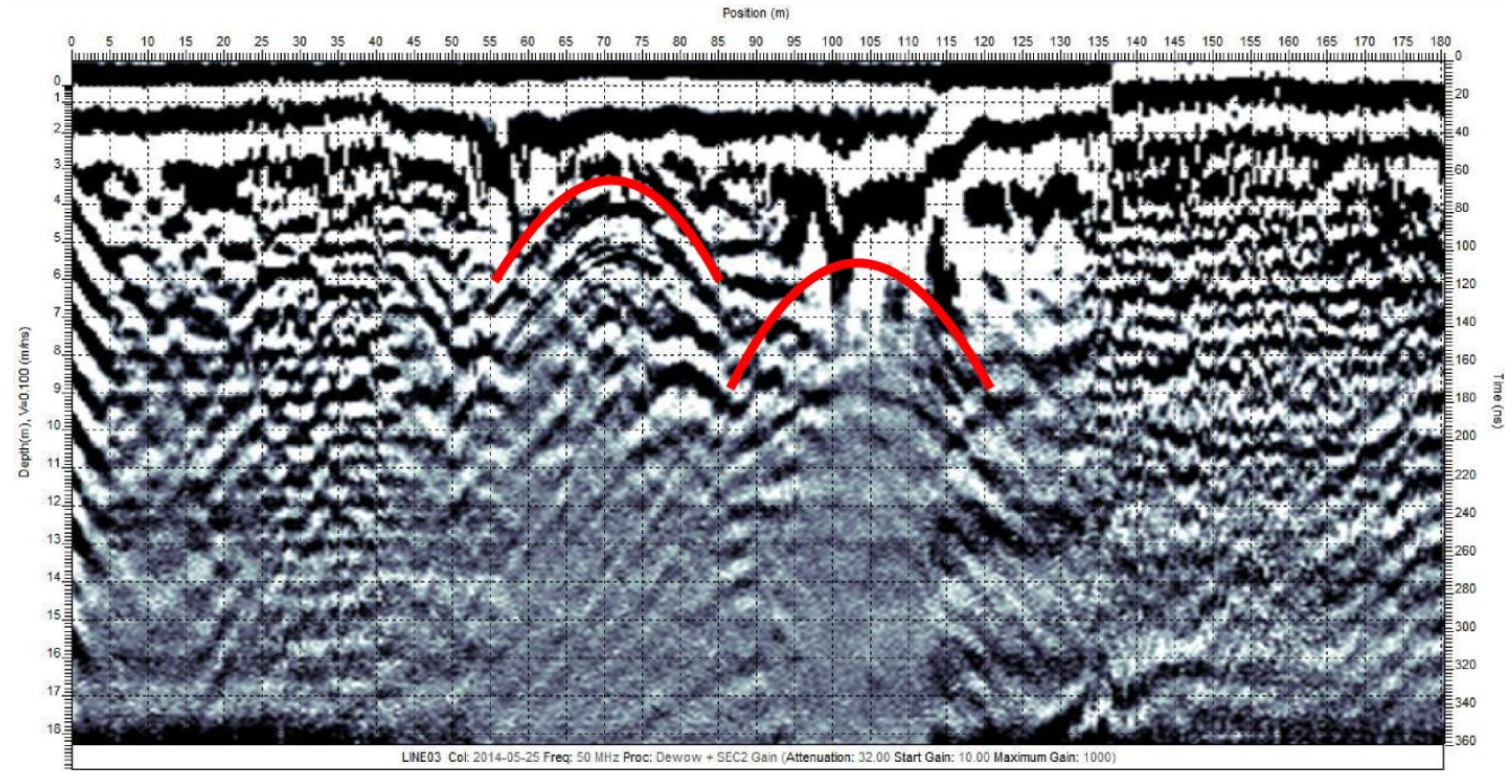

Topographically shifted

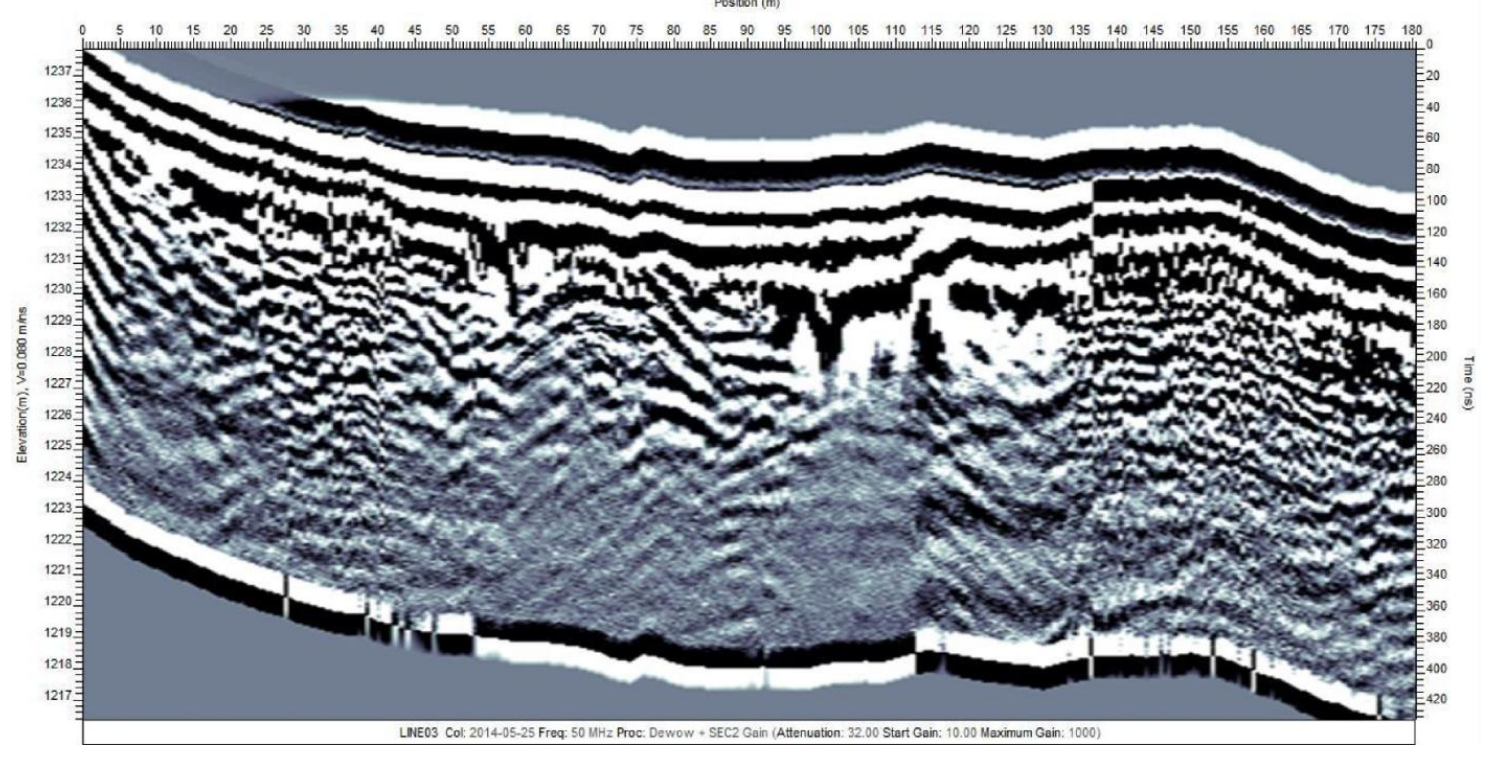

Figure 24: Original GPR data (top) and topographically corrected data (bottom, using ground velocity of $0.08 \mathrm{~m} / \mathrm{us}$ ) for track 3 with $50 \mathrm{MHz}$ antennas. Parabolic reflections (red lines) are present under the area of the high temperature springs and may indicate the pathway for the rising hydrothermal fluid. 


\section{Survey Details}

Track 1 was surveyed using first the $50 \mathrm{MHz}$ antennas, then the $100 \mathrm{MHz}$ antennas, over a distance of $222 \mathrm{~m}$. The track started at the high point of the silicified sandstone, passed just north of the central depression of feature Q4, crossed the center of feature D1, and terminated before the east fence of the ACEC. A five meter gap in the $50 \mathrm{MHz}$ track on the crest of Q4 was caused by temporary disconnection of the antennas from the recording computer.

Track 2 was surveyed using $50 \mathrm{MHz}$ antennae over a distance of $265 \mathrm{~m}$. This track traversed feature D1, crossed the west flank of the sinter apron of Q9, passed west of Q12, crossed the center of the high temperature spring area, and terminated at the south fence of the ACEC.

Track 3 was surveyed using the $50 \mathrm{MHz}$ antennae over a distance of $180 \mathrm{~m}$. The track began west of the sandstone ridge over vegetated soil, where no outcrop was present, crossed the high temperature area just north of the mudpots and high temperature spring outflows, and over a small rise east of the high temperature springs, terminating at the east fence of the ACEC.

\section{Visible Features}

The GPR transects provide subsurface information that constrains interpretation of the evolution of the Mickey Springs site. The raw data for the transects are reproduced here and the stratigraphic interpretations based on these data are illustrated below each transect. 
Common features visible in the 50 and $100 \mathrm{MHz}$ images are the dipping beds of the silicified sandstone, deterioration of signal due to thick silt at the ground surface, and alteration of signal due to shallow groundwater. All three GPR transects terminated near the fence line of the ACEC. Strong reflectors in the GPR tracks rise toward the termination point of each track, and are interpreted as air-wave signals from the fence posts, and determined not to be indicative of subsurface structure.

Broad parabolic reflections are visible in all three GPR tracks before addition of topography (Figures 21-24). Once topography was added, the parabolic reflectors are distorted. The width of the parabola indicate the presence of a zone rather than a point feature, as the peak of the parabola for a point feature is typically much more sharp. These broad parabolas can be produced by zones of material with a different density or electrical properties to that of the surrounding area. Possible causes for these could be the damage zone around a fault, or a zone of hydrothermal alteration around a conduit for hydrothermal fluid.

The dominant texture in the GPR tracks is sub-horizontal to gently dipping lines, found primarily in the lower $2 / 3$ of the imaged areas. This is interpreted to be a relatively uniform unit of underlying sediment, indicating that all sinter precipitated at Mickey Springs is near the surface and forms a relatively thin capping unit, as discussed in the following paragraphs. 
The silica-cemented sandstone and conglomerate was exposed at the surface on the western portion of track 1. The GPR image shows some thick (compared to the thin sub-horizontal bedding of the underlying sediment) horizontal bedding accompanied by east-dipping lines. The thick horizontal bedding extends 5-10 $\mathrm{m}$ in depth and is thicker than the thin horizontal lines of the bottom $2 / 3$ of the transect. Because these lines are coincident with the sandstone outcrop, they are interpreted to trace the subsurface extent of the sandstone, and indicate the sandstone/conglomerate unit is only $\sim 10 \mathrm{~m}$ thick. Similar texture is not visible in the GPR data from the eastern portion of track 1 , nor in track 2 or 3.

The east-dipping lines in the sandstone/conglomerate in track 1 continue at depth in the thinner-bedded sediment as discontinuities in bedding. These discontinuities are interpreted as faults, and are in proximity to many parabolics indicating a damage zone. Three faults are also interpreted from track 2 at discontinuities in bedding. These faults are coincident with the slope break between the topographic bench containing the sinter mounds and depressions at $1235 \mathrm{~m}$, dipping toward the current high-temperature springs to the southeast.

Areas below sinter aprons have non-uniform bedding planes and discontinuities, typically approximating the width of the apron or depression and narrowing downward. From the exposure in the depression of Q4, the planar-bedded sediments below the laminar sinter appear as primary deposition that remains unaltered by the thermal 
waters that deposited the sinter, however, the GPR data suggests a zone of alteration underlying each feature.

The area of the high temperature springs in the E/W transect of track 3 appears blocky and undulating down to $10 \mathrm{~m}$, while the N/S transect of track 2 does not have similar blocky features. Both transects indicate a discontinuity of bedding at 5-10 m beneath the high temperature area. Some of the largest blocky light and dark zones in track 3 coincide with the main high-temperature springs which flow from cracks primarily oriented N/S. The blocky features are therefore likely showing the shallow subsurface structure on which the fluid is rising. Several parabolics are also present just beneath the blocky area, and may indicate the continuation of the conduit at depth. 


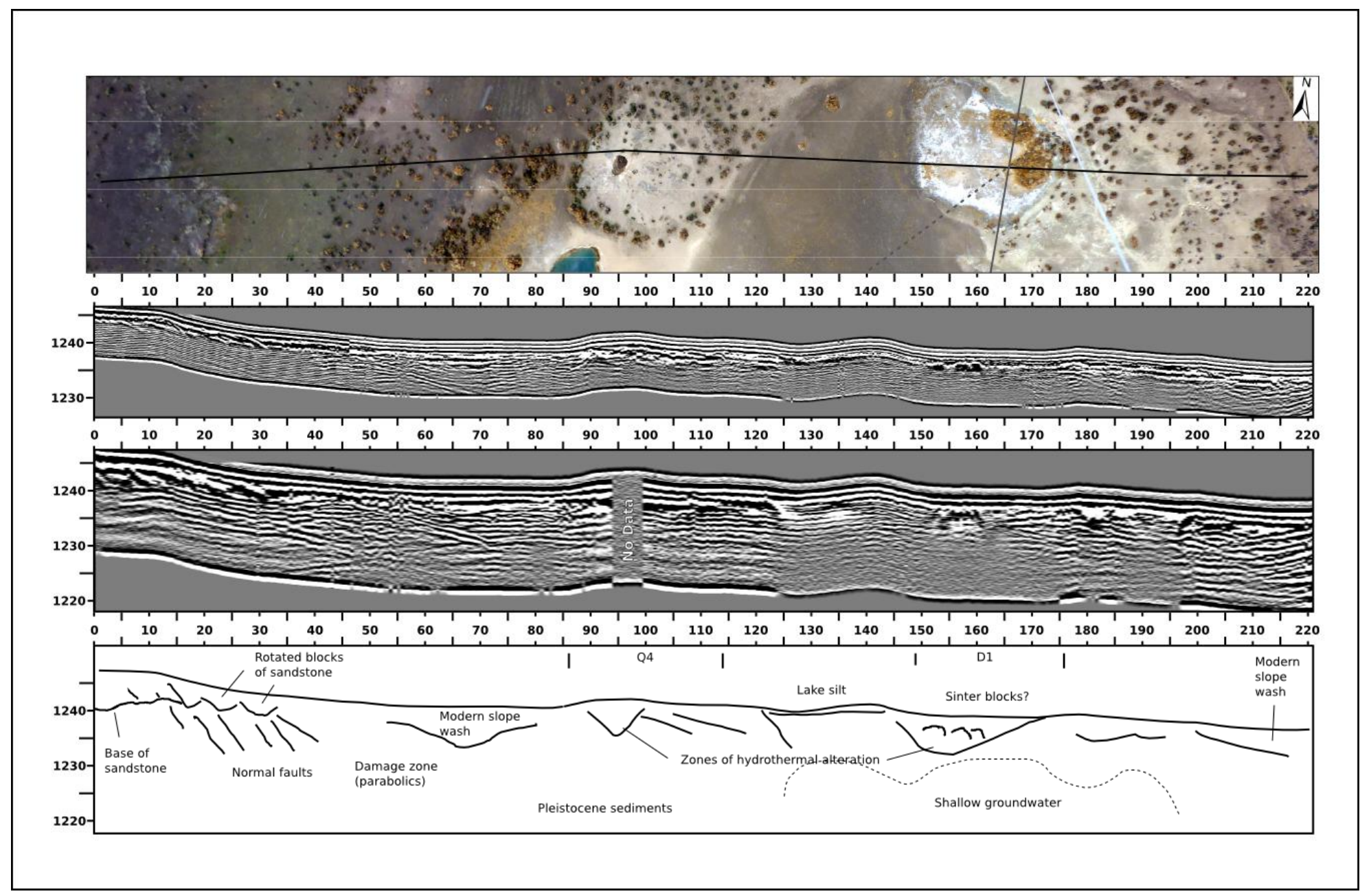

Figure 25: GPR transect from west to east, descending from the silicified sandstone outcrop, across feature Q3 and D1, and terminating at the east fence of the ACEC. 


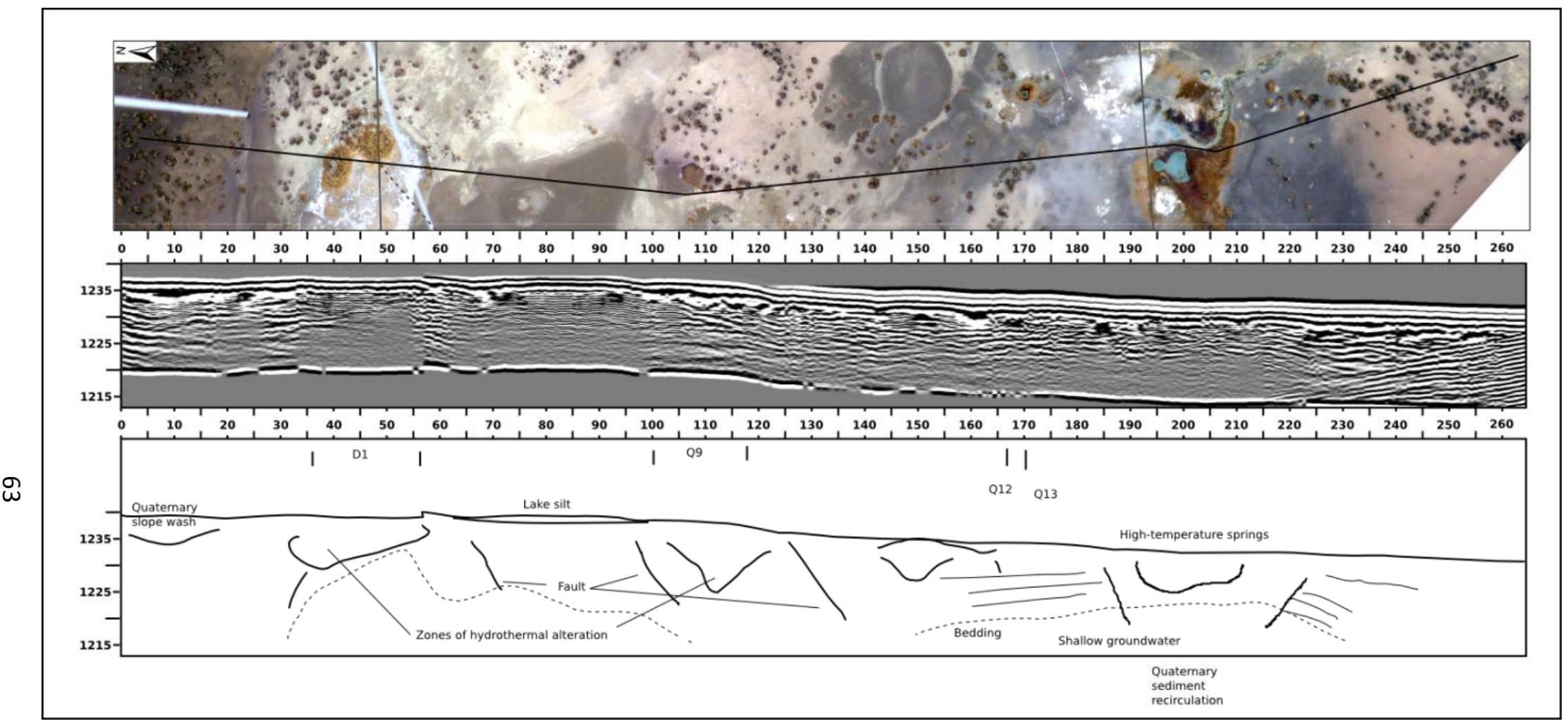

Figure 26: GPR transect from north to south crossing sinter feature D1, west flank of sinter apron of Q9, and the high temperature spring area, terminating at the south fence of the ACEC. Three normal faults are interpreted from the GPR data, striking northeast. These faults control the elevation of the topographic bench at $1235 \mathrm{~m}$ and may provide permeable pathways for the spring water. 


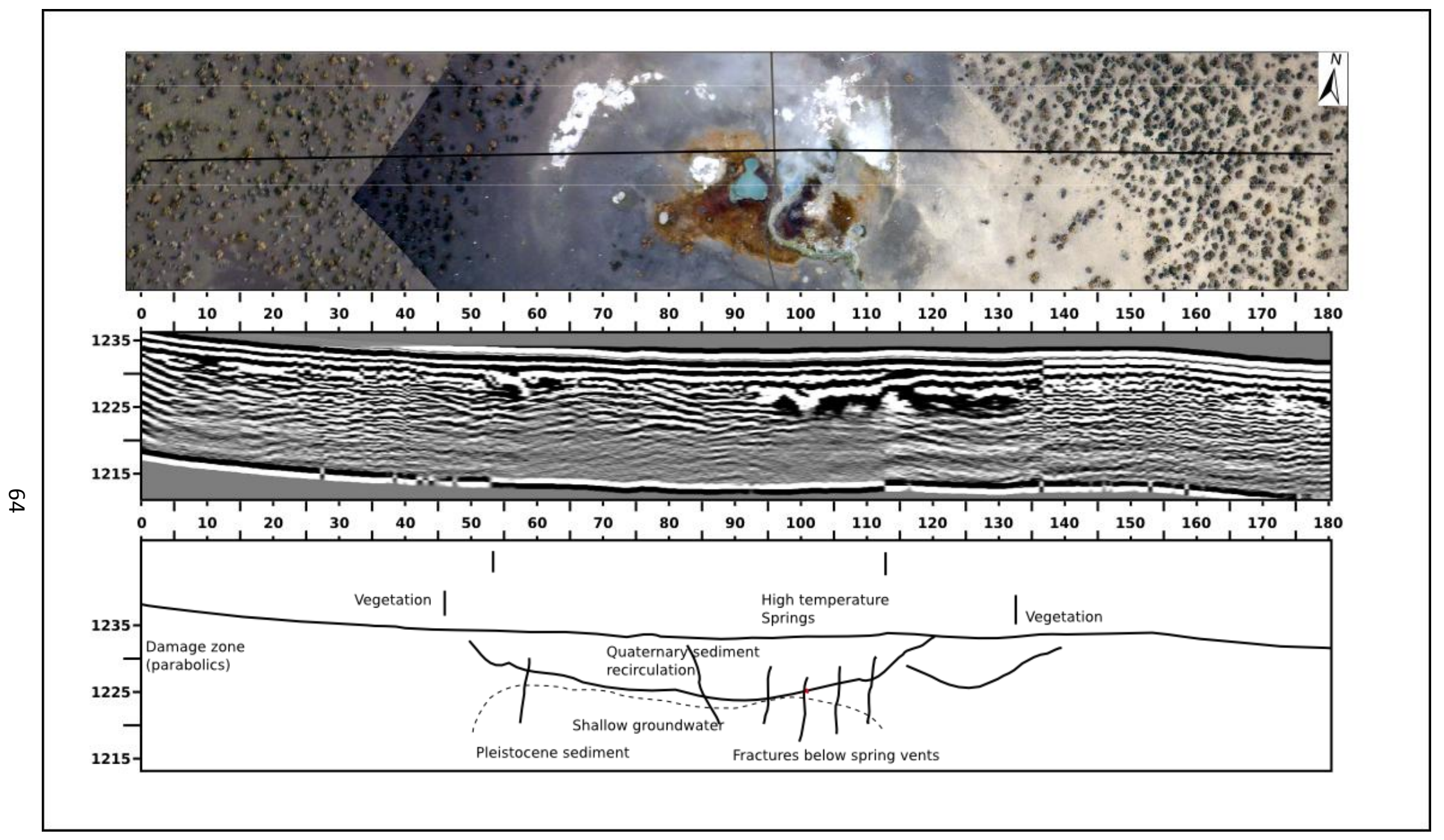

Figure 27: GPR transect from west to east across the high temperature area of Mickey Springs. An unconformity underlies the unvegetated area of the high temperature springs. Thick peaks and undulating bedding may indicate location of fluid pathways for surface springs. 


\section{Interpretation of stratigraphy}

Two questions were investigated with these transects. The first was the stratigraphic relation between the silica cemented sandstone and conglomerates that crops out west of the sinter area. The second was the characteristics of the subsurface environment beneath the sinter deposits.

The depositional environment of the silicified sandstones and conglomerates that crop out west of the sinter mounds and broad depressions has been interpreted in various ways. Cummings and St. John (1993) interpreted the dip of bedding in outcrops bordering the sinter deposits as reflecting foreset beds in a prograding delta and placed the time of sedimentation as concurrent with the presence of pluvial Lake Alvord. The U-Th disequilibrium date available at that time was consistent with this interpretation of coeval sedimentation and sinter deposition. This interpretation suggested that subaerial sinter deposition in the mounds and depressions had occurred at Mickey Springs after pluvial Lake Alvord dried. This interpretation guided the thinking in Mowbray and Cummings (2014) as they presented a climate-driven model for the evolution of the Mickey Springs site. The preliminary GPR study reported by Mowbray and Cummings (2014) used $250 \mathrm{MHz}$ shielded antennas spaced $0.5 \mathrm{~m}$ apart operating at 165 Volts with a horizontal resolution of $20 \mathrm{~cm}$ and $2 \mathrm{~m}$ penetration depth. At the depth attained with the $250 \mathrm{MHz}$ antennas, the GPR seemed to confirm that the foresets of the silicified delta continued and underlie the sinter deposits Figure 28. 


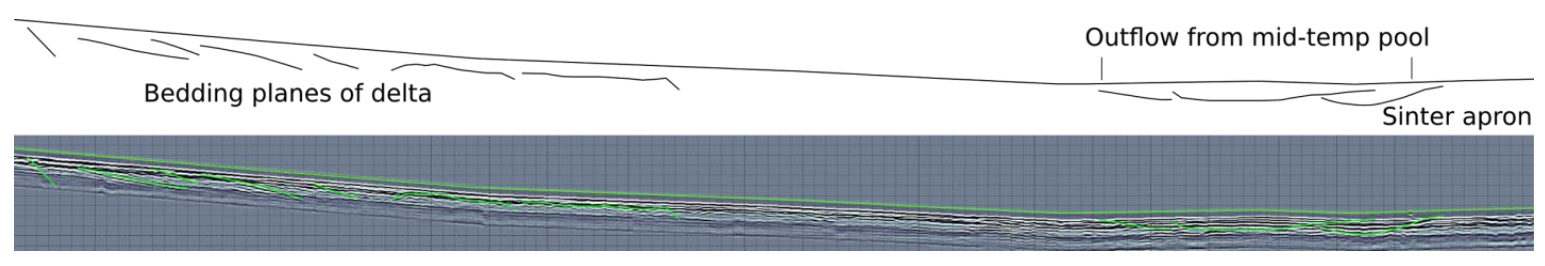

Figure 28: Interpretation of $250 \mathrm{MHz}$ GPR transect from Mowbray and Cummings (2014). Interpretation of this shallow survey (compared to the $17 \mathrm{~m}$ penetration of the $50 \mathrm{MHz}$ antennas used in this study) seemed to indicate continuation of "delta" bedding planes under a current spring outflow channel and sinter apron.

In the current study, the eastward dip on the beds of sandstone and conglomerate are interpreted as being fault related. In Figure 7, a series of left-stepping normal faults are shown separating the sinter area from the silicified sandstone and conglomerate unit. This reinterpretation also aligns better with sedimentological details in outcrops where the depositional architecture of bedding and relations between sandstone and conglomerate layers are more consistent with deposition on an alluvial fan rather than deposition on a delta front. GPR data are consistent with this reinterpretation. However, the deeper resolution of the $50 \mathrm{MHz}$ antennas shows that these features are not continuous at depth under the spring area. As a result, the outcrops of silicified sandstone and conglomerate are interpreted instead as blocks of sandstone, uplifted and rotated along a north-striking fault. In the current study, track 1 and 3 both suggest structure on the slope, and show no evidence of the sandstone/conglomerate unit to the depth of resolution east of the slope.

Assuming the sandstone unit was once more extensive, normal faulting may have down-dropped the sandstone east of the fault below the resolution of the GPR. The loose sediment exposed beneath feature Q4 may overlie and is thus younger than 
the cemented sandstone. Taking the 30 kya age of these sediments as a minimum age for the sandstone, and a total fault offset of $35 \mathrm{~m}$ (from the highest point on the sandstone ridge to the lowest point in the GPR transects) gives a loosely-approximated slip rate of $1.2 \mathrm{~mm} /$ year, which is plausible for the area given the slip rate estimates from Oldow and Singleton (2008) of up to $4 \mathrm{~mm} / \mathrm{yr}$.

The GPR data and outcrops at sites such as Q4 and Q9 indicate that the sinter aprons around springs are thin. At Q4 the total sinter thickness exposed in the vent walls is $2 \mathrm{~m}$. This is similar to direct and indirect observations at other sinter mounds and sinter rims around broad depressions. There is no evidence from observation or in the GPR transects of stacking of sinter deposits at several levels beneath the features observed at the modern surface.

\section{Discussion}

Silica sinter deposition requires discharge of hot water with colloidal silica suspended in the effluent. Deposition of the colloidal silica occurs as the solution cools to form pool edge sinter and outflow channels across the surrounding apron. Encrustation of algae in the pool and outflow channels and vegetation growing on the apron are well documented (Rimstidt and Cole, 1983; Cady and Farmer, 1993; Oestreicher, 2004).

The quaquaversal sinter mounds and depressions rimmed with sinter at Mickey Springs are interpreted to be fossil hot spring vents. Oestricher (2004) studied the sinter 
in these features and compared the preserved biofabric textures in the sinter to biofilms in the outflow channels from the high-temperature springs. He determined the outflow temperature at time of silicification to be $40-60^{\circ} \mathrm{C}$. The modern, high-temperature springs are not depositing silica sinter.

The time span over which silica sinter was depositing at Mickey Springs was examined through TL dating, GPR surveys, SfM photogrammetry, granulometry, and stratigraphic relations. From these methods the deposition of silica sinter started at approximately $30 \mathrm{ka}$ and persisted until pluvial Lake Alvord occupied the Alvord basin. In the following discussion, the lines of evidence are examined in support of this interpretation. In addition, the hypotheses of controls on spring discharge will be examined, and the evolution of the Mickey Springs system presented.

\section{Timing of sinter deposition}

The three sinter morphologies (silica sinter supported sandstone and conglomerate, sinter mounds, and broad depressions) frame the time when silica sinter deposition was occurring at Mickey Springs. The earliest evidence is the silica sinter supported clasts in the conglomeratic beds of the silicified sandstone outcrops. These are interpreted to mean co-eval sedimentation and sinter deposition. The extent of the area of silica cemented sandstone and conglomerate (Figure 6) suggest discharge of thermal water may have been less focused at the time of sedimentation and co-eval sinter deposition. 
Cummings and St. John (1993) report an U-Th diequilibrium age date of less than 16 kya for sinter in this setting. The analyses were performed at Argonne National Laboratories. Dating silica sinter deposition by this method was experimental at that time. One sample from the sinter mounds was found to be too porous and a meaningful age was not determined. The silica sinter in the conglomerate matrix was viewed as dense enough to allow successful dating, but even under those conditions the best possible determination was less than 16 kya. Stratigraphic and structural interpretations determined herein and discussed below suggest this date is too young.

The suggested age of sinter deposition in the silica sinter mounds based on the crystallinity of the sinter (opal-CT) presented by Nicholson et al. (2004), 30 kya, is believed to be more likely for the time of deposition of the sinter mounds. This is consistent with the TL date presented in this study for feature Q4, where a sample recovered by inserting the sampling tube along the contact between the layered sinter deposit and underlying un-cemented sediment yielded an age of 30 kya, but with relatively large error.

Sinter deposition had ceased at Mickey Springs prior to submersion in pluvial Lake Alvord. Two lines of evidence support this interpretation. The sediment that infills the vents of the sinter mounds and broad depressions is dominated by silt and clay size materials with sand to cobble size fragments of sinter, up to blocks of pool edge sinter ensconced in the infilling material. The fine grain size and sorting of the sediment 
suggests lacustrine transport and deposition, and the buried sinter blocks requires the sinter was present before sedimentation.

The second line of evidence is the TL dates for these infilling sediments. The materials submitted for TL dating from the sinter mounds and broad depressions were opportunistically collected at the depth where hand augering was successful. Thus, the dates do not mark specific horizons within the filling sediment. However, the oldest date from this setting, 18.1 kya, from the Q12 site (sample W4829) is consistent with age determinations for the times when pluvial Lake Alvord occupied the Alvord basin (Personius et al., 2006). Younger ages for these infilling materials at the D1 site were for a sample collected near the contact between rooted sedimentary material characteristic of the upper part of this hole and underlying clayey silt deposits. This age, 12.8 kya, suggests deposition during the late stages of pluvial Lake Alvord.

Sediment covering the aprons of sinter mounds postdates sinter deposition. At the D1 broad depression this material near the contact between silty sediment that overlies the silica sinter apron was dated at 17.9 kya (W4830). This date again corresponds to the determined age of the early filling stage of pluvial Lake Alvord. Uncertainty of the age of this sample and that from Q12 (W4829) overlap within the precision of the technique.

An age date for sediment near the mud pot site in the high temperature area, 9.2 kya (W4831), was collected from a site with no known sinter deposits. The sample 
was collected from a topographic ridge that surrounds the southwest portion of the high temperature area. The GPR image suggests a discontinuity in bedding of sediments within the high temperature area, and the ridge delineates the boundary of this area.

The youngest age was determined for sandy sediment including basalt lithics ( 25\%) and angular silica sinter clasts (75\%) at the Q3 site. The Q3 site is one of the northernmost sinter deposits and is at an elevation similar to the landscape that lies north and northwest of the sinter deposits. This age, 0.8 kya, may reflect inundation of this sinter deposit by sheet wash from a flash flood event originating on Mickey Butte. The relief of the sinter apron around Q4 may have prevented outwash from filling the throat of that feature, leaving the deep depression seen today.

The grain size data and TL dates are consistent with sedimentation from pluvial Lake Alvord infilling vents of hot springs that had previously produced sinter deposits. The TL age dates are consistent with the span of ages reported for pluvial Lake Alvord and the grain sizes are consistent with those likely produced from the glacial flour released into the basin from melting glaciers on Steen Mountain.

\section{Evaluation of models for control of fluid transport}

Mowbray and Cummings (2014) presented two models to explain the relations observed at the Mickey Springs site. The first model (transport-limited and structurally controlled) assumed a continuous supply of hydrothermal fluid exists at depth. The second model (supply-limited and climate driven) explored the possibility that the supply of hydrothermal fluid was not continuous and that it was related to changing 
climate conditions at the end of the Pleistocene. Since these models were proposed, TL dates, three $50 \mathrm{MHz}$ GPR lines, and new photogrammetry and field site investigations have been added to the available data.

The supply-limited and climate driven model as stated by Mowbray and Cummings (2014) is undercut by the TL dates which indicated silica sinter deposition occurred before pluvial Lake Alvord developed in the late Pleistocene. The TL dates for silt recovered from cores within central depressions and overlying sinter aprons indicate burial of sinter mounds and infilling of vents while pluvial Lake Alvord occupied the Alvord basin. Thus, a climate signal produced by late Pleistocene warming and subsequent drying is not supported. The TL dates suggest hydrothermal discharge has occurred at the Mickey Springs site for at least 30 thousand years.

Photogrammetry and additional field investigations have resulted in reinterpretation of the dipping beds in the silicified sandstones and conglomerates that lie west of the sinter deposits. It is within these sediments that the first indications of sinter deposition are identified. In Figure 7 north-striking, left-stepping faults are shown that separate the silicified sandstones and conglomerates from the sinter deposits. These faults have down to the east sense of displacement and they displace already silicified sedimentary deposits. Fractures in sinter mounds such as Q12, also have a north-strike orientation. Reinterpretation of field relations in this study from the delta model presented by Cummings and St. John (1993) and the fault distribution patterns presented by J.S. Oldow (fide Anderson and Fairley, 2008) add important pieces to the 
puzzle. The interpreted position of faults by J.S. Oldow (fide Anderson and Fairley, 2008) are presented alongside the faults interpreted from this study in Figure 29 with the north-striking, left-stepping, down to the east normal faults, and the northeast-striking, down to the southeast normal fault in Figure 7 added. The structural reinterpretation is also supported by the GPR line that crosses this boundary (track 1). The persistent discharge of hot water at the Mickey Springs site for at least 30 thousand years may have started at fault tip transfer points on faults shown by J.S. Oldow (fide Anderson and Farley, 2008), but became trapped in this location as faulting occurred on the northstriking, left-stepping normal faults.

The thin sinter deposits suggest that sinter deposition was short lived. GPR data suggest there is no stacking of sinter deposits one upon the other at least within the 17 $\mathrm{m}$ resolved by the $50 \mathrm{MHz}$ antenna surveys. TL dates suggest that deposition occurred over a relatively short period of time bracketed by the 30 kya date at Q4 and the ages of lacustrine silt deposited in inactive vents by at least 18 kya. Structural reinterpretation of the site, GPR lines, and TL dates support the transport-limited and structurally controlled model. 


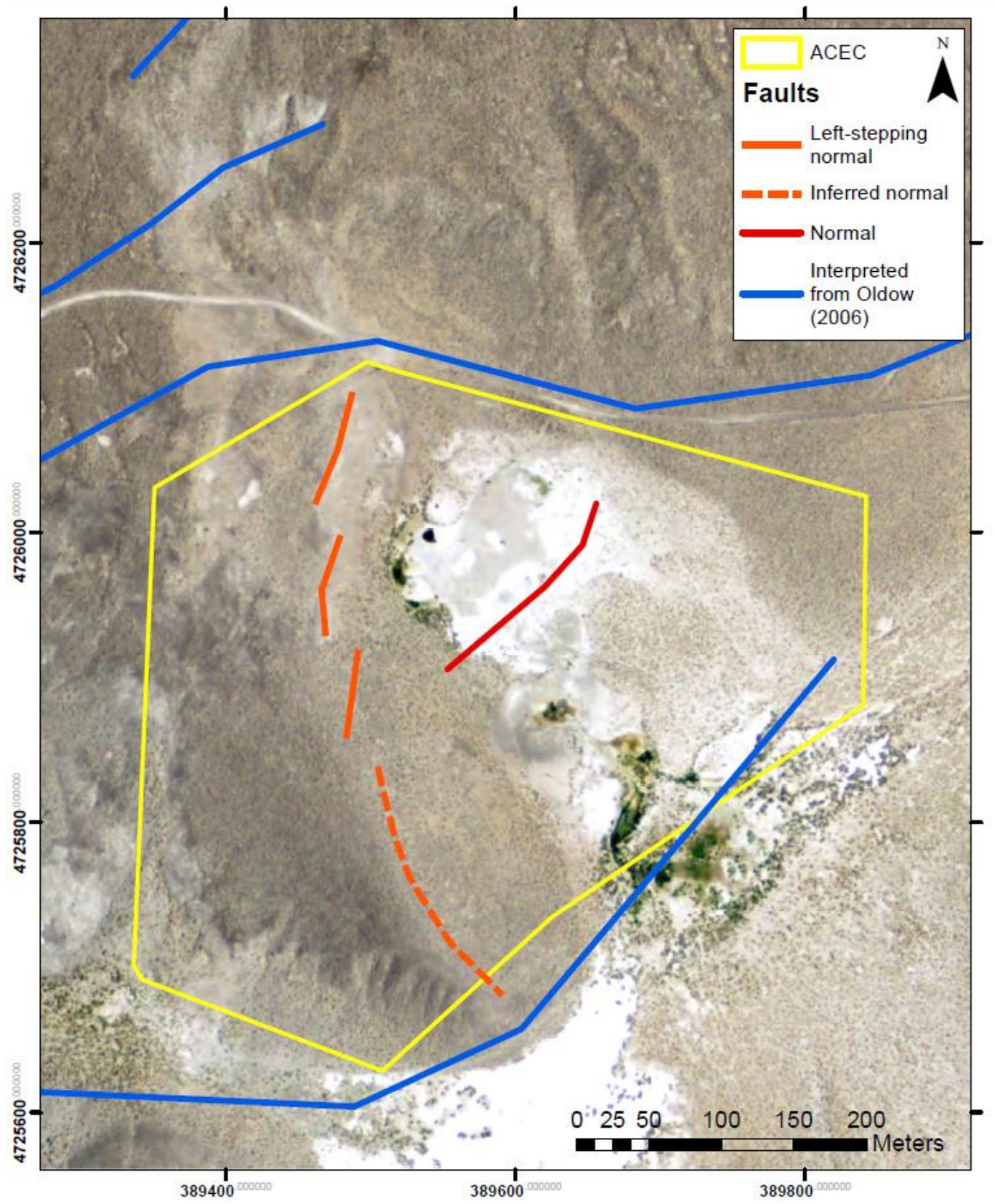

Figure 29: Structural map of Mickey Springs area. Interacting fault tips proposed by Oldow (fide Anderson and Fairley, 2008) constrained location of hydrothermal activity during cementation of sandstone and conglomerate unit (blue lines). All Sinter at Mickey Springs is contained within this area. Development of a north-striking, left-stepping fault before 30 kya offset the sandstone and further constrained the fluid pathways in the subsurface (orange lines). All sinter mounds and depressions are east of this fault. Most sinter mounds and all depressions are on a topographic bench between 1235 and $1240 \mathrm{~m}$, which is bound to the south by a northeast-striking, down to the south normal fault (red line). Elongate sinter aprons along this fault indicate it was present before or during sinter deposition. Currently, the majority of high-temperature springs are constrained in a $50 \times 50 \mathrm{~m}$ area east of the leftstepping fault and south of the sinter mounds and depressions. 


\section{Timeline of depositional facies}

With the above interpretations of stratigraphy and the TL ages, a chronology of activity at Mickey Springs can be reconstructed (Figure 30). Early silica sinter deposition coincided with deposition of sand and conglomerate on a prograding alluvial fan probably concurrent with faulting along Mickey Butte. Introduction of silica-rich thermal waters cemented the sands and conglomerate and locally silica sinter developed as suggested by clasts floating in silica. Petrified wood (Cummings and St. John, 1993) and fossils of vascular plants are present in these silica-cemented sediments. This activity was occurring prior to 30 kya, but how long before is not known. The most intense silica cementation occurs in the sandstone and conglomerate outcrops immediately west of the main sinter area (Figure 6). Less intensely cemented sandstone and conglomerate are exposed in valleys north northwest of the Mickey Springs site. However, sand and conglomerate forming low hills immediately north of the site are only weakly to uncemented. Based on the distribution of cementation and sinter, the focus of hot spring activity was in the area near modern Mickey Springs. The faults along which the hot water rose to the surface have not been identified. However, the conduits were likely controlled by the fault tip intersections of northeast-striking faults. Deformation on the left-stepping, north-striking faults that separate the outcrops of silicified sandstone and conglomerate from the area underlain by sinter mounds and sinter-rimmed broad depressions occurred in rocks that had already been silica cemented. 


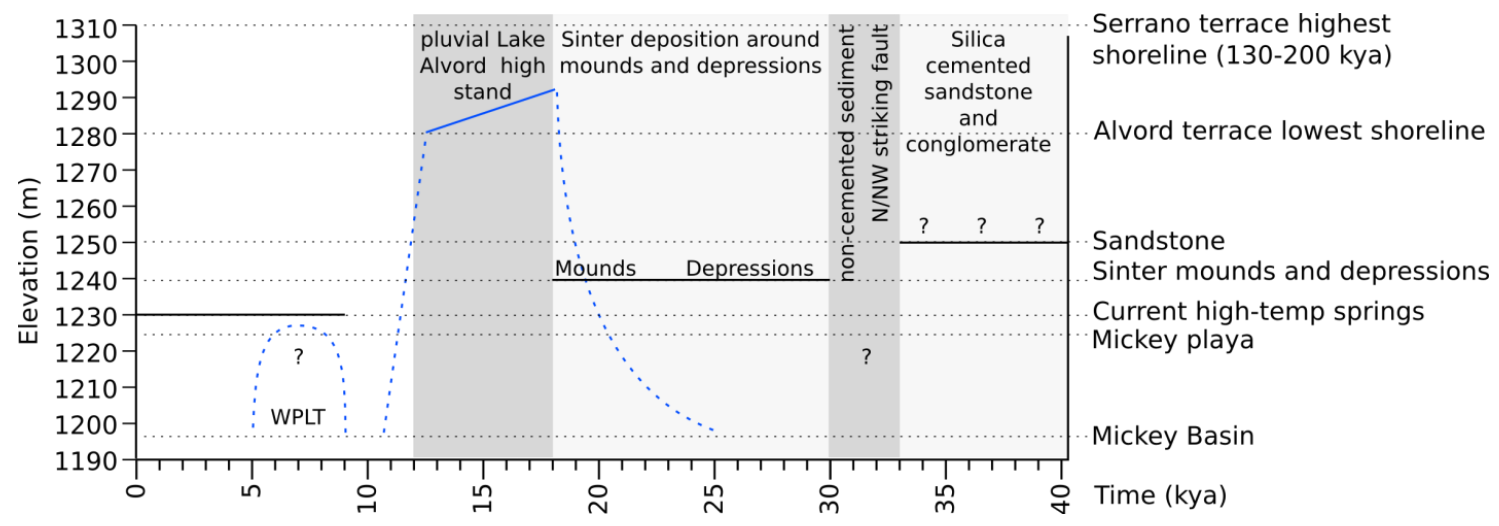

Figure 30: Timeline Timeline of major events at Mickey Springs. Scale at left is current elevation, and elevation of relevant features are labeled at right and indicated by dashed grey line. Bottom time scale indicates thousands of years before present. Timeline of hydrothermal activity at Mickey Springs is described in five steps, proceeding from right to left. (1) Silica cementation of sand and conglomerate prior to 30 kya (solid black line). (2) Offsetting of sandstone/conglomerate unit along N/NW striking fault, and deposition of uncemented sediments. (3) Deposition of laminar and pool-edge sinter around hot springs from 30 to 18 kya (solid black line). (4) Infilling of springs with lake sediment from pluvial Lake Alvord between 18 and 12 kya. (5) Current high-temperature springs (solid black line) active at lower elevation (1230 m), no sinter deposition, drying of climate to current desert conditions. Hypothesized (blue dashed line) and dated (solid blue line) level of pluvial Lake Alvord, including drying at 12 kya and slight resurgence during presence of Western Pluvial Lakes Tradition (WPLT).

The lack of silica cementation in poorly sorted, lithic-rich fluvial sedimentary deposits that underlie the sinter aprons of the sinter mounds and broad depressions may suggest a period of time when sinter deposition was not occurring. The sinterrimmed broad depressions are interpreted as forming first. This is suggested by exposures in the walls of Q4 where gently dipping sinter layers interbedded with lithicrich sand underlie more robust wavy sinter and pool edge sinter of the Q4 sinter mound. The sinter mounds appear to flank the area characterized by the sinter rimmed broad depressions.

Sinter deposition ceased prior to the onset of pluvial lake conditions. Pluvial Lake Alvord began to fill as the climate warmed and melted glaciers on Steens Mountain, and 
the lake level approached and eventually submerged Mickey Springs. When the elevation of the shoreline coincided with the elevation of the springs, wave action broke the sinter aprons, lodging blocks of sinter in the spring vents. As the depth of water increased in pluvial Lake Alvord silt and clay size sediment was deposited in the previously active vents along with sand-size fragments of angular sinter as a minor component. Most vents had ceased discharging water by this time. However, a few, such as Q4 and Q5, apparently were active while submerged in the lake and flushed the fine-grained sediment from their vents.

As the climate dried and the lake level dropped, wave action again broke blocks of sinter from the pool edges and scattered them on the now filled pool floors. The TL dates for silt and clay size sediment within the pools and overlying the sinter aprons are between 18 and 12 kya. Subsequently, the lake sediment that had been deposited upon the aprons surrounding the vents was largely eroded either during the receding stage of the lake or by subsequent fluvial activity.

Since the drying of pluvial Lake Alvord the location of the high temperature springs has shifted to their current location. However, low volume hot springs and gas vents are still active within the ancestral vents of the sinter mounds and broad depressions rimmed by sinter. 


\section{Conclusion}

Three morphologies of silica sinter deposition have been identified at Mickey

Springs. These are (1) silica cemented sandstone and conglomerate, (2) large depressions rimmed with sinter, and (3) quaquaversal sinter mounds. In this study, three ground penetrating radar transects and six thermoluminescence dates were used to interpret the stratigraphic relationship between these three sinter morphologies, and constrain their ages and depositional setting.

Silica-cemented sandstone and conglomerate were the first features formed by hydrothermal processes, and were emplaced prior to 30 kya. Structure between two interacting fault tips may have constrained the extent of silica cementation. By 30 kya, a left-stepping fault oriented roughly north/south further constrained the permeable zone. Between 30 and 20 kya, hydrothermal springs emitting water saturated with amorphous silica created sinter aprons around several spring pools of various sizes. Location of these features was dictated by development of the left-stepping fault. As pluvial Lake Alvord filled at the end of the Pleistocene, lake sediment filled most vents which were largely inactive.

Today, hydrothermal activity persists in two modes: (1) The current hightemperature springs, steam vents and mud pots concentrated in a $50 \times 50 \mathrm{~m}$ area, and (2) scattered springs and steam vents that exploit previous permeable pathways that once provided the hydrothermal fluid which precipitated the sinter aprons. Currently there is no active silica sinter deposition at Mickey Springs. 
Structures and stratigraphic relationships identified through this study favored a transport-limited and structurally controlled model of fluid transport. Sinter deposition is determined to have occurred before the most recent high stand of pluvial Lake Alvord, undercutting the climate-driven model. 


\section{References Cited}

Aitken, M.J., 1985, Thermoluminescence dating: Academic press.

Allison, I.S., 1982, Geology of pluvial lake Chewaucan, Lake County, Oregon: Corvallis, Oregon: Oregon State University Press.

Anderson, K.B., Spotila, J.A., and Hole, J.A., 2003, Application of geomorphic analysis and ground-penetrating radar to characterization of paleoseismic sites in dynamic alluvial environments: An example from southern California: Tectonophysics, v. 368, no. 1, p. 2532.

Anderson, T.R., and Fairley, J.P., 2008, Relating permeability to the structural setting of a faultcontrolled hydrothermal system in southeast Oregon, USA: Journal of Geophysical Research: Solid Earth (1978-2012), v. 113, no. B5.

Beck, C., 1984, Steens Mountain surface archaeology: the sites [Ph.D. thesis]: University of Washington.

Bedwell, S.F., 1973, Fort Rock basin: Prehistory and environment: University of Oregon Press.

Benson, L., and Thompson, R., 1987, Lake-level variation in the Lahontan basin for the past 50,000 years: Quaternary Research, v. 28, no. 1, p. 69-85.

Blackwell, D.D., Hull, D., Bowen, R., and Steele, J., 1978, Heat flow of Oregon, Oregon Department of Geology and Mineral Industries, Portland, OR.

Bradford, J.H., Liberty, L.M., Lyle, M.W., Clement, W.P., and Hess, S., 2006, Imaging complex structure in shallow seismic-reflection data using prestack depth migration: Geophysics, v. 71 , no. 6, p. B175-B181.

Cady, S., and Farmer, J., 1996, Fossilization processes in siliceous thermal springs: trends in preservation along thermal gradients, in Bock, G. and Goode, J., eds., Ciba Foundation Symposium 202 - Evolution of hydrothermal ecosystems on Earth (and Mars?), Wiley, Chichester, p. 150-173.

Carter, D.T., Ely, L.L., O'Connor, J.E., and Fenton, C.R., 2006, Late pleistocene outburst flooding from pluvial lake Alvord into the Owyhee river, Oregon: Geomorphology, v. 75, no. 3, p. 346-367.

Catchings, R., 1990, Seismic implications for crustal composition and deformation along the Basin and Range/Cascade Range boundary: American Geophysical Union Transactions, v. 71, p. 1613.

Cignoni, P., and Ranzuglia, G., 2014, Meshlab v1.3.3: Retrieved from http://meshlab.sourceforge.net/, an open source program for editing points and triangulated meshes. 
Cummings, M., and St John, A., 1993, Hydrogeochemical characterization of the Alvord Valley Known Geothermal Resources Area (kgra), Harney county, Oregon, Procurement No. De. PR79-91BP19408 and Modification A001, Report prepared for Bonneville Power Administration.

Curewitz, D., and Karson, J.A., 1997, Structural settings of hydrothermal outflow: Fracture permeability maintained by fault propagation and interaction: Journal of Volcanology and Geothermal Research, v. 79, no. 3, p. 149-168.

Davis, J., and Annan, A., 1989, Ground-penetrating radar for high-resolution mapping of soil and rock stratigraphy: Geophysical Prospecting, v. 37, no. 5, p. 531-551.

Dougherty, A., and Lynne, B., 2010, Utilizing ground penetrating radar to image vents and fractures in geothermal environments: American Geophysical Union Fall Meeting Abstracts, v. 1: p. 2358.

ESRI, 2014, Arcgis desktop: Release 10.2.1: Redlands, CA: Environmental Systems Research Institute.

Faulds, J.E., Coolbaugh, M., Blewitt, G., and Henry, C.D., 2004, Why is nevada in hot water? structural controls and tectonic model of geothermal systems in the northwestern great basin: Geothermal Resources Council Transactions, v. 28, p. 649-654.

Faulds, J.E., Coolbaugh, M.F., Vice, G.S., and Edwards, M.L., 2006, Characterizing structural controls of geothermal fields in the northwestern Great Basin: A progress report: Geothermal Resources Council Transactions, v. 30, p. 69-76.

Fournier, R.O., and Rowe, J.J., 1977, Solubility of amorphous silica in water at high temperatures and high pressure: American Mineralogist, v. 62. p. 9-10.

Fullagar, R.L., Price, D.M., and Head, L., 1996, Early human occupation of northern Australia: Archaeology and thermoluminescence dating of Jinmium rock-shelter, Northern Territory: Antiquity, v. 70, no. 270, p. 751-773.

Girardeau-Montaut, D., 2012, Cloudcompare, v2.4: Retrieved from http://www.cloudcompare.org/, open source software for 3D point cloud and mesh procesing.

Green, S., Bevan, A., and Shapland, M., 2014, A comparative assessment of structure from motion methods for archaeological research: Journal of Archaeological Science, v. 46, p. 173-181.

Groube, L., Chappell, J., Muke, J., and Price, D., 1986, A 40,000 year-old human occupation site at Huon Peninsula, Papua New Guinea: Nature, v. 342, p. 453-455.

Hemphill-Haley, M., Page, W., Burke, R., and Carver, G., 1989, Holocene activity of the alvord fault, Steens Mountain, southeastern Oregon: Woodward-Clyde Consultants. 
Hemphill-Haley, M.A., 1987, Quaternary stratigraphy and late Holocene faulting along the base of the eastern escarpment of Steens Mountain, southeastern Oregon [Ph.D. thesis]: Humboldt State University.

Hooper, P., Binger, G., and Lees, K., 2002, Ages of the Steens and Columbia River flood basalts and their relationship to extension-related calc-alkalic volcanism in eastern Oregon: Geological Society of America Bulletin, v. 114, no. 1, p. 43-50.

Javernick, L.A., 2013, Modeling flood-induced processes causing russell lupin mortality in the braided Ahuriri River, New Zealand [Ph.D. thesis]: University of Canterbury.

Landtwing, M.R., Furrer, C., Redmond, P.B., Pettke, T., Guillong, M., and Heinrich, C.A., 2010, The Bingham Canyon porphyry cu-mo-au deposit. iii. zoned copper-gold ore deposition by magmatic vapor expansion: Economic Geology, v. 105, no. 1, p. 91-118.

Lynne, B., and Dougherty, A., 2010, Ground penetrating radar successful in imaging hot spring deposits: A new geothermal exploration tool: American Geophysical Uniont Fall Meeting abstracts, v. 1: p. 06.

McKenna, J.R., and Blackwell, D.D., 2004, Numerical modeling of transient Basin and Range extensional geothermal systems: Geothermics, v. 33, no. 4, p. 457-476.

Meyers, R.A., Smith, D.G., Jol, H.M., and Peterson, C.D., 1996, Evidence for eight great earthquake-subsidence events detected with ground penetrating radar, Willapa Barrier, Washington: Geology, v. 24, no. 2, p. 99-102.

Mowbray, L.A., and Cummings, M.L., 2014, Supply-limited, climate-driven model for Holocene spring activity at Mickey Springs, Oregon, USA: Geothermal Resources Council Transactions 2014 annual meeting, Portland, Oregon: p. 11-18.

Negrini, R.M., 2002, Pluvial lake sizes in the northwestern Great Basin throughout the Quaternary period: Great Basin aquatic systems history, Smithsonian contributions to the earth sciences, v. 33, p. 11-52.

Nicholson, K.N., Link, K.N., and Garringer, L., 2004, Relative ages of the Borax Lake and Mickey geothermal systems, Alvord basin, Oregon USA: Preliminary evidence from silica phase transitions, in Simmons, S.F., ed., Proceedings 26th NZ Geothermal Workshop, p. 40-45.

Oestreicher, Z.W.J., 2004, Geomicrobiology investigation of Mickey Hot Springs, southeastern oregon [M.S. thesis]: Portland State University.

Oldow, J.S., and Singleton, E.S., 2008, Application of terrestrial laser scanning in determining the pattern of late Pleistocene and Holocene fault displacement from the offset of pluvial lake shorelines in the Alvord extensional basin, northern Great Basin, USA: Geosphere, v. 4, no. 3, p. 536-563.

Personius, S.F., Crone, A.J., Machette, M.N., Kyung, J.B., Cisneros, H., Lidke, D.J., and Mahan, S.A., 2006, Trench logs and scarp data from an investigation of the Steens fault zone, Bog 
Hot Valley and Pueblo Valley, Humboldt County, Nevada: U.S. Geological Survey, http://pubs.usgs.gov/sim/2006/2952/.

Pettigrew, R.M., 1984, Prehistoric human land-use patterns in the Alvord basin, southeastern Oregon: Journal of California and Great Basin Anthropology, p. 61-90.

Price, D.M., 2010, Thermoluminescence dating: University of Wollongong, flier provided for information about the TL procedure used at University of Wollongong.

Reynolds, M.W., 1979, Character and extent of basin-range faulting, western Montana and eastcentral Idaho, in Newman, G., and Goode, H., eds., Basin and Range symposium: Rocky Mountain Association of Geologists, p. 185-193.

Rimstidt, J., and Cole, D.R., 1983, Geothermal mineralization. i. the mechanism of formation of the beowawe, nevada, siliceous sinter deposit: American Journal of Science, v. 283, p. 861-875.

Scarberry, K.C., Meigs, A.J., and Grunder, A.L., 2010, Faulting in a propagating continental rift: Insight from the late Miocene structural development of the Abert Rim fault, southern Oregon, USA: Tectonophysics, v. 488, no. 1, p. 71-86.

Sibson, R.H., 1987, Earthquake rupturing as a mineralizing agent in hydrothermal systems: Geology, v. 15, no. 8, p. 701-704.

Singleton, E.S., 2005, Late Pleistocene to Holocene deformation rates in the Alvord extensional basin, southeastern Oregon, from ground-based lidar determined fault offset of paleolake terraces [Ph.D. thesis]: University of Idaho.

Smith, D.G., and Jol, H.M., 1997, Radar structure of a Gilbert-type delta, Peyto Lake, Banff National Park, Canada: Sedimentary Geology, v. 113, no. 3, p. 195-209.

Smith, G.I., and Stuiver, M., 1979, Subsurface stratigraphy and geochemistry of late Quaternary evaporites, Searles Lake, California: Geological Survey Professional Paper 1043: United States Department of the Interior.

Software, S.., 2009, Ekko View Deluxe, v.1.4 : http://www.sensof t.ca/, proprietary software for visualizing GPR data.

St. John, A.M., 1993, Hydrogeochemical characterization of the Alvord Valley Known Geothermal Resources Area, Harney county, Oregon [M.S. thesis]: Portland State University

Stal, C., Bourgeois, J., De Maeyer, P., De Mulder, G., De Wulf, A., Goossens, R., Hendrickx, M., Nuttens, T., and Stichelbaut, B., 2012, Test case on the quality analysis of structure from motion in airborne applications: 32nd earsel symposium: Advances in geosciences: European Association of Remote Sensing Laboratories (EARSeL), p. 11.

Waibel, A., 2011, Structural controls on the location of geothermal cells in and adjacent to Dixie Valley, Nevada: Geothermal Resource Council Transactions, v. 35, no. 8. 
Walker, G., and Repenning, C., 1965, Reconnaissance geologic map of the Adel quadrangle, Lake, Harney, and Malheur counties, Oregon: U.S. Geological Survey Map, I-466, scale $1: 250,000$.

Western Regional Climate Center, D.R.I., , Period of record monthly climate summary for fields, oregon, station id 352876 (5/1/73 to 3/31/2013): http://www.wrcc.dri.edu/cgibin/cliMAIN.pl?or2876, accessed: 5/5/2014.

Westoby, M., Brasington, J., Glasser, N., Hambrey, M., and Reynolds, J., 2012, structure-frommotion photogrammetry: A low-cost, effective tool for geoscience applications: Geomorphology, v. 179, p. 300-314.

Wisian, K.W., and Blackwell, D.D., 2004, Numerical modeling of Basin and Range geothermal systems: Geothermics, v. 33, no. 6, p. 713-741.

Wu, C., 2011, Visualsfm: A visual structure from motion system: http://ccwu.me/vsfm, a software package for Structure from Motion, creating dense point construction from photographs. 


\title{
Appendix: TL dating report
}

\author{
Allen Mowbray \\ Department of Geology \\ Portland State University \\ 17 Cramer Hall \\ 1721 SE Broadway \\ PORTLAND OR 97201 \\ OREGON, USA \\ $23^{\text {rd }}$ December 2014
}

Dear Allen,

The thermoluminescence (TL) analysis of the six samples taken from the Mickey Hot Springs area in SE Oregon is now complete. I enclose tabulated details of all measurements made leading to the final depositional ages determined for each of these samples. In general the TL characteristics of these samples proved less than ideal with low TL sensitivity and widely scattered data. The age uncertainties associated with the resultant ages is therefore somewhat greater than that generally recorded.

These samples were analysed by means of the combined additive and regenerative methods using the 90 to 125 micrometre quartz grain fraction separated by wet sieving and suitable chemical treatment followed by heavy liquid separation. This method provides a means of checking for possible TL sensitivity change due to the laboratory procedure followed. As a modern sample analogue was not available the TL starting level at the time of final deposition for each sample was assumed to be that reached following a 24-hour prepared sample exposure beneath a laboratory ultraviolet lamp (Philips MLU300W). In order to correct for sample aliquot variations all TL outputs recorded were nomalised using a second glow method following a standard irradiation of approximately 19.8 Grays. Each sample analysis utilised 28 sample aliquots in total, eight of these were used to determine the natural TL accumulated since the time of deposition, six to check for sensitivity change and fourteen in the preparation of a TL growth curve to which the mean natural TL value was fitted. By this means the equivalent radiation dose accumulated since the time of deposition was determined.

The annual radiation dose for each sample was determined by means of thick source alpha counting (TSAC) to determine the uranium and thorium specific activity and atomic emission spectroscopy to measure the potassium content. Corrections were made for cosmic radiation, sample rubidium content and measured sample moisture content. In some cases the latter value was high which served to elevate the final ages determined. Sample moisture moderates the radiation received by the sample thus increasing the age determined by approximately $1 \%$ for each $1 \%$ increase in moisture.

9 Sample \# 1 (W4823) The temperature plateau comparison for this sample extended only between 275 and $350^{\circ} \mathrm{C}$ due to low TL sensitivity. This resulted in widely scattered TL data 
and a larger than usual associated age uncertainty. The more easily reset electron trap level at a temperature of $325^{\circ} \mathrm{C}$ was selected for this sample.

33 Sample \#2 (W4828) This sample tube contained a large rock fragment occupying about $50 \%$ of the tube itself. This may have distorted the radiation flux received by the sample undergoing analysis and hence distorting the resultant TL age. If the fragment contains the same uranium, thorium and potassium as the sediment then no correction to the final age would be necessary.

19 Sample \#4 (W4829) This sample consisted of a loose gritty sand with only a very few, if any, small pebbles. The TL output proved reasonable with a plateau comparison extending between 300 and $500^{\circ} \mathrm{C}$ lending confidence in the final depositional age determined.

5 Sample \#9 (W4830) This sample exhibited a reasonable plateau comparison extending between 275 and $450^{\circ} \mathrm{C}$ and similar TL sensitivity as Sample \#4. The ages of these two samples in fact overlap at the one standard deviation level.

8 Sample \#11 (W4831) The TL sensitivity of this sample was low and there was a violent reaction when treated in hydrofluoric acid possibly due to a high feldspar content. The temperature comparison exhibited by the sample proved shortened and the resultant age of only $0.8 \mathrm{ka}$ the most recent of all samples analysed but with a large associated age uncertainty.

1 Sample \# 12 (W4832) The TL sensitivity of this a sample again proved low and the TL data again scattered leading to a large associated TL age uncertainty.

These samples have not proved to be ideally suited to TL analysis but I hope that the exercise has proved beneficial from your view point. If I am able to further assist in the interpretation of these results please don't hesitate to contact me. I will returning to work most likely on the $5^{\text {th }}$ January but will check my email from home during the Christmas - New Year break.

Best wishes

David M. Price

Honorary Research Fellow

Thermoluminescence Dating Laboratory 


\begin{tabular}{lcccccc} 
UW lab Specimen No. & W4832 & W4830 & W4831 & W4823 & W4829 & W4828 \\
\hline Plateau Region $\left({ }^{\circ} \mathrm{C}\right)$ & $275-400$ & $275-450$ & $350-450$ & $275-350$ & $300-500$ & $275-450$ \\
Analysis Temp. $\left({ }^{\circ} \mathrm{C}\right)$ & 375 & 375 & 375 & 325 & 375 & 375 \\
Palaeodose (Grays) & $18.8+/-$ & $34.5+/-$ & $1.5+/-$ & $45.3+/-$ & $27.5+/-$ & $25.4+/-$ \\
& 6.4 & 5.8 & 0.9 & 11.7 & 3.1 & 2.7 \\
K Content (\% by AES) & $1.44+/-$ & $1.78+/-$ & $1.14+/-$ & $1.17+/-$ & $1.29+/-$ & $1.89+/-$ \\
& 0.05 & 0.05 & 0.05 & 0.05 & 0.05 & 0.05 \\
Rb Content (ppm assumed) & $100+/-$ & $100+/-$ & $100+/-$ & $100+/-$ & $100+/-$ & $100+/-$ \\
& 25 & 25 & 25 & 25 & 25 & 25 \\
Moisture Content $(\%$ by weight) & $47.0+/-3$ & $32.2+/-3$ & $4.1+/-3$ & $22.2+/-3$ & $34.3+/-3$ & $10.1+/-3$ \\
Specific Activity $(\mathrm{Bq} / \mathrm{kg} \mathrm{U}+\mathrm{Th})$ & $25.9+/-$ & $29.8+/-$ & $32.3+/-$ & $22.3+/-$ & $27.2+/-$ & $42.3+/-$ \\
& 0.7 & 0.9 & 0.9 & 0.6 & 0.9 & 1.1 \\
& $180+/-$ & $170+/-$ & $168+/-$ & $123+/-$ & $175+/-$ & $170+/-$ \\
Cosmic Contribution $(\mu \mathrm{Gy} / \mathrm{yr}$ & 25 & 25 & 25 & 25 & 25 & 25 \\
assumed) & $1469+/-$ & $1969+/-$ & $1978+/-$ & $1476+/-$ & $1522+/-$ & $2766+/-$ \\
Annual Radiation Dose $(\mu \mathrm{Gy} / \mathrm{yr})$ & 39 & 44 & 58 & 33 & 43 & 55 \\
TL Age $(\mathrm{ka})$ & $12.8+/-$ & $17.5+/-$ & $0.8+/-$ & $30.7+/-$ & $18.1+/-$ & $9.2+/-$ \\
& 4.4 & 3.0 & 0.5 & 7.9 & 2.1 & 1.0
\end{tabular}

